\title{
Socioeconomic health differences in old age : unravelling the role of biomedical, behavioural, and psychosocial factors
}

Citation for published version (APA):

Koster, A. (2005). Socioeconomic health differences in old age : unravelling the role of biomedical, behavioural, and psychosocial factors. [Doctoral Thesis, Maastricht University]. Maastricht University. https://doi.org/10.26481/dis.20051222ak

Document status and date:

Published: 01/01/2005

DOI:

10.26481/dis.20051222ak

Document Version:

Publisher's PDF, also known as Version of record

Please check the document version of this publication:

- A submitted manuscript is the version of the article upon submission and before peer-review. There can be important differences between the submitted version and the official published version of record.

People interested in the research are advised to contact the author for the final version of the publication, or visit the DOI to the publisher's website.

- The final author version and the galley proof are versions of the publication after peer review.

- The final published version features the final layout of the paper including the volume, issue and page numbers.

Link to publication

\footnotetext{
General rights rights.

- You may freely distribute the URL identifying the publication in the public portal. please follow below link for the End User Agreement:

www.umlib.nl/taverne-license

Take down policy

If you believe that this document breaches copyright please contact us at:

repository@maastrichtuniversity.nl

providing details and we will investigate your claim.
}

Copyright and moral rights for the publications made accessible in the public portal are retained by the authors and/or other copyright owners and it is a condition of accessing publications that users recognise and abide by the legal requirements associated with these

- Users may download and print one copy of any publication from the public portal for the purpose of private study or research.

- You may not further distribute the material or use it for any profit-making activity or commercial gain

If the publication is distributed under the terms of Article $25 \mathrm{fa}$ of the Dutch Copyright Act, indicated by the "Taverne" license above, 
SOCIOECONOMIC HEALTH DIFFERENCES IN OLD AGE: UNRAVELING THE ROLE OF BIOMEDICAL, BEHAVIORAL, AND PSYCHOSOCIAL FACTORS 
The studies presented in this thesis were performed at the Care and Public Health Research Institute (CAPHRI) of the Universiteit Maastricht. CAPHRI participates in the Netherlands School of Primary Care Research ( $\mathrm{CaRe}$ ), re-acknowledged by the Royal Dutch Academy of Science (KNAW) in 2000.

Financial support by the faculty of Health Sciences of the Universiteit Maastricht for printing this thesis is gratefully acknowledged.

ISBN-10: $90-9020076-2$

ISBN-13: $978-90-9020076-7$

Printed by PrintPartners Ipskamp. Enschede

Cover design by Martien Frijns, Doetinchem

Cover photo of sculpture "The Thinker" adapted by Costa Bachas, original sculpture designed by Corry Ammerlaan-van Niekerk, Artihove Art Centre te Bergschenhoek

Copyright $\odot 2005$, A. Koster, Maastricht

All rights reserved. No part of this book may be reproduced, stored in a retrieval system, or transmitted, in any form or by any means, electronic, mechanical, photocopying, recording, or otherwise, without prior written permission of the author. 


\title{
SOCIOECONOMIC HEALTH DIFFERENCES IN OLD AGE: UNRAVELING THE ROLE OF BIOMEDICAL, BEHAVIORAL, AND PSYCHOSOCIAL FACTORS
}

\author{
PROEFSCHRIFT \\ ter verkrijging van de graad van doctor \\ aan de Universiteit Maastricht, \\ op gezag van de Rector Magnificus, \\ Prof. mr. G.P.M.F. Mols
}

volgens het besluit van het College van Decanen, in het openbaar te verdedigen op donderdag 22 december 2005 om 14.00 uur

door

Annemarie Koster 
Promotores:

Prof. dr. J.Th.M. van Eijk

Prof. dr. G.I.J.M. Kempen

Copromotores:

Dr. H. Bosma

Dr. B.W.J.H. Penninx (Vrije Universiteit Amsterdam)

Beoordelingscommissie:

Prof. dr. J. van Os (voorzitter)

Prof. dr. R.A. de Bie

Prof. dr. G.A.M. van den Bos (Universiteit van Amsterdam)

Prof. dr. J.M.J.P. van der Linden 
Voor papa en mama 



\section{Contents}

1 General introduction 1

2 Socioeconomic inequalities in mobility decline in chronic disease 13 groups (asthma/COPD, heart disease, diabetes mellitus, low back pain): only a minor role for disease severity and comorbidity

3 The role of psychosocial factors in explaining socioeconomic differences in mobility decline in a chronically ill population: results from the GLOBE study

4 Explanations of socioeconomic differences in changes in physical function in older adults

5 Association of inflammatory markers with socioeconomic status

6 Is there a biomedical explanation for socioeconomic differences in incident mobility limitation?

7 Socioeconomic differences in cognitive decline and the role of biomedical factors

8 Explaining socioeconomic differences in incident depression in ollder adults

9 General discussion

Summary

Samenvatting

List of publications

Dankwoord (Acknowledgement)

About the author

De auteur 



\section{1}

General introduction 


\section{SOCIOECONOMIC DIFFERENCES IN HEALTH}

We live in an ageing society. In the Netherlands in 2002, $14 \%$ of the population was 65 years or older and this is expected to increase to $23 \%$ in 2040 (1). Between 1950 and 2003 , life expectancy has increased from 70.4 to 76.2 years for men and from 72.7 to 80.9 years for women. Life expectancy is estimated to further increase to 79.2 years for men and 82.6 years for women in 2050 (1). Socioeconomic status (SES) is an important predictor of life expectancy. SES refers to a person's position on the social hierarchy. Income, education, and occupation are the most frequently used indicators of SES. LOW SES is associated with a higher risk of mortality. Also among oider persons, SES differences in mortality are found (2-5). In the Netherlands, for example, the difference in life expectancy between lower and higher educated people is 4.9 years for men and 2.6 years for women (1). In addition, SES differences are also present in healthy life expectancy. People with a low SES do not only live shorter than their better-off counterparts; they also live a greater proportion of their lives in poor health $(6,7)$. In the Netherlands, highly educated men and women live respectively 9.9 and 8.6 years longer without physical limitations than lower educated persons (1). A study in the United States showed that these SES differences in healthy life expectancy have increased over the last decades (8).

SES differences have been found in various health outcomes and across many countries (9-11). Although SES differences in health accur in different age groups, these health differences have been less examined in older age groups than in younger age groups. Some studies report that SES differences in health attenuate in old age $(12,13)$, although evidence is contradictory (14). In an older population, function is an important health outcome. Different types of function, such as physical, cognitive, and mental function, cover larger dimensions of a person's health status. Overall, functional stalus measures are strong predictors of hospitall outcomes for example length of stay), nursing home admission, and mortality (15-18). Poor physical function can lead to disability (difficulty doing activities of daily living) which is related to many diseases and, especially in older adults, physical disability has been shown to be an important predictor of mortality (19). Cognitive impairment is a major problem among older persons and maintaining good cognitive function is an essential part of successful aging (20). Depression (mental function) also has negative consequences for well-being and daily functioning and is associated with higher mortality rates (21-23).

LOW SES has been shown to be an important predictor of various functional outcomes. Particularly the association between SES and physical function has been well described in the literature (24-27). Low SES is a predictor of declines in physical 
function which has been found in both younger and older adults $(28,29)$. The association between SES and cognitive function is relatively understudied. There is some evidence that low SES is also related to poor cognitive function; longitudinal studies are, however, limited at present $(30,31)$. Furthermore, SES differences have been found in mental disorders, including depression $(25,32,33)$. A higher prevalence and incidence of depression has been observed among low SES groups compared to people with a higher SES. In general, relatively few studies have investigated the association between SES and functional outcomes in older persons and longitudinal studies are limited.

\section{EXPLAINING SOCIOECONOMIC DIFFERENCES IN HEALTH}

In order to prevent the negative consequences of poor function and especially the SES differences therein and to develop intervention strategies, understanding the pathways underlying these associations is important. In 1980, the Black Report provided theoretical explanations for SES differences in health (34). Two main mechanisms have been proposed: the selection mechanism and the causation mechanism. The selection mechanism assumes that health affects social mobility; healthy people may move up in the social hierarchy whereas unhealthy people may move down. The causation mechanism is believed to be more important in the explanation for SES differences in health (34). Social causation assumes that SES has an effect on health through an unequal distribution of determinants of health across SES groups. Based on the causation mechanism, there are several pathways in which SES may affect health outcomes. In this thesis, three important groups of factors will be examined in the explanation of SES differences in functional outcomes: biomedical, behavioral, and psychosocial factors. These groups of factors will be discussed below.

\section{Biomedical factors}

Biomedical factors, such as diseases and biological risk factors, are likely to be important in the mechanism through which low SES leads to poor functional outcomes. Low SES is related to a higher prevalence of many diseases, such as cardiovascular disease, stroke, and diabetes (35-37). Biological risk factors, such as hypertension, glucose intolerance, and reduced lung function are also more prevalent among low SES groups (38-40). Many diseases and their risk factors are directly related to physical function $(26,41)$. Biomedical factors are also related to poor cognitive function and increased symptoms of depression (42-44). Accumulating 
evidence shows that inflammation, being a biological response of the immune system, might also be important. Recent research shows that high serum levels of inflammatory markers are inversely related to SES (45-47). High serum levels of inflammatory markers are related to poor physical and cognitive function and a higher prevalence of depression (48-50). Despite the knowledge that diseases and their risk factors are associated with both low SES and poor functional outcomes, the extent to which biomedical factors can explain SES differences in function has not been studied extensively.

\section{Behavioral factors}

The behavioral explanation of SES differences in health implies that people with low SES suffer from poor health due to higher rates of smoking, excessive alcohol consumption, physical inactivity, and obesity. Compared to high SES people, persons with a low SES generally have an unhealthier lifestylle. They smoke more often, drink more alcohol, consume unhealthier diets, and are less physically active $(51-53)$. These adverse behavioral factors are negatively associated with functional outcomes $(41,54-57)$. Previous studies have found that behavioral factors contribute to SES differences in physical function, self-reported health, and mortality $(25,58$, 59).

\section{Psychosocial factors}

Psychosocial factors may aiso moderate the impact of SES on function (60), Generally, people with low SES have fewer psychosocial resources than their betteroff counterparts. Low SES is, for example, related to low control beliefs, negative coping styles, poor social support, and more stressful life events (60-62). Psychosocial factors influence the perception of events and the degree to which they are experienced as stressful. How people cope with these stressful situations affects various health outcomes, for example physical function $(41,63-65)$. The association between psychosocial factors and depression has been studied extensively, especially the positive effect of social support on mental health (66-69). The contribution of psychosocial factors in the explanation of SES differences in function has not been studied elaborately.

\section{AIM AND OUTLINE OF THIS THESIS}

The first objective of this thesis is to describe the associations between SES and three different aspects of function: physical, cognitive, and mental function. The 
second objective of this thesis is to explore the role of biomedical, behavioral, and psychosocial factors in the explanation of SES differences in the three functional outcomes. This will contribute to a better understanding of the mechanisms underlying SES health differences. Figure 1 shows the research model in which the numbers refer to the different chapters in this dissertation.

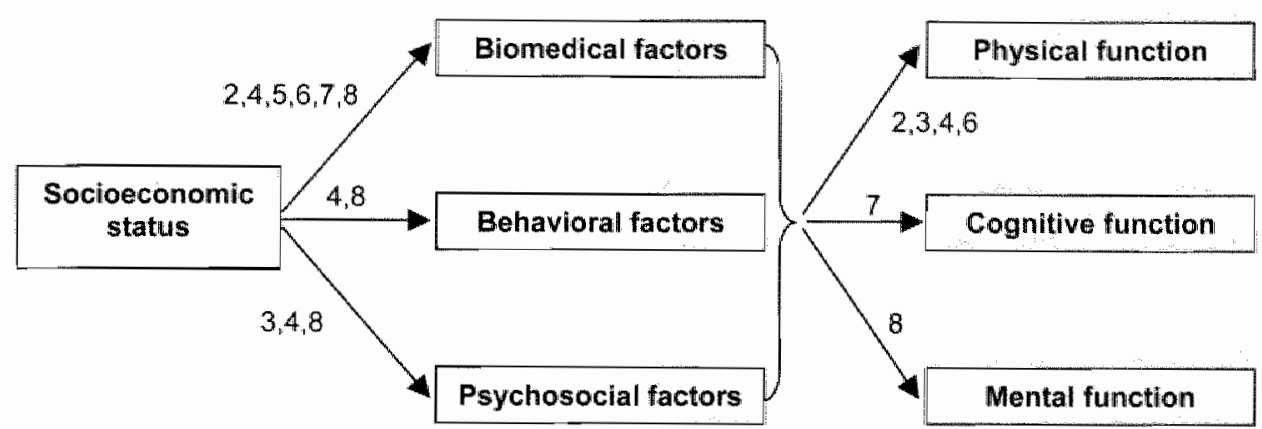

Figure 1. Research model of this thesis. Numbers indicate the chapters in this thesis

The studies that are presented in this thesis have important strengths. First, the associations between SES and three different types of function, that represent different aspects of a person's health status ${ }_{t}$ are studied. Second, the role of three different groups of explanatory factors is studied. Most studies in this thesis will focus on the contribution of one group of explanatory variables in the association between SES and physical, cognitive, or mental function. The contribution of biomedical, behavioral, and psychosocial factors, however, will also be studied simultaneously in order to determine the relative contribution of these factors in the explanation of SES differences in function. Third, the associations between SES and function are studied longitudinally. Especially longitudinal studies between SES and cognitive function are limited at present. Fourth, it will be determined whether SES differences in function still exist in old age. Finally, different indicators of SES, including education and income, that represent different dimensions of SES, will be used. For example, education is the socio-cultural dimension of SES and represents social class in an early stage of the life course compared to income representing a later life stage.

Data from three different longitudinal cohort studies were used. The first study is the GLOBE (Dutch acronym for Health and Living conditions of the population of 
the city of Eindhoven and surroundings in the Netherlands) study with six years of follow-up. The particular sub-study consists of 2,867 men and women, aged 15 to 74 years, in which chronically ill patients were over-represented. Using these data, the association between SES and physical function is studied in both younger and older adults. The second study is the Longitudinal Aging Study Amsterdam (LASA), consisting of 3,107 men and women between 55 and 85 years old in different parts of the Netherlands. Nine years of follow-up were included. The third study is the Health, Aging and Body Composition (Health $A B C$ ) study, consisting of 3,075 black and white men and women, aged 70 to 79 years, from Memphis, Tennessee and Pittsburg, Pennsylvania in the US. Four and a half years of follow-up could be used.

In Chapter 2 the association between SES and mobility decline is examined in four chronic disease groups (asthma/COPD, heart disease, diabetes mellitus, low back pain) and it was examined whether this association was explained by disease severity and comorbidity. Data from the GLOBE study were used.

Chapter 3 elaborates on the previous chapter by examining the role of psychosocial factors in the explanation of SES differences in mobility decline, independent of disease severity, comorbidity, and health-related behavior, in the same population (GLOBE study).

The association between SES and changes in physical function in younger-old (aged 55 to 70 years) and older-old (aged 70 to 85 years) adults is studied in Chapter 4. using data from LASA. Additionally, this study seeks to simultaneously examine the relative contribution of diseases, behavioral, and psychosocial factors in explaining this association.

Whether SES differences exist at a pathophysiological level is examined in Chapter 5. Therefore, the association between SES and inflammatory markers is studied more in detail in well-functioning older adults and it will be determined whether any association remains after adjusting for diseases and behavioral factors typically related to elevated serum levels of inflammatory markers. Data from the Health $A B C$ study were used.

Chapter 6 reports on the association between SES and incident mobility limitation in well-functioning older adults and the role of biomedical factors, including inflammatory markers, in explaining this link in the Health $A B C$ study.

Chapter 7 describes the association between SES and cognitive decline in well-functioning older adults participating in the Health ABC study. Furthermore, the role of biomedical factors is examined in explaining this association. 
Using data from LASA, the association between SES and the onset of depression in older adults is presented in Chapter 8 . Moreover, the role of psychosocial factors, physical health status, and behavioral factors is studied in the explanation of this link.

Finally, the findings of the previous chapters are summarized and discussed in Chapter 9 . 


\section{REFERENCES}

1. Volksgezondheid Toekomst Verkenning. Nationaal Kompas Volksgezondheid "versie 3.2. Bitthoven: RIVM, http:/Www nationaalkompas.ni, 2005.

2. Husman M, Kunst AE, Andersen $D$, et al. Socioecoinomic inequalities in mortality among elderly people in 11 European populations. I Epidemiol Community Health 2004;58:468-75.

3. Mackenbach JP, Kunst AE, Cavelaars AE, Groenhof F, Geurts JJ. Socioeconomic inequalities in morbidity and mortality in western Europe. The EU Working Group on Socioeconomic Inequalities in Health. Lancet 1997;349:1655-9.

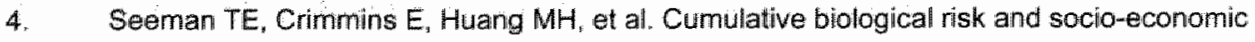
differences in mortality: MacArthur studies of successful aging. Soc Sci Ned 2004;58:1985-97.

5. Manton KG, Stallard E, Conder L. Education-specific estimates of life expectancy and agespecific disability in the U.S. elderly population: 1982 to 1991. J Aging Health 1997:9:419-50.

6. Guralnik JM, Land KC, Blazer D. Fillenbaum GG, Branch LG. Educational status and active life expectancy among older blacks and whites. N Engl J Med 1993;329:110-6.

7. Melzer D, McWilliams B, Brayne $C$; Johnson T, Bond J. Socioeconomic status and the expectation of disability in old age: estimates for England. $\mathrm{J}$ Epidemiol Community Health $2000 ; 54: 286-92$.

8. Crimmins EM, Saito $Y$. Trends in healthy life expectancy in the United States, 1970-1990: gender, racial, and educational differences. Soc Sci Med 2001;52:1629-41.

9. Huisman $M_{2}$ Kunst AE, Mackenbach JP. Socioeconomic inequalities in morbidity among the elderly; a European overview. Soc Sci Med 2003;57:861-73.

10. Kunst $A E$, Bos $V$, Lahelma $E$, et al. Trends in socioeconomic inequalities in self-assessed heaith in 10 European countries. Int J Epidemiol 2005;34:295-305.

11. Kunst $A E$, Geurts $\mathrm{J} J$, van den Berg J. International variation in socioeconomic inequalities in self reported health. J Epidemiol Community Health 1995;49:117-23.

12. Mishra GD, Ball K, Dobson A., Byles JE. Do socioeconomic gradients in women's health widen over time and with age? Soc Sci Med 2004;58:1585-95.

13. Mustard CA, Derksen S, Berthelot JM, Wolfson M, Roos LL. Age-specific education and income gradients in morbidity and mortality in a Canadian province. Soc Sci Med $1997 ; 45: 383-97$.

14. Berkman $\mathrm{CS}_{\mathrm{s}}$ Gurland BJ. The relationship among income, other socioeconomic indicators, and functional level in older persons. J Aging Health 1998; 10:81-98.

15. Inouye SK, Peduzzi PN, Robison JT, Hughes JS, Horwitz RI, Concalto J. Importance of functional measures in predicting mortality among older hospitalized patients. JAMA $1998: 279: 11187-93$.

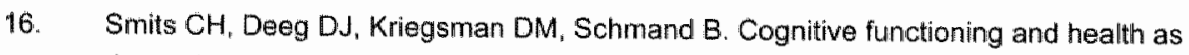
determinants of mortality in an older population. Am J Epidemiol 1999;150:978-86.

17. Penninx BW, Geerlings SW, Deeg DJ, van Eijk JT, van Tilburg W, Beekman AT. Minor and major depression and the risk of death in older persons. Arch Gen Psychiatry 1999;56:889-95.

18. Guralnik JM, Simonsick EM, Ferrucci L, et al. A short physical performance battery assessing lower extremity function: association with self-reported disability and prediction of mortality and nursing home admission. J Gerontol 1994;49:M85-M94.

19. Gurainik JM, Fried LP. Salive ME. Disability as a public health outcome in the aging population. Annu Rev Public Health 1996;17:25-46. 
20. Rowe JW, Kahn RL. Successful aging. Gerontologist 1997:37 433-440.

21. Beekman AT, Deeg DJ, Braam AW, Smit.JH, Van Tilburg W. Consequences of major and minor depression in later life: a study of disability, well-being and service utilization. Psychol Med 1997;27:1397-409.

22. Schulz R, Beach SR, Ives DG, Martire LM, Ariyo AA, Kop WJ. Association between depression and mortality in older adults: the Cardiowascular Health Study. Arch Intern Med $2000 ; 160: 1761-8$.

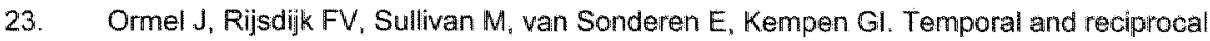
relationship between IADL/ADL disability and depressive symptoms in late life. J Gerontol B Psychol Sci Soc Sci 2002;57:P338-47.

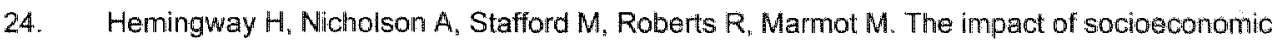
status on health functioning as assessed by the SF-36 questionnaire: the Whitehall II Study. Am J Public Health 1997:87:1484-1490.

25. Martikainen P, Stansfeld S, Hemingway H, Marmot M. Determinants of socioeconomic differences in change in physical and mental functioning. Soc Sci Med 1999:49:499-507.

26. Seeman TE, Charpentier PA, Berkman LF, et al. Predicting changes in physical performance in a high-functioning elderly cohort: MacArthur studies of successful aging. J Gerontol A. Biol Sci Med Sci 1994:49:M97-108.

27. Grundy E, Glaser K. Socio-demographic differences in the onset and progression of disability in early old age: a longitudinal study. Age Ageing 2000;29:149-57.

28. Broese van Groenou MI, Deeg DJ, Penninx BW. Income differentials in functional disability in old age: relative risks of onset, recovery, decline, attrition and mortality. Aging Clin Exp Res 2003;15:174-183.

29. Melzer D, Izmirlian G, Leveille SG, Guralnik JM. Educational differences in the prevallence of mobility disability in old age: the dymamics of incidence, mortality, and recovery. $\downarrow$ Gerontol $B$ Psychol Sci Soc Sci 2001;56:294-301.

30. Lee S, Kawachi I, Berkman LF, Grodstein F. Education, other socioeconomic indicators, and cognitive function. Am $J$ Epidemiol. 2003;157:712-720.

31. Dartigues JF, Gagnon $\mathrm{M}_{\mathrm{z}}$ Mazaux $\mathrm{JM}$, et al. Occupation during life and memory performance in nondemented French elderly community residents. Neurology 1992;42:1697-1701.

32. Lorant $V$, Deliege $D$, Eaton $W$, Robert $A$, Philippot $P$. Ansseau M. Socioeconomic inequalities in depression; a meta-analysis. Am J Epidemiol 2003;157:98-112.

33. Stansfeld $S A$, Head J, Fuhrer $R$, Wardle J, Cattell $V$. Social inequalities in depressive symptoms and physical functioning in the Whitehall II study: exploring a common cause explanation. J Epidemiol Community Health 2003;57:361-7.

34. Townsend P, Davidson N. The Black Report. In: Townsend P, Davidson N, Whitehead M, eds. Inequalities in health. London: Penguin Books, 1988.

35. Avendano $M$, Kunst $A E$, wan Lenthe $F$, et al. Trends in socioeconomic disparities in stroke mortality in six european countries between 1981-1985 and 1991-1995. Am J Epidemiol $2005 ; 161: 52-61$.

36. Kaplan GA, Keil JE. Socioeconomic factors and cardiovascular disease: a review of the literature. Circulation 1993;88:1973-1998.

37. Everson SA, Maty SC, Lynch JW, Kaplan GA. Epidemiologic evidence for the relation between socioeconomic status and depression, obesity, and diabetes. \Psychosom Res 2002; $53: 891-895$ 
38. Brunner EJ, Marmot MG Nanchahal $\mathrm{K}$, et al. Social inequality in coronary risk: central obesity and the metabolic syndrome. Evidence from the Whitehat! II study. Diabetologita 1997;40: 1341-1349.

39. Prescott E, Vestbo J. Socioeconomic status and chronic obstructive pulmonary disease. Thorax 1999,54:737-741.

40. Galobardes B; Costanza MC, Bemstein MS, Delhumeau C Morabia A. Trends in risk factors for lifestyle related disealses by socioeconomic position in Geneva, Switzerland, 1993-2000: health inequallities persist. Am I Public Health 2003,93:1302-1309.

41. Stuck AE, Walthert JM, Nikolaus T, Bula CJ, Hohmann C, Beck JC. Risk factors for functiona! status decline in community-living elderiy people: a systematic literature review. Soc Sci Med 1999:48:445-69.

42. Bisschop MI, Kriegsman DM, Deeg DJ, Beekman AT, van Tilburg W. The longitudinal relation between chronic diseases and depression in older persons in the community: the Longitudinal Aging Study Amsterdam. J Clin Epidemiol 2004:57:187-94.

43. Teunissen CE, de Vente J, von Bergmann $K$, et al. Serum cholesterol precursors and metabolites and cognitive performance in an aging population. Neurobiol Aging 2003:24:147155.

44. Pavlik WN, Hyman DJ, Doody R. Cardiovascular risk factors and cognitive function in adults 30-59 years of age (NHANES III). Neuroepidemiology 2005;24:42-50.

45. Jousilahti $P$, Salomaa $V$, Rasi $V$, Vahtera $E$, Palosuo T. Association of markers of systemic inflammation, $C$ reactive protein, serum amyloid $A$, and fibrinogen, with socioeconomic status. $J$ Epidemiol Community Health 2003;57:730-733.

46. Steptoe A, Owen N, Kunz Ebrecht S, Mohamed All V. Inflammatory cytokines, socioeconomic status, and acute stress responsivity. Brain Behav Immun 2002;16:774-784.

47. Owen N, Poulton T, Hay FC, Mohamed-Ali V, Steptoe A. Socioeconomic status, C-reactive

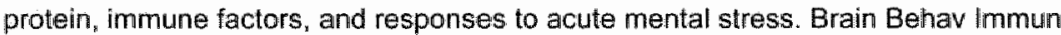
2003:17:286-295

48. Yaffe $K$, Lindquist $K$, Penninx BW, et al. Inflammatory markers and cognition in wellfunctioning African-American and white elders. Neurology 2003;61:76-80.

49. Penninx BW, Kritchevsky SB, Yaffe K, et al. Inflammatory markers and depressed mood in older persons: results from the Health "Aging and Body Composition study. Biol Psychiatry $2003 ; 54: 566-572$

50. Penininx BW, Kritchevsky SB. Newman AB, et al. Inflammatory marker's and incident mobility limitation in the elderly. J Am Geriati Soc 2004;52:1105-13.

51. Droomers M, Schrijwers CT, Mackenbach JP. Educational level and decreases in leisure time physical activity: predictors from the longitudinal GLOBE study. J Epidemiol Community Health 2001,55:562-8.

52. Droomers M. Schrijvers CT, Mackenbach JP. Educational differences in starting excessive alcohol consumption: explanations from the longitudinal GLOBE study. Soc Sci Med 2004;58:2023-33.

53. Martikainen P. Brunner $E$. Marmot M. Socioeconomic differences in dietary patterns among middle-aged men and women. Soc Sci Med 2003;56:1397-410.

54. Paperwalla KN, Levin TT, Weiner J, Saravay SM. Smoking and depression. Med Clin North Am 2004;88:1483-94, $x$-xi. 
55. Mackenbach JP, Borsboom GJ, Nusselder WJ, Looman CW, Schrijvers CT. Determinants of levels and changes of physical functioning in chronically ill persons: results from the GLOBE Study. J Epidiemiol Community Health 2001;55:631-8.

56. Kalmijn S. Fatty acid intake and the risk of dementia and cognitive decline: a revew of clinical and epidemiological studies. J Nutr Health Aging 2000,4:202-7.

57. Kalmijn S, van Boxtel MP, Verschuren MW, Jolles J, Launer LJ. Cigarette smoking and alcohol consumption in relation to cognilive performance in middle age. Am $\downarrow$ Epidemio: 2002; 156:936-44.

58. van Lenthe FJ "Schrijvers CT, Droomers M, Joung IM, Louwman MJ, Mackenbach JP. Investigating explanations of socio-economic inequalities in health: the Dutch GLOBE study. Eur J Public Health 2004;14:63-70.

59. Schrijvers CT, Stronks $K_{n}$ wan de Mheen HD, Mackenbach JP. Explaining educational differences in mortality: the role of behavioral and material factors. Am J Public Health $1999 ; 89: 535-40$

60. Taylor SE, Seeman TE. PSychosacial resources and the SES-health relationship. Ann $N$ Y Acad Sci 1999:896:210-25.

61. Bosma H, Van Jaarsveld $\mathrm{CH}$. Tuinstra $ل$, et al. Low control beliefs, classical coronary risk factors, and socio-economic differences in heart disease in older persons. Soc Sci Med 2005;60:737-45.

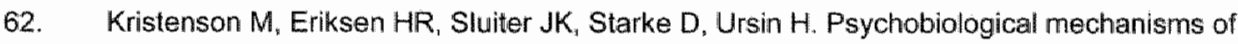
sacioeconomic differences in health. Soc Sci Med 2004;58:1511-22.

63. Baum A, Garofalo JP, Yali AM. Socioeconomic status and chronic stress. Does stress account for SES effects on health? Ann N Y Acad Sci 1999:896:131-44.

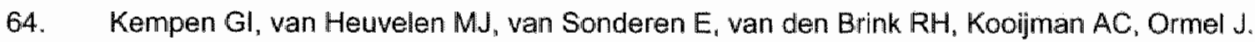
The relationship of functional limitations to disability and the moderating effects of psychological attributes in community-dwelling older persons. Soc Sci Med 1999:48:1161-72.

65. Siegrist $\mathrm{J}$, Marmot M. Health inequalities and the psychosocial environment-two scientific challenges. Soc Sci Med 2004;58:1463-73.

66. Oxman TE, Berkman LF , Kas $\mid \mathrm{S}$, Freeman DH, Jr "Barrett J. Social support and depressive symptoms in the elderly. Am J Epidemiol 1992;135:356-68.

67. Stansfeld SA, Fuhrer R. Shipley MJ. Types of social support as predictors of psychiatric morbidity in a cohort of British Civil Servants (Whitehall II Study). Psychol Med 1998;28:88192.

68. Glass TA, KasI SV, Berkman LF. Stressful life events and depressive symptoms among the elderiy. Evidence from a prospective community study. J Aging Health 1997;9:70-89.

69. Penninx BW, van Tilburg T, Deeg D.l, Kriegsman DM, Boeke AJ, van Eijk JT. Direct and buffer effects of social support and personal coping resources in individuals with arthritis. Soc Sci Med 1997:44:393-402. 



\section{2}

Socioeconomic inequalities in mobility decline in chronic disease groups (asthma/COPD, heart disease, diabetes mellitus, low back pain): only a minor role for disease severity and comorbidity

\section{Published as}

Koster A, Bosma H. Kempen GI, van Lenthe FJ, van Eijk JT, Mackenbach JP. Socioeconomic inequalities in mobility decline in chronic disease groups (asthma/COPD, heart disease, diabetes mellitus, low back pain): only a minor role for disease severity and comorbidity. J Epidemiol Community Health 2004;58:862-9. 


\section{ABSTRACT}

Objective. In chronically ill patients, mobility develops more unfavorable in persons with a low socioeconomic status than in their better-off counterparts. It is not clear, whether the adverse course of physical functioning in persons with a low socioeconomic status can be explained by a higher prevalence of more severe disease or comorbidity in these persons. Using longitudinal data from the Dutch GLOBE study, the present study examined the association between socioeconomic status and mobility decline and whether this could be explained by disease severity and comorbidity in four different chronic disease groups (asthma/COPD, heart disease, diabetes mellitus, and low back pain).

Methods. Data were from 1,384 men and woman, aged 15-74 years, suffering from at least one of the four chronic diseases. Three indicators of socioeconomic status were used: education, occupational class, and income. Change in physical mobility between 1991 and 1997 was measured with the Nottingham Health Profile (NHP).

Results. Odds ratios of mobility decline between 1991 and 1997, adjusted for age, sex, marital status, and baseline mobility, were significantly higher in low socioeconomic groups in comparison to high socioeconomic groups. Only very little of this association could be explained by the higher disease severity and comorbidity in these patients. Findings were similar in patients with asthma/COPD, heart disease, diabetes mellitus, and chronic low back pain.

Conclusions. Our findings indicate that in order to reduce physical disabilities and particularly the sociceconomic differences therein, it may not be sufficient to solely intervene upon the risks of severe disease and comorbidities. 


\section{INTRODUCTION}

There is substantiall evidence that physical functioning, such as mobility, develops more unfavorably in persons with a low socioeconomic status (SES) (1-4). The same effects are also found in chronically ill persons (5-8). Chronically ill persons, who have a low level of education, belong to a low occupational class, or have a low household income, develop more disabilities than chronically ill persons with a high SES (7). Less clear, however, is whether the adverse course of physical functioning in persons with a low SES can be explained by a higher prevalence of more severe disease or comorbidity in these persons. A recent study showed that disease severity is associated with physical disabilities (7). Another study shows that people with a low socioeconomic position report a greater disease severity than people with a high socioeconomic position $(9,10)$. Low SES is also positively related to comorbidity which is also likely to increase disabilities (11). It is not clear whether previous studies in chronic disease patients have sufficiently controlled for a potentially higher disease severity and comorbidity in low SES groups. This is relevant for determining the extent to which any low SES - restricted mobility association is confounded by disease severity and/or comorbidity. Furthermore, in order to reduce physical disabilities and particularly the SES differences therein, it is important to know whether it is sufficient to reduce severe disease and comorbidities in chronically ill persons with a low SES or whether other socially patterned factors should be tackled as well.

Using longitudinal data this study examines the association between SES and mobility decline and whether this could be explained by disease severity and comorbidity in four different chronic disease groups (asthma/chronic obstructive pulmonary disease (COPD), heart disease, diabetes mellitus, and low back pain). These four diseases were chosen because they are fairly common, cover a wide range of possible consequences of disease for daily functioning (12), and represent varying body systems, i.e. respiratory (asthma/COPD), cardiovascular (heart disease), metabolic (diabetes mellitus), and muscular-skeletal (low back pain).

\section{METHODS}

\section{Study population}

Data were obtained from the GLOBE (a Dutch acronym for Health and Living Conditions of the Population of Eindhoven and surroundings) study, a longitudinal study that started in 1991 in the south east of the Netherlands, aimed at explaining 
SES imequalities in health (13). It is based on a cohort of 15 to 74 year old, noninstitutionalized people of Dutch nationality. In 1991 the study started with a baseline measurement consisting of a postal survey and an oral interview. A sample of 27,070 inhabitants of 18 municipalities received a postal questionnaire; the sample was drawn from population registers stratified by age and postal code (45-74 years old and people from the highest and lowest SES groups were overrepresented). The response rate of the postal survey was $70.1 \%$ resulting in a study population of 18,973 respondents. A sub-sample of 3,968 persons drawn from respondents to the postal survey was approached for an oral interview. Participants completed an interview and a self-administered questionnaire; the response was $72.2 \%(n=2,867)$. In this sub-sample, people who reported one or more of the following chronic diseases were overrepresented: asthma/COPD, heart disease, diabetes mellitus, and severe low back pain. For the analyses presented in this paper, respondents suffering from at least one of the four chronic diseases were selected, resulting in 2,015 respondents in 1991. Response at follow-up in 1997 was $69.8 \%$ of the 2,015 respondents in 1991, resulting in 1,407 respondents. For 23 participants outcome data were missing, leaving 1,384 participants for the present analyses. The number of respondents in each group was: asthma/COPD; $n=465$, heart disease, $n=788$, diabetes mellitus; $n=137$, and low back pain; $n=707$. There were 580 respondents who suffered from more than one condition.

\section{Measures}

Socioeconomic status. We used three indicators of SES: levell of education, equivalent income, and occupational class. Three categories of level of education were created: high (university, higher wocational training); medium (higher secondary, intermediate vocational training); and low (lower secondary, lower vocational training). Occupational class was measured according to Erikson, Goldthorpe, and Portocarero (EGP) cllassification (14) that originally consisted of 11 categories. In this study four categories were created: (1) (higher) grade professionals; (2) routine nonmanual workers and high skilled manual workers; (3) self-employed; and (4) low skilled and unskilled manual workers. Net equivalent income per month was measured by adding all income components of all household members adjusted for household size. Three categories of equivalent income, in euros, were distinguished: high (>947); medium (658-947); and low ( $<658$ ). Education data were missing for 28 participants; this was 171 for occupation and 215 for income.

Physical mobinity. Physical mobility was measured with the Nottingham Health Profile (NHP). The NHP is a self-administered questionnaire designed to measure perceived health problems (15). The part that measures physical mobility consists of 
8 statements that reflect problems with mobility (see appendix). Responidents had to answer "yes' or "no" to each of these statements. Because the statements vary in severity, they have been weighted by. means of Thurstone's Method of Paired Comparisons (16). The minimum score is 0 and the maximum score is 100 , which represents a situation where the respondent answers affirmatively to all the statements. The higher the score, the greater the mobility problems are. To determine whether there was a decline or not between 1991 and 1997 , a reliable change index was computed using Edwards-Nunnally method of determining improvement rates. This method takes into account the measurement reliability of the NHP mobility scale (17). Decline conform the Edwards-Nunnally method was defined as a $1991-1997$ difference score greater than 6 .

Disease severity. Disease-specific questionnaires on asthma/COPD (18), heart disease $(19,20)$, diabetes mellitus $(21)$, and low back pain $(22,23)$ were used to determine the severity of the chronic disease $(7,8)$. Four categories for asthma/COPD were distinguished: $(1,2,3)$ three categories indicating increasing severity of asthma/COPD (grade 1 to grade 3); and (4) other forms of asthma (18). For heart disease, five categories were distinguished: (1) non-specific symptoms" (2) angina pectoris without heart failure; (3) heart failure without angina pectoris; (4) angina pectoris with heart failure; and (5) other forms of heart disease $(19,20)$. Two categories of diabetes mellitus were distinguished: (1) diabetes without complications; and (2) diabetes with at least one complication (21). Finally, five categories of low back pain were distinguished: (1) low back pain, no radiation, less than three months; (2) low back pain, with radiation, less than three months; (3) low back pain, no radiation, at least three months; (4) low back pain, with radiation, at least three months; and (5) other forms of back complaints $(22,23)$.

Comorbidity. Comorbidity was defined as the number of other diseases that respondents reported. Comorbidity was measured with two variables. The first variable reflects the number of additional severe comorbid diseases that people had (asthma/COPD, coronary, stroke, stomach ulcer, kidney disease, diabetes mellitus, arthritis, rheumatoid arthritis, disease on nervous system, cancer). The second variable indicates the number of less severe comorbid diseases (intestinal disorders, high blood pressure, gallstones, kidney stones, prostate complaints, back pain, joint problems, migraine, depression, chronic skin disease, prolapse, varicose veins, and accidental injury).

\section{Statistical analyses}

All analyses, using SPSS version 10.1, were carried out separately for each chronic disease group and every SES indicator. To determine if there were 
differences in baseline mobility between SES groups, a KrusKal-Wallis test was used. A non-parametric test was used because the NHP-score did not have a normal distribution; many respondents were free of mobility problems. The chi-square test was used to determine whether there were differences in the percent of people with a decline in mobility between SES groups. Logistic regression models were fitted to study the association between SES and disease severity and comorbidity. Disease severity and comorbidity were the dependent variables in these models and were therefore dichotomized. Disease severity was dichotomized as the most severe category compared with the other ones and comorbidity as any comorbid diseases compared with no comorbid disease. These analyses were adjusted for age (continuous variable), sex, and marital status (never married, married, divorced, widowed). Logistic regression models were also fitted to study the association between disease severity and comorbidity on the one hand and mobility decline, as the dependent variable, on the other hand, adjusting for age sex, martial status, and baseline mobility (continuous variable). Finally, the main logistic regression analyses were carried out where the dependent variable was the decline in mobility between 1991 and 1997. The determinant of interest was SES, where the highest SES group was always the reference category. Two logistic regression models were fitted, the first model adjusted for baseline mobility, age, sex, and marital status. Model 2 contained all variables of the first model, as well as severity of the chronic disease and comorbidity. The goodness of fit of the logistic regression models was tested using the Hosmer and Lemeshow test, which tells us something about predicted versus observed classifications. The significance of all logistic regression models was greater than 0.05 , which means that the model's estimates fit the data at an acceptable level. After removing outliers from the data set for the logistic regression analyses, using the studentized residuals and Cook's distance, results were very similar or the same.

\section{RESULTS}

Table 1 presents the number of people at baseline, the median mobility score at baseline, and the percentage of people with a decline in mobility for every SES indicator and for every disease group. At baseline, people in a low SES group had more mobility problems than people in the high SES groups. This was statistically significant for every SES indicator in the asthma/COPD group, the heart disease group and the group with low back pain. In the diabetes group, there were no statistically significant differences between SES groups. The percentage of people 
with a decline in mobility problems generaliy was also highest in the low SES groups. For example, in the asthma/COPD group $42.3 \%$ of the people with a low educational level had a decline in mobility between 1991 and 1997 in comparison to $22.7 \%$ with a high educational level. These higher percentages were not significant for the diabetes group and the low back pain group.

Table 2 presents the results of the association between SES on the one hand and disease severity and severe comorbid diseases on the other hand. Risks of having a severe chronic disease and more severe comorbid diseases generally were higher for lower SES groups, although the heightened risks were not always statistically significant. For example, odds ratios of disease severity in low education groups were $1.92(95 \%$ confidence interval $(\mathrm{Cl}): 1.04-3.55)$ for asthma/COPD, 2.00 (95\% Cl: $0.87-4.60)$ for heart disease, $2.63(95 \% \mathrm{Cl}: 0.61-11.26)$ for diabetes, and $1.10(95 \% \mathrm{Cl}: 0.64-1.88$ ) for low back pain. Odds ratios of severe comorbid diseases in low education groups were 1.94 (95\% Cl: 1.05-3.57) for asthma/COPD, 1.74 (95\% $\mathrm{Cl}: 1.09-2.78)$ for heart disease, 1.47 (95\% Cl: 0.41-5.35) for diabetes, and 1.80 (95\% Cl: 1.11-2.92) for low back pain. The associations between SES and less severe comorbid diseases were highly similar (not tabulated).

The association between disease severity, comorbidity and mobility decline is shown in table 3. A more severe disease increased the risk of getting more mobility problems. The strongest association was found in the most severe category for each disease; asthma/COPD grade 3 (odds ratio (OR): $1.72 ; 95 \% \mathrm{Cl}: 0.97-3.08$ ), angina pectoris and heart failure (OR: $1.62 ; 95 \% \mathrm{Cl}: 1.00-2.62$ ), diabetes with complications (OR: $4.98 ; 95 \% \mathrm{Cl}: 2.02-12.29$ ), low back pain with radiation and at least 3 months (OR: $1.54 ; 95 \% \mathrm{Cl}: 0.97-2.46$ ). Having additional severe comorbid diseases also increased the risk of getting more mobility problems. These results were statistically significant in all disease groups except in the diabetes group. There was only an association with less severe comorbid diseases in the heart disease group (OR: 1.25; $95 \%$ Cil: 1.10-1.42).

Generally, odds ratios of mobility decline, adjusted for age, sex, marital status, and baseline mobility, were significantly higher in low SES groups in comparison to high SES groups (Table 4, Model 1). Low income showed particularly heightened risks of mobility decline; odds ratios were $2.83(95 \% \mathrm{Cl}: 1.58-5.09), 1.97(95 \% \mathrm{Cl}$ : $1.29-3.02), 2.28(95 \% \mathrm{Cl}: 0.70-7.37)$, and $1.81(95 \% \mathrm{Cl}: 1.16-2.83)$ for asthma/COPD, heart disease, diabetes, and low back pain, respectively. In the diabetes group, odds of mobility decline for low SES were not significantly different from the odds for high SES. Furthermore, low educational level did not affect mobility decline in the group with low back pain. Controlling for comorbidity and disease 


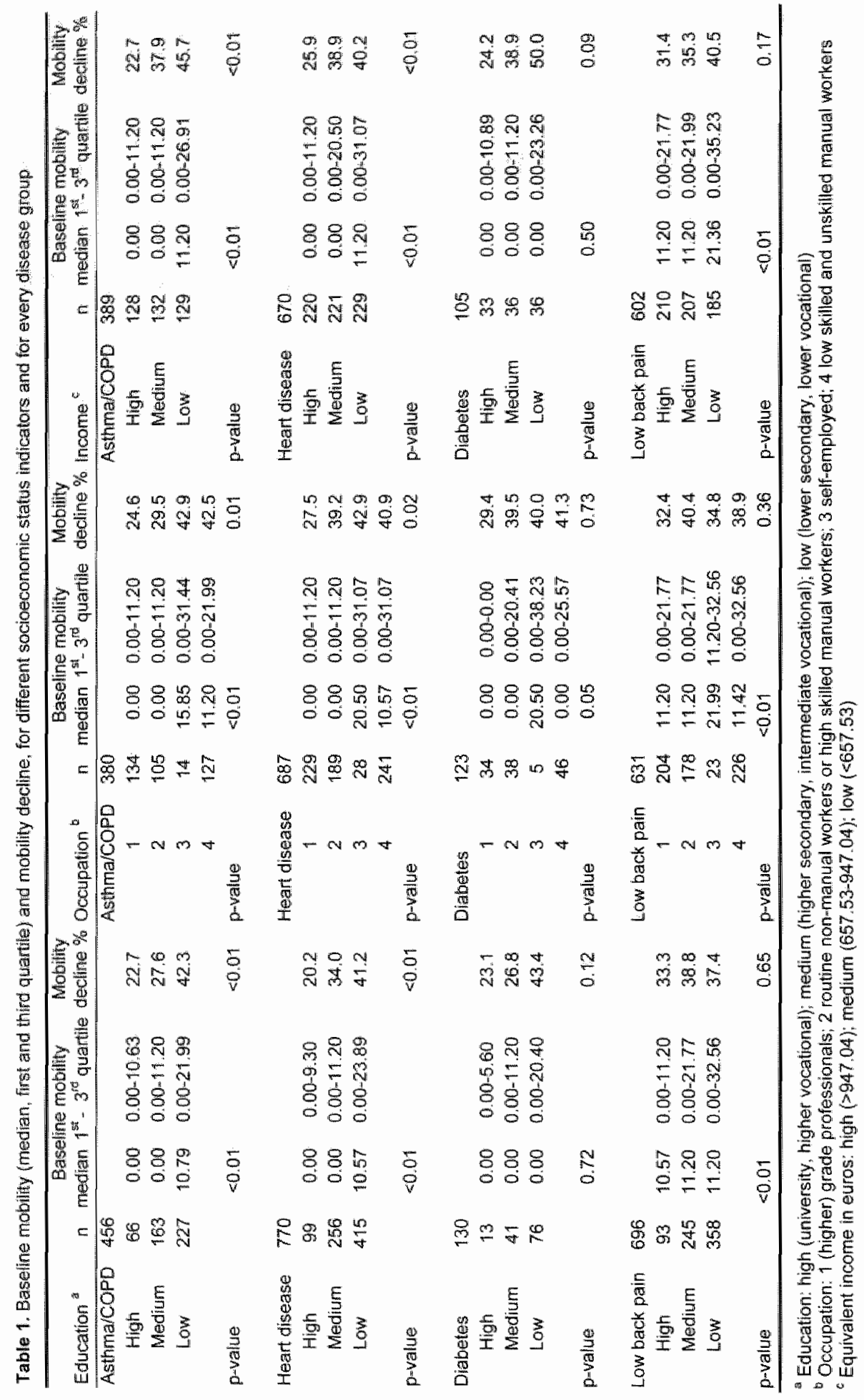




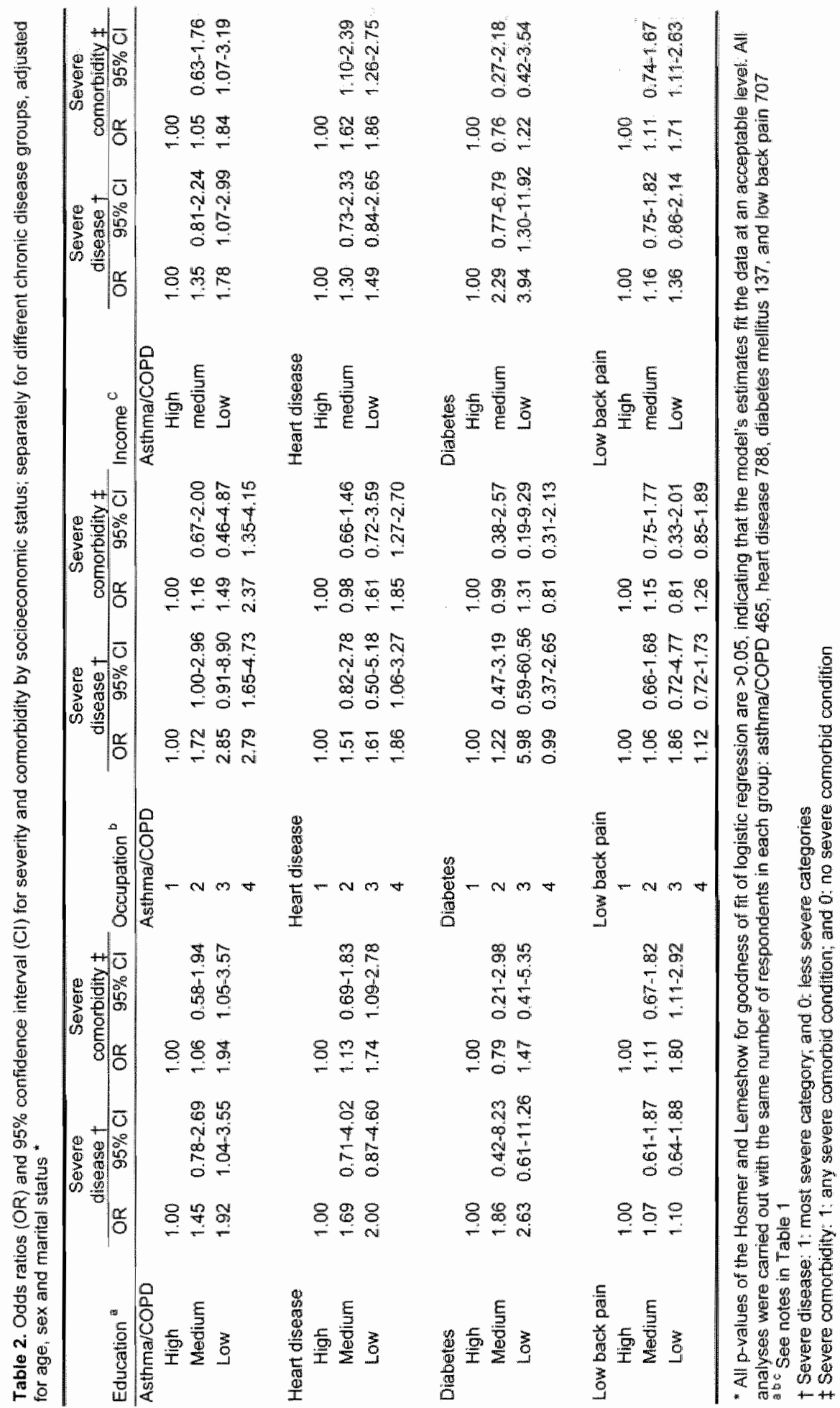


Table 3 odds fatio (OR) and $95 \%$ confidence intarval (C) for decline in mobility by disease sewerify and comorbidivy; separately for diferent chronic disease groups, adjusted for age, sex, marital status, and baselline mobilly ${ }^{*}$

\begin{tabular}{|c|c|c|c|}
\hline \multirow{3}{*}{ Asthma/COPD } & \multirow[b]{4}{*}{ cimale 1} & \multicolumn{2}{|c|}{ Mobilily decline } \\
\hline & & \multirow[t]{2}{*}{ OR } & \multirow[t]{2}{*}{$95 \% \mathrm{Cl}$} \\
\hline & & & \\
\hline \multirow[t]{4}{*}{ Severity } & & 1.00 & \\
\hline & grade 2 & 1.01 & $0.51-201$ \\
\hline & grade $3 t$ & 1.72 & $0.97-3.08$ \\
\hline & other forms of asthma/COPD & 0.78 & $0.38-1.59$ \\
\hline \multicolumn{2}{|c|}{ Severe comorbid disenses } & 1.66 & $1.24-2.22$ \\
\hline \multicolumn{2}{|c|}{ Less severe comorbid diseases } & 1.10 & $0.93-1.30$ \\
\hline \multicolumn{4}{|c|}{ Heart disease } \\
\hline \multirow[t]{5}{*}{ Severity } & non-specific symptoms & 1.00 & \\
\hline & angina pectoris without heart fallure & 1.29 & $0.88-1.88$ \\
\hline & heart failure without angina pectoris & 0.81 & $0.47-1.41$ \\
\hline & angina pectoris with heart fallure $t$ & 1.62 & $1.00-2.62$ \\
\hline & other forms of heart disease & 077 & $0.44-1.36$ \\
\hline \multicolumn{2}{|c|}{ Severe comorbid diseases } & 1.38 & $1.10-1.72$ \\
\hline \multicolumn{2}{|c|}{ Less severe comorbid diseases } & 1.25 & $1.10-1.42$ \\
\hline \multicolumn{4}{|l|}{ Dlabetes } \\
\hline \multirow[t]{2}{*}{ Severity } & without complications & 1.00 & \\
\hline & with complications $\uparrow$ & 4.98 & $2.02-12.29$ \\
\hline \multicolumn{2}{|c|}{ Severe comorbid diseases } & 0.95 & $0.56-1.63$ \\
\hline \multicolumn{2}{|c|}{ Less severe comorbid diseases } & 1.01 & $0.71-9.44$ \\
\hline \multicolumn{4}{|l|}{ Low back pain } \\
\hline \multirow[t]{5}{*}{ Severity } & no radiation, less than 3 months & 1.00 & \\
\hline & with radiation "less than 3 months & 0.95 & $0.60-1.50$ \\
\hline & no radiation, at least 3 months & 1.02 & $0.61-1.72$ \\
\hline & with radiation, at least 3 months + & 1.54 & $0.97-2.46$ \\
\hline & other forms of back complaints & 0.91 & $0.36-2.31$ \\
\hline \multicolumn{2}{|c|}{ Sovere comorbid diseases } & 1.27 & $1.06-1.52$ \\
\hline \multicolumn{2}{|c|}{ Less severe comorbid diserases } & 0.98 & $0.97-0.99$ \\
\hline
\end{tabular}

- See corresponding note in Table 2

- Most severe disease category

severity had only little effect on the odds ratios of mobility decline for low SES (Table 4. Model 2). Almost all significant odds ratios of model 1 remained statistically significant in model 2. In model 1,12 odds ratios were statistically significant. After controlling for disease severity and comorbidity, 10 odds ratios were still statistically significant. Odds ratios also decreased only little between model 1 and 2 . Interaction terms between SES and age, and SES and sex were not statistically significant, which confirmed that the association between SES and mobility decline was similar for all ages and men and women. 
Table 4. Odds ratios (OR) and $95 \%$ confidence interval (Cl) for decline in physical unctioning by sow oweonomio status; separately for different chronic disease groups *

\begin{tabular}{|c|c|c|c|c|c|c|c|c|c|}
\hline & & \multicolumn{2}{|c|}{ AsthmalCOPD } & \multicolumn{2}{|c|}{ Heart disease } & \multicolumn{2}{|c|}{ Diabetes } & \multicolumn{2}{|c|}{ Low back pain } \\
\hline & & OR & $95 \% \mathrm{Cl}$ & OR & $95 \% \mathrm{cl}$ & $\mathrm{OR}$ & $95 \% \mathrm{Cl}$ & OR & $95 \% \mathrm{OI}$ \\
\hline \multicolumn{10}{|l|}{ Education ${ }^{2}$} \\
\hline \multirow[t]{3}{*}{ Model 11} & High & 1.00 & & 1.00 & & 1.00 & & 1.00 & \\
\hline & Medium & 1.18 & $0.58-2.38$ & 1.88 & $1.06 \cdot 3.32$ & 0.98 & $0.19-4.99$ & 1.04 & $0.62-1.76$ \\
\hline & Low & 1.90 & $0.95-3.79$ & 2.40 & 1.384 .16 & 1.77 & 0.388 .33 & 1.03 & $0.62-1.72$ \\
\hline \multirow[t]{3}{*}{ Model $2 \div$} & High & 1.00 & & 1.00 & & 1.00 & & 1.00 & \\
\hline & Medium & 1.07 & $0.52-2.20$ & 1.75 & $0.98-3.12$ & 0.76 & $0.14-4.26$ & 1.02 & $0.60-1.74$ \\
\hline & Low & 1.73 & $0.85-3.53$ & 2.37 & $1.35-4.14$ & 1.18 & $0.87-1.02$ & 1.01 & $0.60-1.70$ \\
\hline \multicolumn{10}{|c|}{ Occupation $^{3}$} \\
\hline \multirow[t]{4}{*}{ Model $1+$} & 1 & 1.00 & & 1.00 & & 1.00 & & 1.00 & \\
\hline & 2 & 1.21 & $0.67-2.17$ & 4.73 & $1.13-2.65$ & 1.65 & $0.55-4.95$ & 1.34 & $0.87-2.08$ \\
\hline & 3 & 2.37 & $0.75-7.50$ & 2.30 & $1.00-5.28$ & 0.97 & $0.11-8.6 \|$ & 1.58 & $0.61-4.07$ \\
\hline & 4 & 2.21 & $1.27-3.86$ & 1.91 & $1.28 \mathrm{~m} 2.86$ & 1. 15 & $0.38-3.44$ & 1.60 & $1.05-2.43$ \\
\hline \multirow[t]{4}{*}{ Model 2 : } & 1 & 1.00 & & 1.00 & & 1.00 & & 1.00 & \\
\hline & 2 & 1.11 & $0.60-2.03$ & 1.67 & $1.09-2.57$ & 1.77 & $0.52-5.96$ & 1,35 & $0.86-2.10$ \\
\hline & 3 & 2.02 & $0.62-6.65$ & 2.21 & $0.95 \cdot 5.16$ & 0.65 & $0.07-6.42$ & 9.61 & $0.62-4.19$ \\
\hline & 4 & 1.79 & $1.00-3.20$ & 1.80 & $1.19 \cdot 2.71$ & 1.45 & $0.42-5.04$ & 1.59 & $1.04-2.45$ \\
\hline \multicolumn{10}{|l|}{ Income: } \\
\hline \multirow[t]{3}{*}{ Madel II } & High & 1.00 & & 1.00 & & 1.00 & & 1.00 & \\
\hline & Medium & 1.81 & $1.02-3.20$ & 1.72 & $1.13-2.61$ & 1.53 & $0.48-4.81$ & 11.26 & $0.82-1.92$ \\
\hline & Low & 2.83 & $1.58-5.09$ & 1.97 & $1.29-3.02$ & 2.28 & $0.70-7.37$ & 1.81 & $1.16-2.83$ \\
\hline \multirow[t]{3}{*}{ Madel 2 t } & High & 1.00 & & 1.00 & & 1.00 & & 1.00 & \\
\hline & Medium & 1.82 & $1.01-3.26$ & 1.69 & $1.10 \cdot 2.59$ & 1.22 & 0.354 .18 & 1.23 & $0.80-1.89$ \\
\hline & Low & 2.60 & $1.43-4.74$ & 1.94 & $1.25-2.99$ & 1.76 & $0.51-6.06$ & 1.69 & $1.07-2.67$ \\
\hline
\end{tabular}

*ee corresponding note in Table 2

ab see noles in Table 1

† Model 1: Adjusted for sex, age, marital status, and baseline mobility

* Model 2: Adjusted for sex, age, marital status, baseline mobility, comorbidity, and baseline severity

\section{DISCUSSION}

In different chronic disease groups (asthma/COPD, heart disease, diabetes mellitus, low back pain), people with a low SES generally had an increased risk of mobility decline in comparison to people with a high SES. Low SES was also associated with more severe chronic diseases and more severe comorbid diseases. Both disease severity and comorbidity were also related to mobility. In spite of these associations disease severity and comorbidity contributed only very little to the SES differentials in mobility decline. This was found across all disease groups and all three SES indicators. Strongest associations were found with equivalent income as SES indicator. Odds ratios in the lowest income groups ranged from 1.69 to 2.60 in the fully adjusted model (Table 4, Model 2). Strongest associations between SES and mobility decline were found in the heart disease group. The contribution of 
disease severity and comorbidity in the heart disease group was not different from the other chronic diseases. Effects were less pronounced in the diabetes group, but this was probably partly due to the small number of people in the diabetes group. These findings imply that in chronically ill patients, low SES is related to decreasing mobility and that the higher prevalence of severe disease and comorbidities in lower SES groups can hardly explain this association.

Because of the longitudinal character of our study, we may conclude that there probably is a causal relation between SES and mobility decline. However, because only baseline data on severity and comorbidity were analyzed, the association between SES on the one hand and disease severity and comorbidity on the other hand might have resulted from reverse causation or health-related mobility (24-26). For example, people having a more severe disease might have ended up in a lower SES group (26). It is likely that this selection effect has a larger effect on income and perhaps occupation than on educational level, as the latter indicator is less sensitive to change during adulthood. In this study, same results were found across all SES indicators, including education. Furthermore, there is substantial evidence that low SES predicts the incidence of all kinds of diseases (27), more severe diseases $(9$, 10), and higher risks of comorbidity (11). Whether based on causation or selection, our findings indicate that the higher prevalence of severe disease and comorbidities in lower social classes can hardly explain the heightened odds of mobility restrictions in these groups.

Our findings imply that there are other factors that explain the association belween low SES and mobility decline. These factors may be related to behavioral factors or psychosocial factors. LOW SES is related to many adverse behavioral factors, such as smoking " excessive alcohol consumption, and decreasing physical activity that on their turn are related to poor health outcomes $(3,28,29)$. There is also evidence that psychosocial factors, such as control belief and stress, play an important role in functional outcomes (30), and also in the association between SES and poor functional outcomes $(31,32)$. Income, being the strongest predictor of mobility, suggests that the direct availability of financial resources might also be important (33). A lack of material resources held by individuals and the availability of public resources might be important in explaining SES differences in health. Life course factors such as lifetime exposures to adverse occupational and social circumstances may also play a role.

Some limitations of the study have to be considered. First, this study was entirely based on self-reports. Despite this limitation, we were able to control for disease severity, using disease-specific questionnaires and comorbidity. However, we only adjusted for disease severity and comorbidity at baseline. Assuming that 
disease severity and comorbidity increase more in low SES groups than in high SES groups over time, the contribution of severity and comorbidity may have been underestimated. Second, our study consists of persons younger than 75 years only. For the present research question, this should be considered a limitation, because generalizability is thus restricted to persons younger than 75 years. SES differences in mobility decline and the role of medical factors therein may be different in persons older than 74 years. Third, we did not have information about the time of onset of disease. It remains unknown whether the time of onset of disease differs between SES groups and the extent to which this affects mobility decline. Fourth, baseline NHP-data were collected during an oral interview, while NHP-data in 1997 with a postal questionnaire. It is possible that people were more likely to admit health problems in the postal survey, therefore we could have overestimated the number of people with a mobility decline. However, it remains unclear whether this affected the association between SES and mobility decline. Fifth, baseline response was $72.2 \%$; and was lower in low SES groups. Attrition due to mortality and non-response was also higher in low SES groups (8). Response at follow up in 1997 was $69.8 \%$. Participants who were lost to follow-up also had statistically significantly worse NHPscores at baseline $(p<0.01)$ in comparison to persons who remained in the study. Furthermore, these persons had more severe chronic diseases and more severe comorbid diseases $(p<0.01)$. The association between SES and mobility decline might therefore be underestimated in this study. Whether the relative contribution of disease severity and comorbidity is equally underestimated remains unknown. Finally, occupation data and income data were missing for 171 and 215, respectively. These persons more often had a lower educational level compared with persons with full data. This may also have led to an underestimation of the effect of occupation and income on mobility decline.

In summary, there is a strong relation between SES and mobility decline among chronically ill persons. Only little of this relation could be explained by disease severity and comorbidity. Findings were similar in patients with asthma/COPD, heart disease, diabetes mellitus, and chronic low back pain. Further research is necessary to determine whether behavioral, material, and/or psychosocial factors additionally contribute to the association between SES and mobility decline among the chronically ill. Our findings are also important for policies aimed at reducing functional limitations in people with chronic diseases, particularly in people from lower SES group. They imply that reducing the risk of severe disease and comorbidities may not be sufficient to reduce physical disabilities and particularly the SES differences therein. 


\section{APPENDIX}

Mobility part of the Nottingham Health Profile

1. I can only walk indoors

2. Ifind it hard to bend

3. I'm unable to walk at all

4. I have trouble getting up and down stairs or steps

5. I find it hard to reach for things

6. I find it hard to dress myself

7. I find it hard to stand for long

8. I need help to walk outside

\section{ACKNOWLEDGEMENT}

The GLOBE study is carried out by the Department of Public Health of the Erasmus Medical Centre Rotterdam, in collaboration with the Public Health Services of the city of Eindhoven and region South-East Brabant. The investiglators are indebted to the participants for their willingness to participate in the study. Over the years, the study is supported by grants of the Ministry of Public Health, Welfare and Sport and the Health Research and Development Council (ZON) and the Netherlands Organisation for Scientific Research (NWO). 


\section{REFERENCES}

1. Grundy $E$, Glaser K. Socio-demographic differences in the onset and progression of disability in early old age: a longitudinal study. Age Ageing 2000;29:149-57.

2. Hemingway $H$, Nicholson $A$, Stafford $M$, Roberts $R$, Marmot $M$. The impact of socioeconomic status on health functioning as assessed by the SF-36 questionnaire the Whitehall II Study. Am $\Downarrow$ Public Health $1997 ; 87 ; 1484-1490$.

3. Martikainen $P$ "Stansfeld $S$, Herningway $H$, Marmot $M$. Determinants of socioeconomic differences in change in physical and mental functioning. Soc Sci Med 1999;49:499-507.

4. Seeman TE, Charpentier PA, Berkman LF, et al. Predicting changes in physical performance in a high-functioning elderly cohort: MacArthur studies of successful aging. J Gerontol A Biol Sci Med Sci 1994:49:M97-108.

5. Brekke M, Hjortdahl $P$, Thelle DS, Kvien TK. Disease activity and severity in patients with rheumatoid arthritis: relations to socioeconomic inequality. Soc Sci Med 1999;48:1743-50.

6. Hemingway $H_{8}$ Stafford $M$, Stansfell $S_{n}$ Shipley $M$, Marmot $M$. Is the SF-36 a valid measure of change in population health? Results from the Whitehall II Study. BMJ 1997;315:1273-9.

7. Mackenbach JP, Borsboom GJ, Nusselder WJ, Looman CW, Schrijvers CT. Determinants of levels and changes of physical functioning in chronically ill persons: results from the GLOBE Study. $J$ Epldemiol Community Health 2001;55:631-8.

8. van der Meer JB, Mackenbach JP. Course of health stattus among chronically ill persons: differentials according to level of education. J Clin Epidemiol 1998;51:171-9.

9. Brekke M, HjortdahI P. Kvien TK. Severity of musculoskeletal pain: relations to socioeconomic inequality. Soc Sci Med 2002:54:221-8.

10. Eachus J, Chan P. Pearson N, Propper C. Davey Smith G. An additional dimension to health inequalities: disease severity and socioeconomic position. J Epidemiol Community Health 1999;53:603-11.

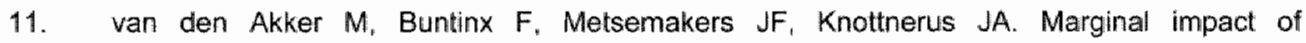
psychosocial factors on multimorbidity: results of an explorative nested case-control study. Soc Sici Med 2000;50:1679-93.

12. Kempen $\mathrm{Gl}$. Ormel $\mathrm{J}$, Brilman $\mathrm{El}$, Relyveld $\mathrm{J}$. Adaptive responses among Dutch elderly: the impact of eight chronic medical conditions on health-related quality of life. Arm J Public Health $1997: 87: 38-44$

13. Mackenbach JP, van de Mheen $H$, Stronks K. A prospective cohort study investigating the explanation of socio-economic inequalities in health in The Netherlands. Soc Sol Med 1994:38:299-308.

14. Erikson R, Goldthorpe $\mathrm{JH}$. The constant flux: a study of class mobility in industrial societies. Oxford: Carendon Press, 1992.

15. Hunt SM, MCEwen J, McKenna SP. Measuring health status. London: Chroom Helm, 1986.

16. McKenna SP. Hunt SM, McEwen J. Weighting the seriousness of perceived health problems using Thurstone"s method of paired comparisons. Int J Epidemiol 1981:10:93-7.

17. Speer DC. Clinically significant change: Jacobson and Truax (1991) revisited. I Consult Clin Psychol 1992;60:402-8.

18. van der Lende $R$, Jansen Koster EJ, Knijpstra S, Meinesz AF, Wever AM, Orie NG. Definitie van CARA in epidemiologie en preventie. Ned Tijdschr Geneeskd 1975;119:1975-80.

19. Baart A. De oudere havenwerker. Aspecten van zijn cardiorespiratoire conditie. Thesis.. 1973 
20. Rose G. Blackburn H. Cardiovascular survey methods. WHO Monograph 1968:56:1-88.

21. Piennings-van der Eerden L. Zelfzorg en motivatie van patienten van diabetes mellitus. Utrecht: Vakgroep Algemene Gezondheidszorg en Epidemiologie; Rijksuniversiteit Utrecht, 1984.

22. Anonymous. Vragentijst ERGO. Rotterdam. Inistituut Epidemiologie \& Biostatistiek. Erasmus Universiteit Rotterdam, 1989.

23. Kuorinka 1. Jonisson B, Kilbom A, at al. Standardised Nordic questionnaires for the analysis of musculoskeletal symptoms. Applied Ergonomics 1987;18:233-237.

24. Blane D, Davey Sinith G, Bartley M. Social selection: what does it contribute to social class differences in health? Soc Health Hilness 1993:15:1-15.

25. Lundberg O. Causal explanations for class inequality in health--an empirical analysis. Soc Sci Med $1991,32: 385-93$.

26. West $P$. Rethinking the health selection explanation for health inequalities. Soc Sci Med 1991;32:373-84.

27. Mackenbach JP, Kunst AE, Cavelaars AE, Groenhof $F$, Geurts JJ. Socioeconomic inequalities in morbidity and mortality in western Europe. The EU Working Group on Socioeconomic Inequalities in Health. Lancet 1997;349:1655-9.

28. Droomers $M$, Schrijvers $C T$, Mackenbach JP. Educational level and decreases in leisure time physical activity: predictors from the Iongitudinal GLOBE study. J Epidemiol Community Health 2001;55:562-8.

29. Marmot MG, Shipley MJ "Rose G. Inequalities in death--specific explanations of a general pattern? Lancet 1984;1:1003-6.

30. Kempen Gl, van Heuvelen MJ, van Sonderen E, van den Brink RH, Kooijman AC, Ormel J. The relationship of functional limitations to disability and the moderating effects of psychological attributes in community-dwelling older persons. Sac Sci Med 1999;48:1161-72.

31. Bosma $H_{\text {e }}$ Schrijwers $C$, Mackenbach JP. Socioeconomic inequalities in mortality and importance of perceived control: cohort study. BMJ 1999;319:1469-70.

32. Stronks $\mathrm{K}$, van de Mheen $\mathrm{H}$, Looman CW, Mackenbach JP. The importance of psychosocial stressors for socio-economic inequalities in perceived health. Soc Sci Med 1998;46:611-23.

33. Lynch JW, Smith GD, Kaplan GA, House JS. Income inequality and mortality: importance to heaith of individual income psychosocial environment, or material conditions. BMJ 2000;320:1200-4. 


\section{3}

The role of psychosocial factors in explaining socioeconomic differences in mobility decline in a chronically ill population: results from the GLOBE study

\section{Published as}

Koster A, Bosma H, van Lenthe FJ, Kempen Gl, Mackenbach JP, van Eijk JT. The role of psychosocial factors in explaining socio-economic differences in mobility decline in a chronically ill population: results from the GLOBE study. Soc Sci Med 2005:61:123-32. 


\section{ABSTRACT}

Objective. In chronically ill patients, mobility develops more unfavorably in persons with low socioeconomic status than in their better-off counterparts. Using longitudinal data from the Dutch GLOBE study (a study of health and living condition of Eindhoven and its surroundings), the present study examines whether psychosocial factors can explain socioeconomic differences in mobility decline, independent of disease severity, comorbidity, and health-related behavior, in a chronically ill population.

Methods. Data were from 1,384 men and woman, aged 15-74 years, suffering from at least one of the four chronic diseases: asthma/COPD, heart disease, diabetes mellitus, and low back pain. Three indicators of socioeconomic status were used: education, occupational class, and income. Change in physical mobility between 1991 and 1997 was measured with the Nottingham Health Profile (NHP). Psychosocial factors were measured extensively and included life events, long term difficulties, coping styles, social support, and personality characteristics.

Results. Low occupational level and low income predicted an increased risk of mobility decline in comparison to people with a higher occupational level and income, even after controlling for sociodemographics, disease severity, comorbidity, and health-related behavior. Additional adjustment for psychosocial factors hardly reduced the socioeconomic status-related odds ratios of mobility decline.

Conclusions. Psychosocial factors (and also health-related behaviors, disease severity, and comorbidity) cannot explain socioeconomic differences in mobility decline in a chronically ill population. Our findings will not give us new tools for prevention and intervention strategies in order to reduce physical disability and particularly the SES differences therein. 


\section{INTRODUCTION}

The association between low socioeconomic status (SES) and poor physical functioning has been well described (1-3). The same associations are also found in chronically ill persons. Chronically ill persons with a low level of education, who belong to a low occupational class, or who have a low income develop more disabilities than their better-off counterparts (4-7). Less clear, however, is how these differences can be explained. Our previous work shows that only very little of the SES differentials in mobility decline could be explained by a higher disease severity and comorbidity in these patients (8). These findings imply that there are other factors important in explaining the association between low SES and mobility decline.

In addition to disease severity and comorbidity, psychosocial factors may be important in explaining the association between low SES and mobility decline. There are studies that show that psychosocial factors explain part of the SES differentials in health $(2,9,10)$. People with low SES generally have a more negative psychosocial profile than people with high SES. LOW SES is related to low personal control beliefs, poor social support, and negative coping styles (10-13). Psychosocial resources influence the perception of events and the degree to which they are experienced as stressful and how people can cope with these stressful situations affects various health outcomes $(10,14)$. Psychosocial factors are linked to ill health and poor functional outcomes $(15,16)$. Aspects of close relationships and negative psychosocial work characteristics have been reported independent predictors of poor health (17). It has also been shown that powerlessness was associated with greater activity limits and greater health problems (18). A review about risk factors for functional decline in community-living elderly shows that there is good evidence that low level of social contacts and poor emotional social support are associated with poor functional outcomes (19). Another sturdy shows that older persons with less psychosocial resources were particularly at risk in developing disabilities (15).

Using longitudinal data from the Dutch GLOBE study we examine the association between SES and mobility decline and whether this can be explained by psychosocial factors (life events, long term difficulties, coping styles, social support, and personality characteristics), independent of disease severity, comorbidity, and health-related behavior, among persons suffering from one or more of four chronic diseases (asthma/ chronic obstructive pulmonary disease (COPD), heart disease, diabetes mellitus, and low back pain). 


\section{METHODS}

\section{Study population}

Data were obtained from the GLOBE (a Dutch acronym for Health and Living Conditions of the Population of the city of Eindhoven and surroundings) study, a longitudinal study that started in 1991 in the south east of the Netherlands, aimed at explaining SES inequalities in health (20). It is based on a cohort of 15 to 74 year old, non-institutionalized people of Dutch nationality. In 1991 the study started with a baseline measurement consisting of a postal survey and an oral interview. A sample of 27,070 inhabitants of 18 municipalities received a postal questionnaire; the sample was drawn from population registers stratified by age and postal code (45-74 years old and people from the highest and lowest SES groups were overrepresented). The response rate of the postal survey was $70.1 \%$ resulting in a study population of 18,973 respondents. A sub-sample of 3,968 persons drawn from respondents to the postal survey was approached for an oral interview. Participants completed an interview and a self-administered questionnaire; the response was $72.2 \%(n=2,867)$. In this sub-sample, people who reported one or more of the following chronic diseases were overrepresented: asthma/COPD, heart disease, diabetes mellitus, and severe low back pain. For the analyses presented in this paper, respondents suffering from at least one of the four chronic diseases were selected, resulting in 2,015 respondents in 1991. Response at follow-up in 1997 was $69.8 \%$ of the 2,015 respondents in 1991, resulting in 1,407 respondents. For 23 participants outcome data were missing, leaving 1,384 participants for the present analyses. The number of respondents in each group was: asthma/COPD; $n=465$, heart disease; $n=788$, diabetes mellitus; $n=137$, and low back pain; $n=707$. There were 580 respondents who suffered from more than one condition.

\section{Measures}

Socioeconomic status. We used three SES indicators: level of education, equivalent income, and accupational class. Three categories of level of education were created: high (university, higher vocational training); medium (higher secondary, intermediate vocational training); low (lower secondary, lower vocational training). Occupational class was measured according to Erikson, Goldthorpe, and Portocarero (EGP) classification (21) that originally consisted of 11 categories. In this study four categories were created: (1) (higher) grade professionals; (2) routine non-manual workers and high skilled manual workers; (3) self-employed; and (4) low skilled and unskilled manual workers. Net equivalent income per month was measured by adding all income components of all household members adjusted for household 
size. Three categories of equivalent income, in euros, were distinguished: high (>947); medium (658-947); and low (<658). Education data were missing for 28 participants; this was 171 for occupation and 215 for income.

Physical mobility. Physical mobility was measured with the Nottingham Health Profile (NHP) (8). The NHP is a self-administered questionnaire designed to measure perceived health problems (22). The part that measures physical mobility consists of 8 statements that reflect problems with mobility (see appendix). Respondents had to answer 'yes' or 'no' to each of these statements. Because the statements vary in severity, they have been weighted by means of Thurstone's Method of Paired Comparisons (23). The minimum score is 0 and the maximum score is 100 , which represents a situation where the respondent answers affirmatively to all the statements. The higher the score, the greater the mobility problems are. To determine whether there was a decline or not between 1991 and 1997, a reliable change index was computed using Eowards-Nunnally method of determining improvement rates. This method takes into account the measurement reliability of the NHP mobility scale (24). Decline conform the Edwards-Nunnally method was defined as a $1991-1997$ difference score greater than 6 .

Psychosocial factors. Psychosocial factors included life events, long term difficulties, coping styles, social support, and personality characteristics. Life events were measured by an nine-item questionnaire about negative events in the past year: moved to another house, substantial drop in income, victim of robbery/theft etc., becoming unemployed, serious illness of partner or other family member, serious illness of parents (or in-laws), child, brother, sister, or good friend, and divorce. Three categories were created; $0,1,2$, or more life events. Long lasting difficulties were measured with an adapted version of the Dutch Long Standing Difficulties List (25). Three different types of long lasting difficulties were distinguished: difficulties with health problems of significant others, problems with relationships including social contacts with parents, partmer, and neighbors, and situational problems including problems with housing and financial problems. For every subscale three categories were created; $0,1,2$, or more problems. Seven coping styles were distinguished: inactive problem focusing, avoidance behavior, depressive reaction pattern, low social support seeking, palliative reaction pattern, low expression of emotions, and pessimism (26). Each coping variable was divided into tertiles. Two dimensions of social support were measured: emotional and instrumental support referring to three significant others; scores were divided into tertiles. Personality characteristics included neuroticism and locus of control. Neuroticism was measured with the 12 item Dutch version of the Eysenck Personality Questionnaire (27); the score was divided into tertiles. Finally, external locus of control was measured by means of the 
11 -item Dutch version of Rotter's locus of control scale (28). This variable was also classified into tertiles.

Disease severity and comorbidity. Disease-specific questionnaires on asthma/COPD (29), heart disease $(30,31)$, diabetes mellitus $(32)$, and low back pain $(33,34)$ were used to determine the severity of the chronic disease. Comorbidity was defined as the number of other diseases that respondents reported. Comorbidity was measured with two variables. The first variable reflects the number of additional severe comorbid diseases that people had, the second variable indicates the number of less severe comorbid diseases. Fuller descriptions of these variables can be found elsewhere (6-8).

Behavioral factors. Behavioral factors included smoking (never, former; current), alcohol consumption (no, low, moderate, excessive), physical activity (no, light, moderate, frequent), and body mass index (BMI) $\left(<20 \mathrm{~kg} / \mathrm{m}^{2}, 20-27 \mathrm{~kg} / \mathrm{m}^{2},>27\right.$ $\left.\mathrm{kg} / \mathrm{m}^{2}\right)$. Behavioral factors are described in more detail elsewhere (35).

Sociodemographics. Sociodemographics included age (continuous), sex, and marital status (never married, married "divorced, widowed)

\section{Statistical analyses}

All analyses were performed using SPSS version 11.5. A chi-square test was used to determine whether there were differences in the percent of people with a decline in mobility between SES groups. To evaluate the association between SES and psychosocial factors, logistic regression models were fitted. Psychosocial factors were the dependent variables in these models and were therefore dichatomized as the worst category versus the other ones. The highest SES group was always the reference category. These analyses were adjusted for sociodemographics, disease severity, and comorbidity. Logistic regression models were also fitted to study the association between psychosocial factors on the one hand and a decline in mobility between 1991 and 1997, as the dependent variable, on the other hand, adjusting for sociodemographics, baseline mobility, disease severity, and comorbidity. Finally, the main logistic regression analyses were carried out to study the association between SES and mobility decline. The model adjusted for sociodemographics, baseline mobility, disease severity, comorbidity, and behavioral factors. To examine the contribution of psychosocial factors, they were separately introduced into that model. 


\section{RESULTS}

The mean age of the study sample $(n=1,384)$ was 53.7 years (standard deviation $(S D)=2.5) ; 50.1 \%$ were women. Table 1 shows the percentage of people in each SES group and the percentage of people with a decline in mobility according to SES. More people with lOw education, Jow occupational level or low income had a decline in mobility than those in higher SES groups. For example, $37.2 \%$ of the people with low education had a decline in mobility between 1991 and 1997 in comparison to $25.4 \%$ with high education.

Table 1. Percentage of moblity decline according to socioeconomic status

\begin{tabular}{|c|c|c|c|}
\hline \multirow{2}{*}{ Socioeconomic status } & \multirow{2}{*}{$\frac{n=1,384}{\%}$} & \multicolumn{2}{|c|}{ Mobility decline } \\
\hline & & $\%$ & $p$-value \\
\hline \multicolumn{4}{|l|}{ Education $^{2}$} \\
\hline High & 14.5 & 25.4 & $<0.01$ \\
\hline Medium & 35.0 & 31.3 & \\
\hline Low & 48.4 & 37.2 & \\
\hline \multicolumn{4}{|l|}{ Occupation" } \\
\hline 1 & 30.1 & 27.3 & 0.01 \\
\hline 2 & 24.9 & 33.7 & \\
\hline 3 & 3.4 & 38.3 & \\
\hline 4 & 29.3 & 37.0 & \\
\hline \multicolumn{4}{|l|}{ Income ${ }^{c}$} \\
\hline High & 30.1 & 25.5 & $<0.01$ \\
\hline Medium & 28.2 & 34.6 & \\
\hline Low & 26.2 & 39.1 & \\
\hline
\end{tabular}

a Education: high (uniwersily, higher vocational); medium (higher secondary, intermediate vocational); low (lower secondary, lower vocational)

- Occupation: 1 (higher) grade professionals; 2 routhe nom-marhual workers of high skilled manual workers; 3 self-employed; 4 low skilled and unskilled manual workers

"Equivalent income in euros" high ( $>947.04)$; medium $(657.53 .947 .04)$; low $(<657.53)$

Generally, people with low SES have a more negative psychosocilal profile than people in high SES groups (Table 2). Inactive problem focusing, an avoiding coping style, and low locus of control were statistically significantly associated with low education. Low occupational level and low income. Low SES showed a particularly increased risk of low locus of control: odds ratios. (OR) were 7.56 (95\% confidence interval (Cl): $4.57-12.47$ ) in the lowest education group, $4.72(95 \% \mathrm{Cl}$ : $3.35-6.66)$ in the group with low skilled and unskilled manual workers, and 3.33 (95\% 


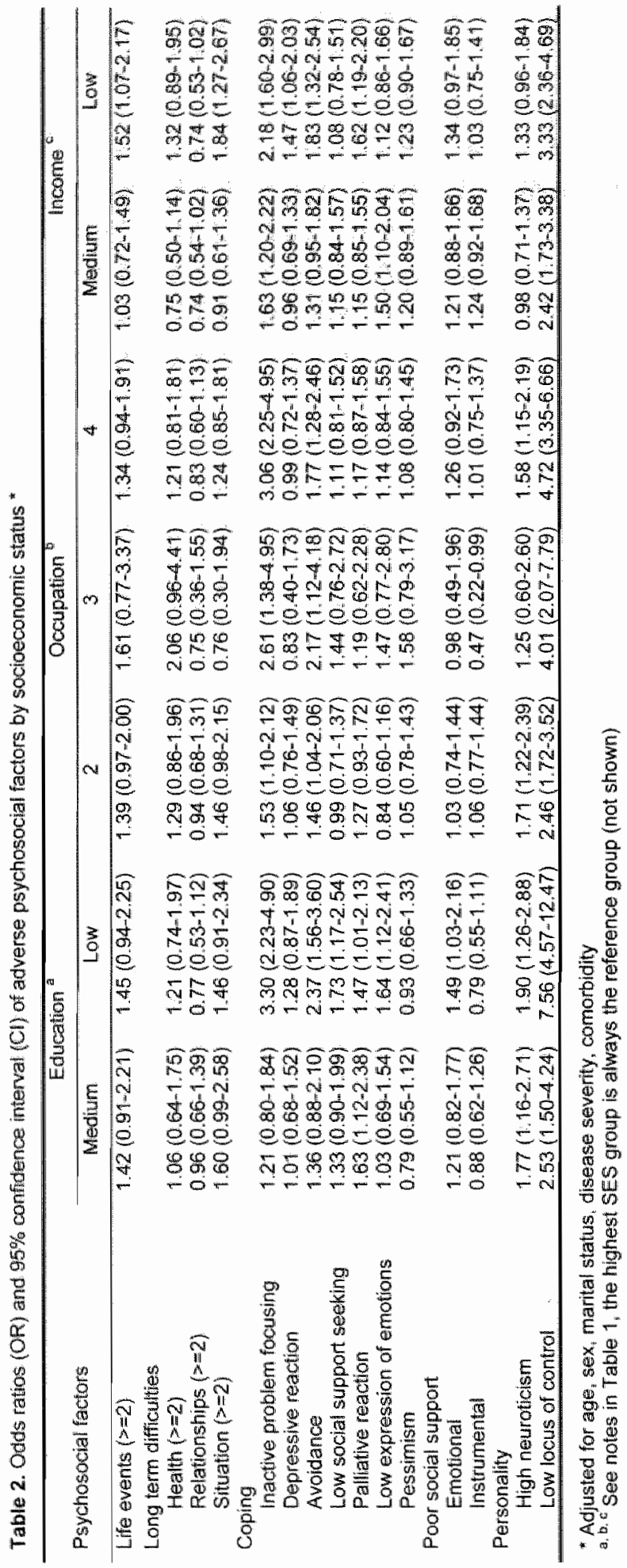


Cl: 2.36-4.69) in the lowest income group. Long term difficuities with respect to health and relationships, and pessimistic coping style were not significantly associated with any of the SES indicators.

Table 3 shows the results of the association between psychosocial characteristics and mobility decline. Only low expressions of emotions (OR: 1.36, $95 \% \mathrm{Cl}: 1.00-1.84$ ) and high neuroticism (OR: 1.68, 95\% Cl: 1.23-2.31) were statistically significant predictors of mobility decline. Results were similar without adjustment for disease severity and comorbidity (data not shown).

Generally, odds ratios of mobility decline, adjusted for sociodemographics, baseline mobility, disease severity, comorbidity, and health-related behavior were higher in low SES groups in comparison to high SES groups (Table 4). Highest risks were found for low income: odds ratios were $1.79(95 \% \mathrm{Cl}: 1.24-2.57)$ for lowest income group and $1.34(95 \% \mathrm{Cl}: 0.94-1.90)$ for the medium income group. Odds ratios of mobility decline for low education were not statistically significant; odds ratios were 1.04 (95\% Cl: 0.68-1.59) for the medium education group and 1.15 (95\% $\mathrm{Cl}: 0.75-1.75)$ in the lowest education group. Life events, long term difficulties, coping styles, social support, and personality characteristics were separately introduced into the first model. Psychosocial factors hardly reduced the odds ratios of the first model. Adjusting for the seven different coping styles even slightly increased the odds ratios. The odds ratio of mobility decline in the lowest income group remains statistically significant even after adjusting for the different psychosocial factors.

In additional analyses (data not shown) the psychosocial factors were added to the final model as continuous variables and we also determined the role of all psychosocial items individually. This did, however, not change our general findings that psychosocial factors hardly reduced to odds ratios of mobility decline. Furthermore, the role of psychosocial factors in explaining the association between SES and mobility decline was not different between the four chronic disease groups. Interactions between life events and long term difficulties on the one hand and coping, sociall support, and personality on the other hand were not statistically significant and did not contribute to the SES/ mobility decline relationship either. 
Chapter 3

Table 3. Odos ratios (OR) and 95\% confidence interval (C) for mabtity decline by prychosocial characteristics *

\begin{tabular}{|c|c|c|c|}
\hline \multirow{2}{*}{ Pychosocial factors } & & \multicolumn{2}{|c|}{ Mobility decline $97-91$} \\
\hline & & OR & $95 \% \mathrm{Cl}$ \\
\hline \multirow[t]{3}{*}{ Lfe events } & lowest tertile & 1.00 & \\
\hline & middle tentile & 1.07 & $0.81 \cdot 1.41$ \\
\hline & highesst tertile & 1.11 & $0.81-1.51$ \\
\hline \multirow[t]{12}{*}{ Long term difficulties } & Health & & \\
\hline & lowes I tertile & 1.00 & \\
\hline & midde lentile & 0.89 & $0.66-1.14$ \\
\hline & highest terthe & 1.35 & $0.96-1.89$ \\
\hline & Relationisnips & & \\
\hline & Iowest thertile & 1.00 & \\
\hline & middle lertle & 1.15 & $0.82-1.61$ \\
\hline & highest tertile & 1.02 & $0.77-1.35$ \\
\hline & Shluation & & \\
\hline & lowest tertle & 1.00 & \\
\hline & middle tertile & 1.25 & $0.91-1.71$ \\
\hline & highest tertile & 1.21 & $0.87-1.66$ \\
\hline \multirow[t]{28}{*}{ Coping } & Inactive problem focusing & & \\
\hline & lowest tertile & 1.00 & \\
\hline & middle tertile & 0.94 & $0.70-1.25$ \\
\hline & highest tertile & 0.86 & $0.64-1.16$ \\
\hline & Depressive reaction & & \\
\hline & lowest tertile & 1.00 & \\
\hline & middle tertile & 0.87 & $0.65-1.16$ \\
\hline & highest tertile & 1.07 & $0.78-1.47$ \\
\hline & Awoidance & & \\
\hline & lowegst tertile & 1.00 & \\
\hline & middle tertile & 0.98 & $0.74-1.30$ \\
\hline & highest tertile & 1.14 & $0.84-1.54$ \\
\hline & Low social support seeking & & \\
\hline & lowest tertile & 1.00 & \\
\hline & middle tertile & 1.11 & $0.82-1.50$ \\
\hline & highest tertile & 1.15 & $0.86-1.54$ \\
\hline & Palliative reaction & & \\
\hline & lowest tertile & 1.00 & \\
\hline & middle tertile & 0.91 & $0.66-1.24$ \\
\hline & highest tertile & 1.05 & $0.79-1.40$ \\
\hline & Low expression of emotions & & \\
\hline & lowest tertile & 1.00 & \\
\hline & middle tertile & 1.07 & $0.78-1.51$ \\
\hline & highest tertile & 1.36 & $1.00-1.84$ \\
\hline & Pessimism & & \\
\hline & lowest tertile & 1.00 & \\
\hline & middle terlile & 1.14 & $0.84-1.53$ \\
\hline & highest tertile & 1.09 & $0.81-1.47$ \\
\hline \multirow[t]{8}{*}{ Poor social suppoit } & Emotional & & \\
\hline & lowest tertile & 1.00 & \\
\hline & middle tertile & 1.05 & $0.78-1.42$ \\
\hline & highest tertile & 0.95 & $0.71-1.28$ \\
\hline & Instrumental & & \\
\hline & lowest tertile & 1.00 & \\
\hline & middle tertile & 0.93 & $0.70 \cdot 1.23$ \\
\hline & highest tertile & 0.90 & $0.67-1.22$ \\
\hline \multirow[t]{8}{*}{ Personality } & Hilgh neuroticism & & \\
\hline & lowest tertile & 1.00 & \\
\hline & midd le tertile & 1.13 & $0.84-1.54$ \\
\hline & highest tertile & 1.68 & $1.23-2.31$ \\
\hline & Low locus of control & & \\
\hline & lowest tertile & 1.00 & \\
\hline & middle tertile & 1.08 & $0.80-1.46$ \\
\hline & highest tertile & 1.25 & $0.91-1.70$ \\
\hline
\end{tabular}

\footnotetext{
* Adjusted for age, sex, marital status, baseline mobility, disease severity, comorbidity
} 


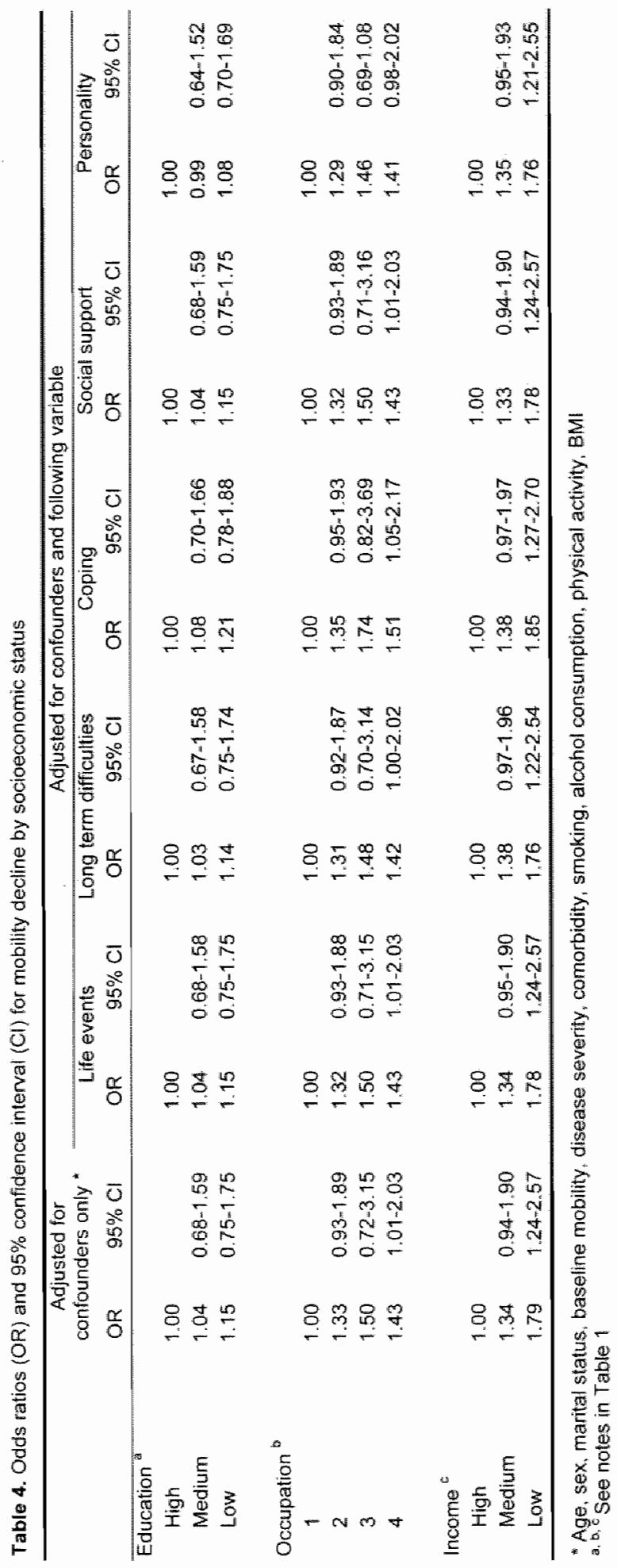




\section{DISCUSSION}

In a chronically ill population, low occupational level and low income predicted an increased risk of mobility decline during six years of follow-up in comparison to people with a higher occupational level and income, even after controlling for sociodemographics, disease severity, comorbidity, and health-related behavior. Low SES was also associated with a more negative psychosocial profile. There was a weak association between psychosocial factors and a decline in mobility; only low expressions of emotions and high neuroticism were significant predictors of a decline in mobility between 1991 and 1997. Psychosocial factors could not explain the SES differentials in mobility decline because additional adjustment for psychosocial factors hardly reduced the SES-related odds ratios of mobility decline.

Psychosocial factors were measured extensively allowing a comprehensive assessment of the role of these factors in the association between SES and mobility decline. However, there could be other psychosocial factors, which we did not measure, involved in the association between SES and mobility decline. For example, job related stressors that are known to be related to low SES and poor health outcomes were not included $(13,17,36,37)$. These stressors were not included because this would substantially reduce the sample size (only the employed). Furthermore, we only adjusted for psychosocial factors at baseline, information about change in psychosocial factors during the life course was not available. Assuming that psychosocial characteristics develop more unfavorably over time in low SES groups than in high SES groups, the contribution of psychosocial factors may have been underestimated. In addition, the role of psychosocial factors in the association between low SES and mobility decline was determined after control for disease severity, comorbidity, and health-related behavior. There is some evidence that psychosocial factors affect health via behavioral factors $(13,38)$. Therefore, we might have underestimated the role of psychosocial variables in the SES/mobility decline relationship. However, in additional analyses, where we did not control for behavioral factors, psychosocial factors still explained only little of the SES differentials in mobility decline (not tabulated).

In this study we found only a weak association between psychosacial factors and mobility decline. This is in contrast with other studies that show much stronger associations between psychosocial factors and functional outcomes $(2,10,15,17$. 19). Most of these studies were carried out in middle-aged and older populations, our study has a rather wide age range. However, in additional analyses where we conducted the same analyses in a group over 55 years old, we found similar results (data not shown). Similar results between psychosocial factors and mobility decline 
were also found in additional analyses with mobility decline as a continuous variable. Stronger associations between psychosocial factors and baseline mobility were found in additional cross-sectional analyses (not tabulated). This is consistent with a study by Mackenbach et al. (2001) where the authors find significant cross-sectional associations between various psychosocial characteristics and physical disability but no significant longitudinal associations. A reason for not finding these longitudinal associations could be the relatively short period of follow-up. In addition, the possibility of reversed causation between psychosocial factors and mobility decline cannot be excluded in the cross-sectional analyses.

Factors that we did not include, which could also be important in explaining the SES differentials in mobility decline, are material factors. Income, being the strongest predictor of mobility decline in our study, suggests that the direct availability of financial resources might be important $(2,39)$. A lack of material resources held by individuals and the differential availability of public resources, such as schooling, health care, social welfare, and working conditions, might be important in explaining SES differences in health. On the other hand, long term situational difficulties, which included financial problems, were not strongly associated with SES and mobility decline in this study. In additional analyses with income, where we also adjusted for difficulties with paying bills for food, rent or electricity (or related aspects) in the past year, low income remained a significant predictor of mobility decline (not tabulated).

This study has some limitations. First, we did not have an objective measure of physical function, our outcome is rather subjective because it was entirely based on self-reports. People with a negative psychosocial profile may report greater problems concerning their physical function, without objective evidence for their reported worse physical performance. This could have led to an overestimation of the association between psychosocial factors and mobility decline. In this study, however, we found only a weak association between psychosocial factors and mobility decline. In addition, our study has a longitudinal character and therefore the potentiall for this effect is minimized because this would be present at baseline as well as follow-up. Second, baseline NHP-data were collected during an oral interview, while NHP-data in 1997 with a postal questionnaire. It is possible that people were more likely to admit health problems in the postal survey, therefore we could have overestimated the number of people with a mobility decline. However, it remains unclear whether this affected the association between SES and mobility decline and the minor role of psychosocial factors therein. Third, baseline response was $72.2 \%$; and was lower in low SES groups. Attrition due to mortality and nonresponse was also higher in low SES groups $(p<0.001)(7)$. Response at follow up in 1997 was $69.8 \%$. Participants without follow-up data also had statistically significantly 
worse NHP-scores at baseline $(\mathrm{p}<0.01)$ in comparison to persons who remained in the study. The association between SES and mobility decline might therefore be underestimated in this study. Finally, occupation data and income data were missing for 171 and 215 , respectively. These persons more often had a lower educational level compared with persons with full data. This may also have led to an underestimation of the effect of occupation and income on mobility decline.

In summary, psychosocial factors (and also health-related behaviors, disease severity, and comorbidity) cannot explain SES differentials in mobility decline in a chronically ill population. Our findings will not give us new tools for prevention and intervention strategies in order to reduce physical disability and particularly the SES differences therein.

\section{APPENDIX}

Mobility part of the Nottingham Health Profile

1. I can only walk indoors

2. I find it hard to bend

3. I'm unable to walk at all

4. I have trouble getting up and down stairs or steps

5. I find it hard to reach for things

6. I find it hard to dress myself

7. I find it hard to stand for long

8. I need help to walk outside

\section{ACKNOWLEDGEMENT}

The GLOBE study is carried out by the Department of Public Health of the Erasmus Medical Centre Rotterdam, in collaboration with the Public Health Services of the city of Eindhoven and region South-East Brabant. The investigators are indebted to the participants for their willingness to participate in the study. Over the years, the study is supported by grants of the Ministry of Public Health, Welfare and Sport and the Health Research and Development Council (ZON) and the Netherlands Organisation for Scientific Research (NWO). 


\section{REFERENCES}

1. Hemingway $H$, Nicholson $A$, Stafford $M$, Roberts $R$, Marmot M. The impact of socioeconomic Sitatus on health functioning as assessed by the SF-36 questionnaire: the Whitehall II Study. Am I Public Health 1997;87:1484-1490.

2. Martikainen P, Stansfeld S, Hemingway $H$, Marmot M. Determinants of socioeconomic differences in change in physical and mental functioning. Soc Sci Med 1999:49:499-507.

3. Seeman TE, Charpentier PA, Berkman LF, et al. Predicting changes in physical performance in a high-functioning elderly cohort: MacArthur studies of successful aging. J Gerontol A Biol Sci Med Sci 1994;49:M97-108.

4. Brekke M. Hjortdahl P. Thelle DS, Kvien TK. Disease activity and severity in patients with rheumatoid arthritis: relations to socioeconomic inequality. Soc Sci Med 1999;48:1743-50.

5. Hemingway $H$, Stafford $M$, Stansfeld $S$, Shipley $M$, Marmot $M$. Is the SF-36 a valid measure of change in population health? Results from the Whitehall II Study. BMJ 1997;315:1273-9.

6. Mackenbach JP, Borsboom GJ, Nusselder WJ, Looman CW, Schrijvers CT. Determinants of levels and changes of physical functioning in chronically ill persons: results from the GLOBE Study. J Epidemiol Community Health 2001;55:631-8.

7. van der Meer JB, Mackenbach JP. Course of health status among chronically ill persons: differentials according to level of education. J Clin Epidemiol 1998:51:171-9.

8. Koster A, Bosma H, Kempen GI, Van Lenthe FJ, Van Eijk JT, Mackenbach JP. Socioeconomic inequalities in mobility decline in chronic disease groups (asthma/COPD, heart disease, diabetes mellitus, low back pain): only a minor role for disease severity and comorbidity. J Epidemiol Community Health 2004;58:862-9.

9. Stronks $K$, van de Mheen $\mathrm{H}$, Looman $\mathrm{CW}$, Mackenbach JP. The importance of psychosocial stressors for socia-economic inequalities in perceived health. Soc Sci Med 1998;46:611-23.

10. Taylor SE, Seeman TE. Psychosocial resources and the SES-health relationship. Ann N $Y$ Acad Sci 1999;896:210-25.

11. Bosma H, Schrijvers $C$, Mackenbach JP. Socioeconomic inequalities in mortality and importance of perceived control: cohort study. BM $\downarrow 1999 ; 319: 1469-70$.

12. Marmot $M$, Wilkinson RG. Psychosocial and material pathways in the relation between income and health: a response to Lynch et al. BMJ 2001;322:1233-6.

13. Kristenson M, Eriksen HR. Sluiter JK, Starke D, Ursin H. Psychobiological mechanisms of socioeconomic differences in health. Soc Sci Med 2004,58:1511-22.

14. Baum A, Garofalo JP. Yali AM. Socioeconomic status and chronic stress. Does stress account for SES effects on health? Ann N Y Acad Sci 1999;896:131-44.

15. Kempen Gl, wan Heuvelen MJ, van Sonderen E, van den Brink RH, Kooijman AC, Omel J. The relationship of functional limitations to disability and the moderating effects of psychological attributes in community-dwelling older persons. Soc Sci Med 1999;48:1161-72.

16. Siegrist $J$ Marmot M. Health inequalities and the psychosocial environment-two scientific challenges. Soc Sici Med 2004;58:1463-73.

17. Stansfeld SA. Bosma $H_{2}$. Hemingway $H_{n}$ Marmot MG. Psychosocial work characteristics and social support as predictors of SF-36 health functioning: the Whitehall II study. Psychol Med $1998 ; 60: 247-255$.

18. Seeman $M_{4}$ Lewis $S$. Powerlessness, health and mortality: a longitudinal study of older men and mature women. Soc Sci Med 1995; 41:517-25. 
19. Stuck AE, Walthert JM, Nikolaus T, Bula CJ, Hohmann C. Beck JC. Risk factors for functional status decline in community-living elderly people: a systematic literature review. Soc Sci Med 1999;48:44:45-69.

20. Mackenbach JP, van de Mheen H. Stronks K. A prospective cohort study investigating the explanation of socio-economic inequalities in health in The Netherlands. Soc Sci Med 1994;38:299-308.

21. Erikson $\mathrm{R}$, Goldthorpe $\mathrm{JH}_{*}$ Portocaero $\mathrm{L}$. Intergenerational class mability and the convergence thesis: England, France and Sweden. Br J Sociol 1983;34:303-343.

22. Hunt SM, McEwen J, McKenna SP. Measuring health status, London: Chroom Hellm, 1986.

23. McKenna SP, Hunt SM, MCEwen J. Weighting the seriousness of perceived heallth problems using Thurstone's method of paired comparisons. Int J Epidemiol 1981;10:93-7.

24. Speer DC. Clinically significant change: Jacobson and Truax (1991) revisited. J Consult Clin Psychol 1992;60:402-8.

25. Hendriks AAJ. Ormel $\mathrm{J}$, van de Willige $\mathrm{G}$. Langdurige moeilikheden gemeten volgens zelf beoordelingsvragenlijst en semi-gestructrureerd interview. Gedrag en Gezondheid $1990 ; 18: 273-83$.

26. Schreurs $P$, Tellegen $B$, Vromans ISY, van de Willige $G$. De ontwikkeling van de Utrechtse coping lijst. Utrecht: Vakgroep Klinische Psychologie, Rijksuniversiteit Utrecht, 1983.

27. Eysenck SBG, Eysenck HJ, Barrett P. A revised version of the psychotism scale. Pers Ind Diff 1985;6:21-29.

28. Rotter JB. Generalized expectancies for internal versus external control of reinforcement. Psychol Monogr 1966;80:1-28.

29. van der Lende $R$, Jansen Koster EJ, Knijpstra $S$, Meinesz AF, Wever AM, Orie NG. Definitie van CARA in epidemiologie en preventie. Ned Tijdschr Geneeskd 1975;119:1975-80.

30. Rose G, Blackburn H. Cardiovascular survey methods. WHO Monograph 1968:56:1-88.

31. Baart A. De oudere thavenwerker. Aspecten van zijn cardiorespiratoire conditie. Thesis., 1973.

32. Pennings-van der Eerden $L$. Zelfzorg en motivatie van patiënten van diabetes mellitus. Utrecht: Vakgroep Algemene Gezondheidszarg en Epidemialogie; Rijksuniversiteit Utrecht, 1984:

33. Kuorinka I, Jansson B, Kilbom A, et al s Standardised Nordic questionnaires for the analysis of musculoskeletal symptoms. Applied Ergonomics 1987;18:233-237.

34. Anonymous. Vragenllijst ERGO. Rotterdam: Instituut Epidemiologie \& Biostatistiek. Erasmus Universiteit Rotterdam, 1989.

35. van Lenthe FJ, Gevers E, Joung IM, Bosma H, Mackenbach JP. Material and behavioral factors in the explanation of educational differences in incidence of acute myocardial infarction: the Globe study. Ann Epidemial 2002;12:535-42.

36. Schrijwers CT, van de Mheen HD, Stronks $K$, Mackenbach JP. Socioeconomic inequalities in health in the working population: the contribution of working conditions. Int $J$ Epidemiol 1998:27:1011-8.

37. Bosma H, Marmot MG, Hemingway $H$, Nicholson AC, Brunner $E$, Stansfeld SA. Low job control and risk of coronary heart disease in Whitehall il (prospective cohort) study. BMJ $1997: 314: 558-65$.

38. Martikainen P, Bartley M, Lahelma E. Psychosocial determinants of health in sociall epidemiology. Int J Epidemiol 2002;31:1091-3. 
39. Lynch JW, Smith GD, Kaplan GA, House JS. Income inequality and mortality: importance to health of individual income, psychosocial environment, or material conditions. BMJ 2000;320:1200-4. 



\section{4}

Explanations of socioeconomic differences in changes in physical function in older adults

Submitted as

Koster A, Bosma H, Broese van Groenou MI, Kempen GI, Penninx BW, van Eijk JT, Deeg DJ. Explanations of socioeconomic differences in changes in physical function in older adults. 


\section{ABSTRACT}

Objective. This study examines the association between socioeconomic status and changes in physical function in younger- (aged 55-70 years) and older-old (aged 7085 years) adults and seeks to determine the relative contribution of diseases, behavioral, and psychosocial factors in explaining this association.

Methods. Data were from 2,366 men and women, aged 55-85 years, participating in the Longitudinal Aging Study Amsterdam (LASA). Two indicators of socioeconomic status were used: education and income. Physical function was measured by selfreported physical ability over nine years of follow-up.

Results. In older adults, low socioeconomic status was related to a poorer level of physical function during nine years of follow-up. In subjects who were between 55 and 70 years old, there was an additional significant socioeconomic-differential decline in physical function, while socioeconomic differentials did not further widen in subjects 70 years and older. Behavioral factors, mainly BMI and physical activity, largely explained the socioeconomic differences in physical function in the youngest age group, while psychosocial factors reduced socioeconomic status differences most in the oldest age group.

Conclusions. The findings indicate age-specificity of both the pattern of socioeconomic status differences in function in older persons and the mechanisms underlying these associations. 


\section{INTRODUCTION}

Low socioeconomic status (SES) is related to poor physical function and the development of physical disabilities in older adults (1-6). Disability, usually defined as the inability to carry out the usual tasks of daily living, is established as a powerful measure of health status in old age (7). In addition, physical disability in older persons is related to many diseases and has been shown to be a predictor of mortality in older adults. Therefore, it is important to understand what factors to intervene upon in order to reduce physical disabilities and the SES differences therein.

Several factors, including biomedical, behavioral, and psychosocial factors, may be important in explaining these SES differences in physical function. Biomedical factors, such as cardiovascular disease, stroke, and diabetes, are related to both low SES and adverse functional outcomes (8-12). A recent study shows that biomedical factors, including a wide range of diseases and biological risk factors, explained part of the SES differences in mobility limitation incidence in older adults (5). Low SES is also related to many adverse behavioral factors, such as smoking, excessive alcohol consumption, and decreasing physical activity "that in turn are related to poor functional outcomes (13-15). Finally, psychosocial factors may be important in explaining SES differences in poor functional outcomes because people with low SES generally have fewer psychosocial resources than people with high SES (16-18). Psychosocial factors, such as control beliefs and social support, are also linked to ill health and poor functional outcomes (19-21).

The present study examines the association between SES and iongitudinal changes in physical function in a representative sample of Dutch older adults, who participated in the Longitudinal Aging Study Amsterdam. The contribution of a number of potential explanatory factors to explain SES differences in physical function has been studied before. In this study, however, we will integrate several explanatory factors, including diseases, behavioral, and psychosocial factors in order to determine the relative contribution of these factors to the explanation of SES inequalities in changes in physical function. Moreover, it is examined whether the effect of SES is different for younger-and older-old and for men and women. 


\section{METHODS}

\section{Study population}

Data were from the Longitudinal Aging Study Amsterdam (LASA), an ongoing cohort study on predictors and consequences of changes in well-being and autonomy in older persons in the Netherlands (22). A random sample of persons, 55 to 85 years of age, was drawn from the population registers of 11 municipalities. This sample was originally recruited for the NESTOR study on Living Arrangements and Social Networks of older adults (LSN) in 1992 (23). The response rate was $62.3 \%$ $(n=3,805)$. About eleven months after the LSN interview, 3,107 (81.7\%) subjects were enrolled in the main baseline interview of LASA conducted between September 1992 and September 1993. At the first follow-up in 1995/1996, 2,545 participants took part in the study: $416(13.4 \%)$ had died and $146(4.7 \%)$ were lost to follow-up for other reasons (refusal, too frail, could not be contacted). At the second follow-up measurement in 1998/1999, 2,076 persons participated in the study; 343 (13.5\%) had died and $126(5.0 \%)$ were lost to follow-up for other reasons. At the third followup measurement in 2001/2002, 1,691 persons took part in the study; $289(13.9 \%)$ had died and $96(4.6 \%)$ were lost to follow-up for other reasons. For the present study, respondents were selected with data on physical function at at least two measurements, resulting in 2,366 participants.

\section{Measures}

Socioeconomic status. Two indicators of SES were used, education and household income. Categories for education were: high (university, college, higher vocational, general secondary, and intermediate vocational education) medium (general intermediate, and lower vocational education), and low (elementary education or less). For monthly net household income, three categories were distinguished: high (greater or equal to 1,035 euro), medium (between 625 and less than 1,035 euro), and low (less than 625 euro). For participants with a partner living in the household, household income was multiplied by 0.7 to make it comparable to the incomes in a one-person household. Income data at baseline were missing for 342 respondents. For 290 respondents imputations were made using income data collected at the LSN measurement in 1992 or follow-up measurements (3). For 52 participants income data were missing at all measurements; therefore they were excluded from the analyses with income, resulting in 2,314 participants for the analyses with income. 
Physical function. Physical function was measured by self-report. At each measurement cycle questions were asked about the degree to which the respondent had difficulty performing six usual daily activities: walking up and down a 15-step staircase without resting, getting (un)dressed, getting up from and sitting down in a chair, cutting own toenails, walking 5 minutes outdoors without resting, and using own or public transport (24). The response categories were: (0) not able to do, (1) oniy with help, (2) with much difficulty, (3) with some difficulty, and (4) without difficulty. The sum score of the six items ranged from 0 to 24 , with lower scores indicating more limitation in physical function.

Covariates. Sociodemographics included age and sex. The presence of diseases at baseline was determined by asking the participants whether they had any of the following chronic diseases: cardiac disease, peripheral arterial disease, stroke, diabetes mellitus, lung disease, cancer, and arthritis (25).

Lifestyle factors, measured at baseline, included smoking, alcohol use, physical activity, and body mass index (BMI). Four categories of smoking were created: current, former, never and missing. Categories of alcohol use were: not drinking, moderate drinking, excessive drinking (at least three glasses daily), and missing. Physical activity was defined as the total number of physical activities performed in the past two weeks including walking, cycling, gardening, performing light and heavy household, and a maximum of two sports. Four categories were created: 6-7, 4-5, 1-3, and missing. BMI (weight in kilograms divided by height in meters squared) was categorized as lower than $25 \mathrm{~kg} / \mathrm{m}^{2}$, between 25 and $30 \mathrm{~kg} / \mathrm{m}^{2}$, greater or equal to $30 \mathrm{~kg} / \mathrm{m}^{2}$, and missing.

Psychosocial factors, measured at baseline, included partner status (presence of a partner, yes or no), network size, instrumental and emotional social support, mastery, and self-efficacy. The size of the personal network was determined by asking the respondent to identify the persons, other than their partner, whom they had frequent contact with and who were important to them (range is 0-75) (26). For a maximum of nine network members with whom contact was most frequent, information was collected regarding the intensity of received instrumental and social emotional support (range is 0 (no social support)-36). Mastery was measured with a five-item version of the Pearlin Mastery Scale (range is 5 (lowest)-25) (27). Selfefficacy was measured with a 12-item version of the General Self-efficacy Scale of Sherer et al. (range is 12 (lowest)-60) $(28,29)$. Missing values for network size $(n=112)$, instrumental support $(n=118)$, emotional support $(n=120)$, mastery $(n=64)$, and self-efficacy $(n=107)$ were replaced by group means in order to maintain an optimal sample size for the analyses. 


\section{Statistical analyses}

Differences in baseline characteristics between SES groups were determined using chi-square test for categorical variables and t-test statistics for continuous variables. Multilevel analyses, using linear mixed models in SPSS, were used to examine the association between SES and the longitudinal change in physical function. A multilevel analysis has the advantage that it is a suitable technique for repeated measurement analyses. Five models were fitted, the first model adjusted for age, sex, and longitudinal time (in terms of the number of the observation). The model also included two interaction terms that were statistically significant; the interaction between age and longitudinal time and between sex and longitudinal time. In model 2, 3, and 4, diseases, behavioral factors, and psychosocial factors were introduced separately into the first model. The fifth model included all variables of the previous models. Analyses were performed using SPSS version 12.0.

\section{RESULTS}

Preliminary analyses indicated a significant interaction between SES and age in this study, therefore all analyses were performed in two age groups: younger than 70 years and 70 years and older. Interactions between SES and sex were not statistically significant. Table 1 shows baseline characteristics of the total study population by SES and age group. In both age groups there were more women in low SES groups and respondents were older in low SES groups. People with higher education or income had significantly higher baseline physical function scores, indicating better function, compared to low SES groups in both age groups $(p<0.01)$. There was no strong association between the prevalence of diseases and SES. In the lowest age group, only the prevalence of peripheral atherosclerosis and arthritis was significantly higher in both the lowest education and income groups. In the highest age group, the prevalence of arthritis was also significantly higher in people with a low level of education. In the lowest SES groups, there were more nonsmokers and less people drank alcohol in both age groups $(p<0.01)$. Persons younger than 70 with high SES were significantly more physically active compared to the lowest SES groups $(p<0.01)$. In the highest age group the association was less clear. In both age groups, people with low SES had a significantly higher BMI compared to people with high SES $(p<0.01)$. Low SES was also associated with a smaller network, less emotional support, lower feelings of mastery (only in the lowest age group), and lower self-efficacy compared to people with high SES. 
Mean physical function scores at the four measurements by age group according to SES are shown in table 2. Low SES groups had worse physical function scores at all measurements compared to high SES groups. The oldest age group had lower physical function scores at all measurements than the youngest age group.

Table 3 shows the results of the multilevel analyses for the group younger than 70 years and table 4 for those 70 years and older. The tables present the intercept and slope of the variable time for each model. The intercept is the parameter estimate (baseline score) of the middle and low SES group compared to the highest SES group. The slope is the coefficient of the SES*longitudinal time interaction term, indicating the effect of longitudinal time on physical function. The fist model is graphically presented in figure 1. People younger than 70 years old in the lowest SES group not only had a significantly worse physical function score at baseline and follow-up, they were also declining significantly more over time compared to people in the highest SES group (Table 3: Model 1, Figure 1). Baseline differences between the lowest and the highest education group were larger in the oldest age group. SES differences did, however, not further widen over time in people of 70 years and older (Table 4: Model 1, Figure 1).

In model 2, 3, and 4 diseases, behavioral factors, and psychosocial factors were introduced separately into the first model. In the youngest age group (Table 3 ), the largest reduction in intercepts was found in model 3 , due to behavioral factors, for both education and income. A percentage reduction in intercept from model 1 was computed by (intercept model 1 - intercept model 3 )/(intercept model 1) $100 \%$. The average reduction due to behavioral factors in the lowest SES groups was $65 \%$. BMI and physical activity most reduced the regression coefficients; smoking and drinking did not further decrease the regression coefficients (not tabulated). Behavioral factors could not explain the SES-differential decline (slope). The SES differences in baseline physical function were completely explained when all factors of the previous models were added to the fifth model. The differences in slope, however, remained statistically significant.

In the oldest age group, the large differences in baseline physical function between the lowest and the highest SES group could not be fully explained by diseases, behavioral or psychosocial factors (Table 4). The largest reduction in intercept differences between the lowest and the highest SES group in this age group was found in model 4 , due to psychosocial factors (on average $28 \%$ ). In additional analyses, we determined which psychosocial factors were most important in reducing the regression coefficients. None of the psychosocial factors, however, had a large 


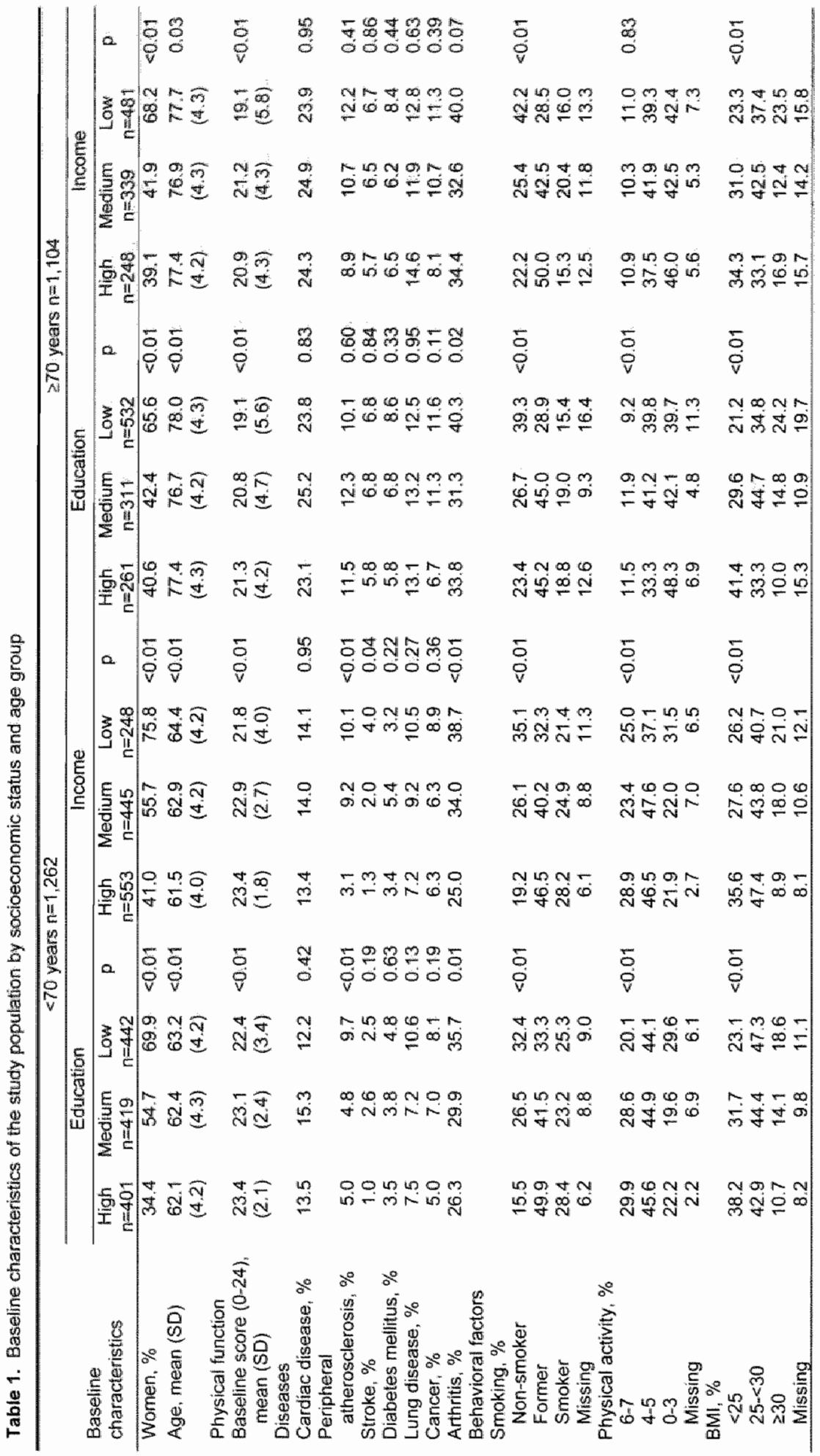


$\begin{array}{lllll}50 & 8 & 8 & 5 \\ 0 \% & 0 & 0 & 0 & 0\end{array}$

ma $=$ 开

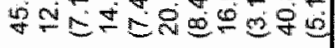

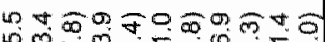

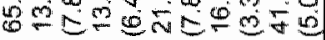

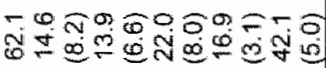

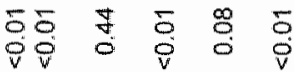

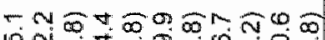

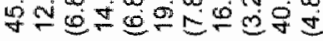

m $\infty$

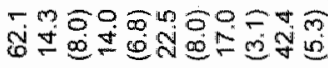
ธธ㇒ 워 $\stackrel{\infty}{4} 5$

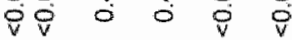

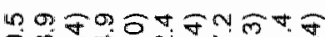

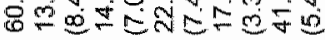

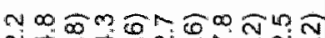

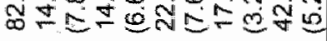
$\infty m \overline{=}=\bar{m}=\pi$

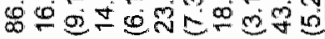

$\begin{array}{lllll}50 & 9 & 5 & 9 & 0 \\ 0 & 0 & 0 & 0 & 0\end{array}$ खक

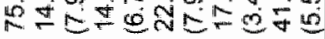

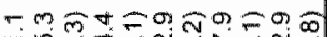

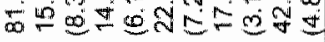

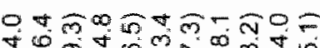

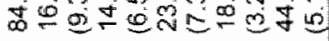

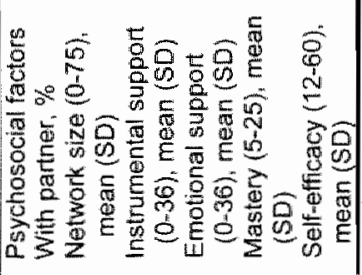




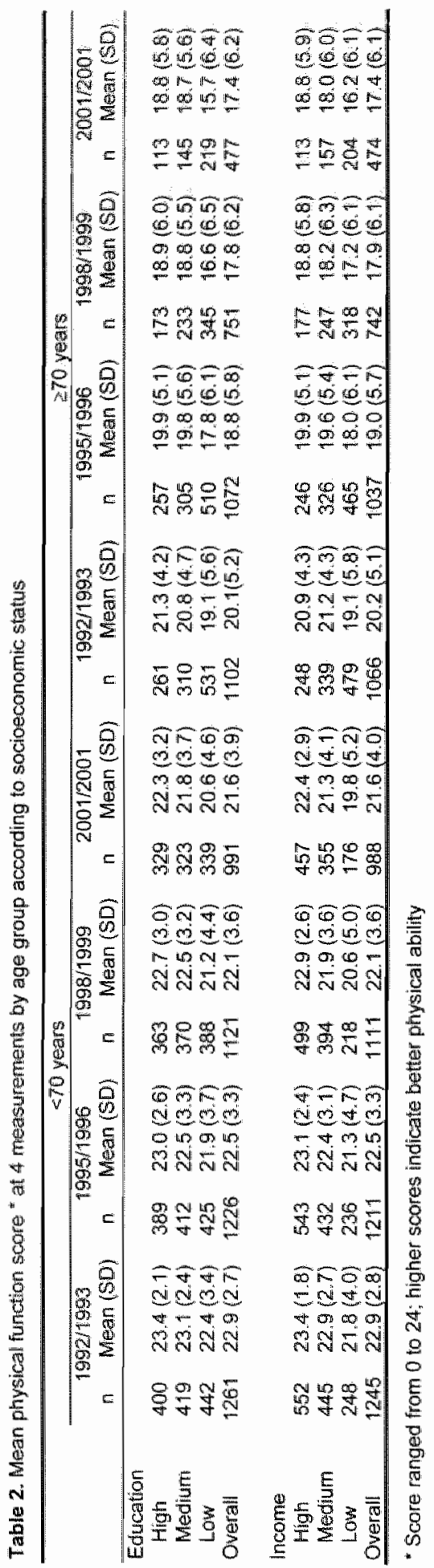


individual contribution. In the full model (Model 5), the intercept of low education still was significantly different from that of higher education.

Because the significant differences in slope between SES groups, that were found in the lowest age group, could not be explained by any of the variables that were added in model 2 to 4 , we determined, in additional analyses, whether interactions between the explanatory factors and longitudinal time would reduce the slope differences. However, the coefficients were difficult to interpret which may be due to the complexity and potential over-fitting of the models and, therefore, did not add to the explanation of the slope differences.

\section{DISCUSSION}

In an older population, low SES was associated with poor physical function during nine years of follow-up. In contrast to people 70 years and older, where SES differentials in physicall function did not further increase over time, SES differentials in physical function significantly increased over nine years in people who were younger than 70 years. Behavioral factors, mainly BMI and physical activity, explained a large part of the SES differentials in baseline physical function in the youngest age group. Behavioral factors could, however, not explain the SES-differential decline in physical function. In people 70 years and older, psychosocial factors reduced the SES differences mast.

A recent study in women showed that SES inequalities in physical health may attenuate by the age of 70 (30). This latter study also found a strong cross-sectional association between SES and physical function, but no association with a decline in physical function (30). The present study shows that even in old age, SES differences in physical function were still present. In people of 70 years and older, SES differences in physical function did not increase over time, but still existed after nine years of follow-up. The lowest SES group probably consists of "healthy survivors" because of selection prior to baseline and attrition due to mortality during the follow-up. It may be due to this healthy survivor effect that SES differentials in physical function did not widen over time in this age group. This may also explain the weak association between the prevalence of diseases and SES that was found. Consequently, diseases explained only very little of the SES differences in physical function in the oldest age group.

In the youngest age group, a high percentage had no physical function problems at baseline (not tabulated). The decline in physical function that was found in this age group was mainly due to the onset of physical function problems rather 


\section{Longitudinal course of physical function according to education in two age groups}

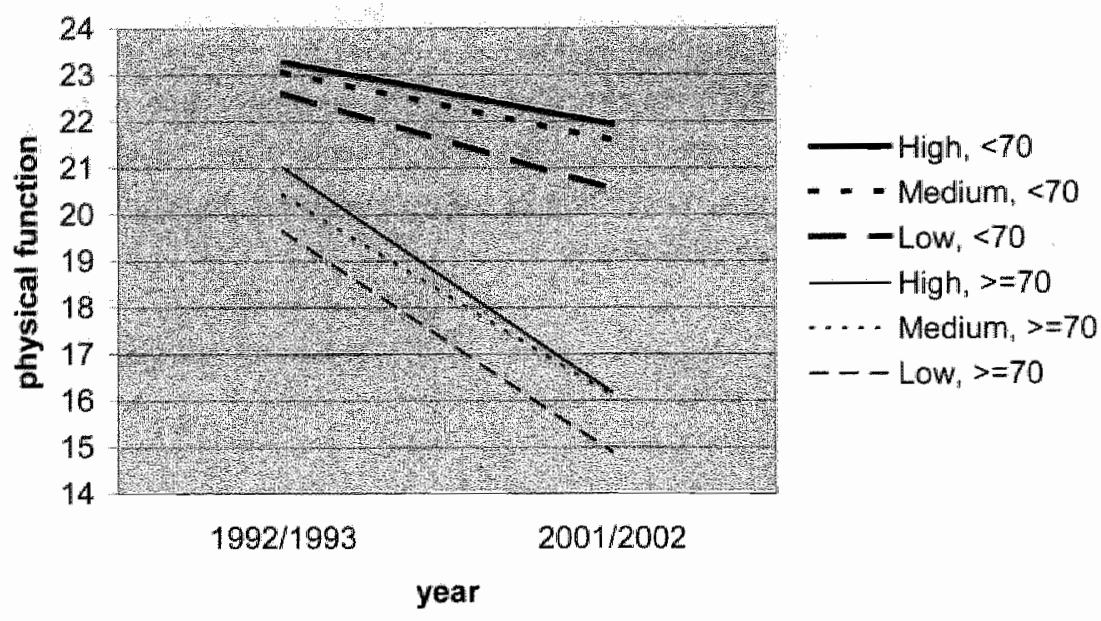

\section{Longitudinal course of physical function according to income in two age groups}

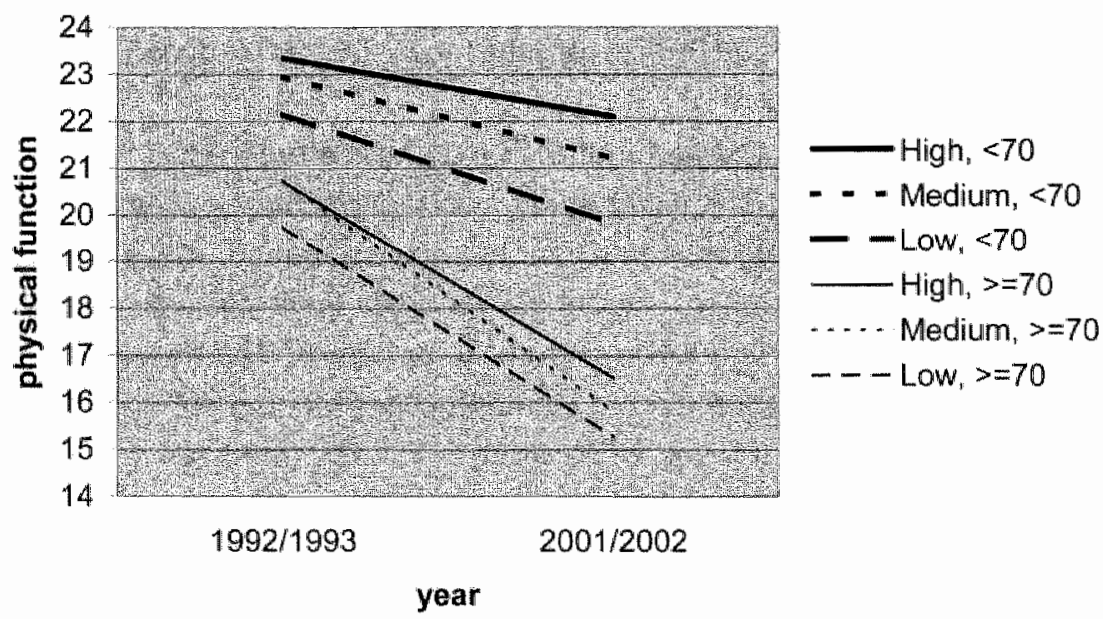

Figure 1. Longitudinal course of physical function * according to socioeconomic status in lwo age groups ( $<70$ years old and $\geq 70$ years old)

* Adjusted for age, sex, and interactions between age and longitudinal time, and sex and longitudinal time 


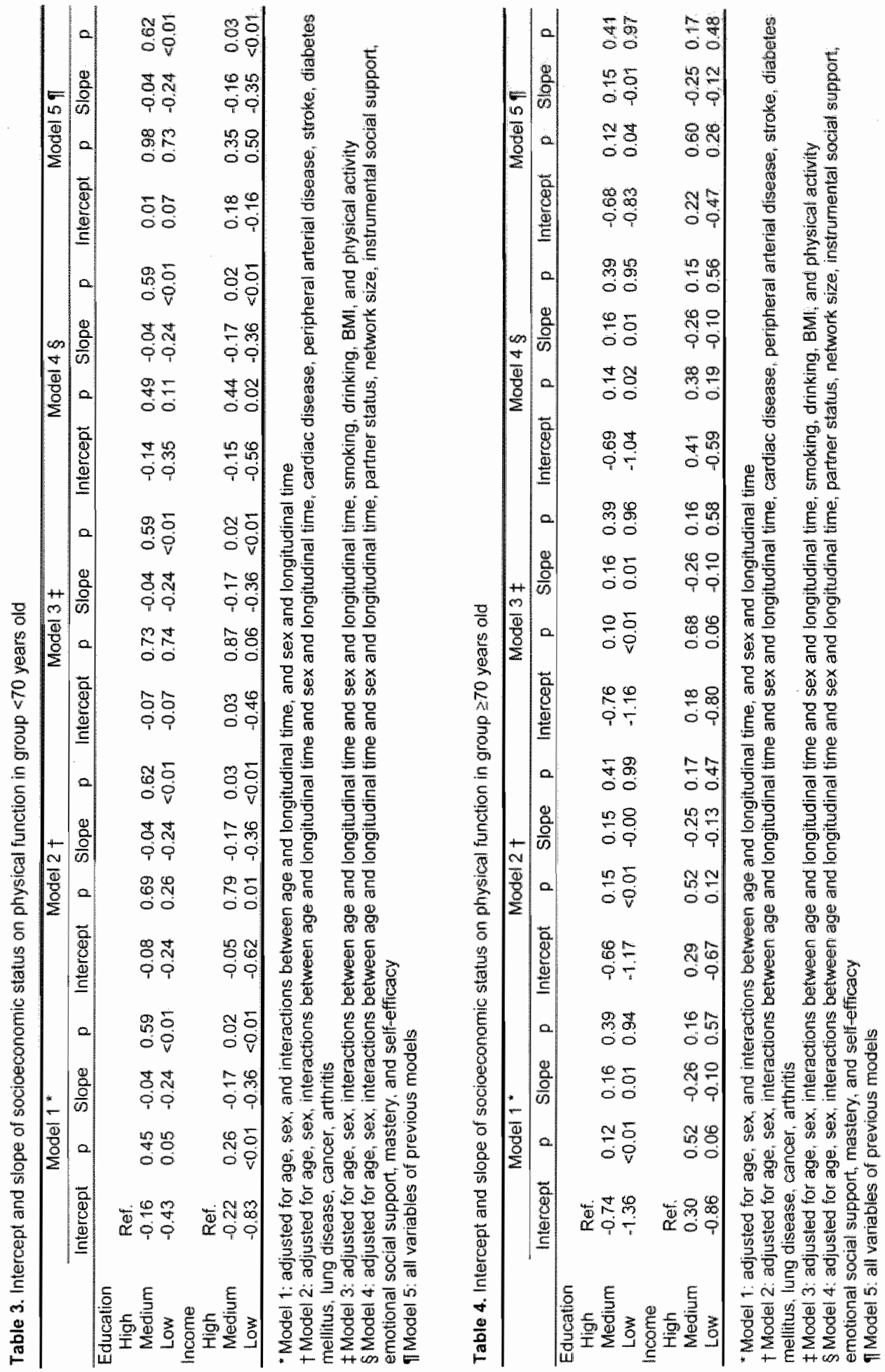


than to a further functional decline related to an already existing disability. This may underlie the age-specificity that was found in both the pattern and the explanation of SES differences in physical function. Behavioral factors, in this study particularly high $\mathrm{BM} \|$ and low physical activity, may be important in predicting the onset of physical function problems in the youngest age group. Adverse psychosocial factors, such as low social support and low self-efficacy, may cause a further decline in physical function in the oldest age group. Existing physical function problems may negatively influence sameone's psychosocial profile, such as lower self-efficacy, which may further accelerate the decline in physical function as in a vicious circle (31). Such pathways and reciprocal associations need further detailed examination.

In this study, a wide range of different explanatory factors was considered in order to get more insight into the explanation of SES inequalities in physical function. A few drawbacks, however, have to be considered. The SES differential decline that was found in the youngest age group could not be explained. This suggests that other factors that were not measured in this study may have caused the widening over time in this age group. Furthermore, the contribution of the explanatory factors in reducing the SES differences and in particular the SES-differential decline in physical function could have been larger if these factors had also been considered longitudinally. However, there is evidence that behavioral factors, mainly smoking and alcohol consumption remain rather stable over time; physical activity showed greater variability over time. These changes in health behavior were, however, not related to SES (32). Psychosocial factors, such as network size and social support, probably also remained rather stable during the follow-up $(26,33)$. The prevalence of diseases, however, was more likely to have changed during the nine years of follow-

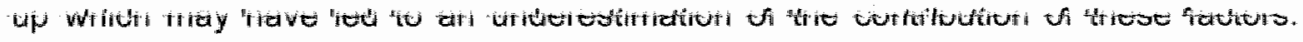
Finally, we must acknowledge that, had more objective information on diseases been available, the reduction in the strength of the SES effect might have been larger.

Loss to follow-up was a limitation of this study. Attrition was mainly due to mortality ( $74 \%$ of the total loss to follow-up). People who were lost to follow-up for other reasons had worse physical function scores at baseline, compared to those who remained in the study (data not shown). In addition, those who were lost to follow-up also had a significantly lower SES compared to our study population. The association between SES and physical function may therefore have been underestimated. Whether the relative contribution of explanatory variables was equally underestimated remains unknown.

This study contributes to the understanding of the mechanisms underlying the association between SES and physical function in older adults. In order to reduce physical disabilities in older adults and in particular the socioeconomic differences 
therein, it may be helpful to improve health-related behaviors in younger-old adults and to intervene upon psychosocial characteristics in older-old adults. Further study is needed to confirm the age-specificity that was found in both the pattern and the explanation of socioeconomic differences in function in older adults.

\section{ACKNOWLEDGMENT}

The Longitudinal Aging Study Amsterdam is largely funded by the Ministry of Health, Welfare and Sports of the Netherlands. The authors like to thank Dr. F.E.S. Tan for his statistical advise. 


\section{REFERENCES}

1. Amaducc L, Maggi S, Langlois J, et al. Education and the risk of physical disability and mortality among men and women aged 65 to 84 : the Italian Longitudinal Study on Aging. $J$ Gerontol A Biol Soi Med Sci 1998;53:M484-90.

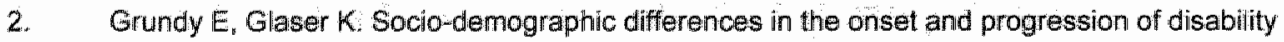
in early old age: a longitudinal study. Age Ageing 2000:29:149-57.

3. Broese van Groenou MI, Deeg D., Penninx BW. Income differentials in functional disability in ald age: relative risks of onset, recovery, decline, attrition and mortality. Aging Clin Exp Res $2003: 15: 174-183$.

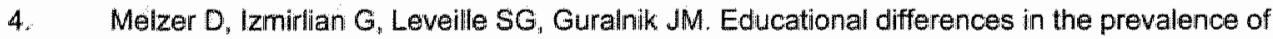
mobility disability in old age: the dynamics of incidence, mortality, and recovery. J Gerontol B Psychol Sci Soc Sci 2001:56:294-301.

5. Koster A, Penninx BW, Bosma H, et al. Is there a biomedicall explanation for socioeconomic differences in incident mobility limitation? J Gerontol A Biol Sci Med Sci 2005;60:1022-7.

6. Huisman M, Kunst AE, Mackenbach JP. Socioeconomic inequalities in morbidity among the elderly; a European overview. Soc Sci Med 2003;57:861-73.

7. Guralnik JM, Fried LP, Salive ME. Disability as a public health outcome in the aging population. Annu Rev Public Health 1996;17:25-46.

8. Kaplari GA, Keill JE. Socioeconomic factors and cardiovascular disease: a review of the literature. Circulation 1993;88:1973-1998.

9. Brunner EJ Marmot MG, Nanchahal $K_{\text {, }}$ et al. Social inequality in coronary risk: central obesity and the metabolic syndrome. Evidence from the Whitehall II study. Diabetologia $1997 ; 40: 1341-1349$.

10. Everson SA, Maty SC, Lynch JW, Kaplan GA. Epidemiologic evidence for the relation between sociaeconomic status and depression, obesity, and diabetes. J Psychosom Res 2002; 53:891-895.

11. Boult C, Kane RL, Louis TA, Boult L, McCaffrey D. Chronic conditions that lead to functional limitation in the elderly. J Gerontol 1994;49:M28-M36.

12. Seeman TE, Charpentier $P A, B e r k m a n L F$, et al. Predicting changes in physical performance in a high-functioning elderly cohort: MacArthur studies of successfull aging. J Gerontol A Biol Sci Med Sci 1994;49:M97-108.

13. Martikainen $P$, Stansfeld $S$, Hemingway $H$, Marmot M. Determinants of socioeconomic differences in change in physical and mental functioning. Soc Sci Med 1999;49:499-507.

14. Marmot MG, Shipley MJ, Rose G. Inequalities in death-mspecific explanations of a general pattern? Lancet 1984:1:1003-6.

15. Droomers $M$, Schrijvers $C T$, Mackenbach JP. Educational level and decreases in leisure time physical activity: predictors from the longitudinal GLOBE study. J Epidemiol Community Health 2001:55:562-8.

16. Bosma H, Schrijvers $C$, Mackenbach JP. Socioeconomic inequalities in mortality and importance of perceived controll: cohort study. BMJ 1999;319:1469-70.

17. Kristenson M. Eriksen HR, Sluiter JK, Starke D, Ursin H. Psychobiological mechanisms of socioeconomic differences in health. Soc Sci Med 2004;58:1511-22.

18. Taylor SE, Seeman TE. Psychosocial resources and the SES-health relationship. Ann $N Y$ Acad Sci 1999;896:210-25. 
19. Siegrist J. Marmot M. Health inequalities and the psychosocial environment-two scientific challenges. Soc Scil Med 2004:58:1463-73.

20. Kempen GI, van Heuvelen MJ, van Sonderen E, van den Brink RH, Kooijman AG, Ormel J. The relationship of functional limitations to disability and the moderating effects of psychological attributes in community-dwelling older persons. Soc Soi Med 1999;48:1161-72.

21. Bosma $\mathrm{H}_{\mathrm{z}}$ Van Jaarsveld $\mathrm{CH}_{3}$, Tuinstra $\mathrm{J}_{3}$ et al. Low controll belliefs, classical coronary risk factors, and socio-economic differences in heart disease in older persons. Soc Sci Med 2005;60:737-45.

22. Deeg DJH, Knipscheer CPM, Van Tillburg W. Autonomy and well-being in the aging population. Concepts and design of the Longitudinal Aging Study Amsterdam. Bunnik: Netherlands Institute of Gerantology, 1993.

23. Knipscheer CPM, de Jong-Gierveld J, Van Tilburg TG, Dykstra PA. Living arrangements and social networks of older adullts. Amsterdam: VU University Press, 1995.

24. van Sonsbeek J. Methodological and substantial aspects of the OECD indicator of chronic functional limitations. Maand bericht Gezondheid (CBS) 1988;88:4-17.

25. Kriegsman DM, Penninx BW, van Eijk JT, Boeke AJ, Deeg DJ. Self-reports and general practitioner information on the presence of chronic diseases in community dwelling elderly. $A$ study on the accuracy of patients' self-reports and on determinants of inaccuracy. $J$ Clin Epidemiol 1996;49:1407-17.

26. van Tilburg T. Losing and gaining in old age: changes in personal network size and social support in a four-year longitudinal study. J Gerontol B Psychol Sci Soc Sci 1998;53:S313-23.

27. Pearlin LI, Schooler C. The structure of coping. Journal of Health and Social Behavior $1978 ; 19: 2-21$.

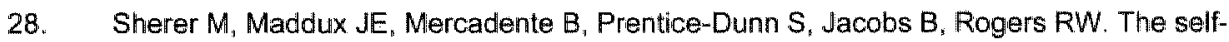
efficacy scale: Construction and validation. Psychol Rep 1982;51:663-671.

29. Bosscher RJ, Smit. JH. Confirmatory factor analysis of the General Self-Efficacy Scale. Behav Res Ther 1998;36.339-43.

30. Mishra GD, Ball K, Dobson AJ, Byles JE. Do socioeconomic gradients in women's health widen over time and with age? Soc Sci Med 2004;58:1585-95.

31. Verbrugge LM, Jette AM. The disablement process. Soc Soi Med 1994;38:1-14.

32. Mulder M. Ranchor AV, Sanderman R, Bouma J, wan den Heuvel Ww. The stability of lifestyle behaviour. Int al Epidemiol 1998;27:199-207.

33. Broese van Groenou M, Van Tilburg $T$. Changles in the support networks of older adults in the Netherlands. J Cross Cult Gerontol 1997;12:23-44. 


\section{Association of inflammatory markers with socioeconomic status}

\section{Submitted as}

Koster A, Bosma $H$, Penninx BW, Newman AB, Harris TB, van Eijk JT, Kempen GI, Simonsick EM, Johnson KC, Rooks RN, Ayonayon HN, Rubin SM, Kritchevsky SB. Association of inflammatory markers with socioeconomic status. 


\section{ABSTRACT}

Objective. This study examines the association between socioeconomic status (SES) and inflammatory markers in well-functioning older adults and seeks to determine whether any association remains after adjusting for biomedical and behavioral factors typically related to elevated serum levels of inflammatory markers. Methods. Data were from 3,044 men and women, aged 70-79 from Pittsburgh, PA and Memphis, TN participating in the Health, Aging and Body Composition sturdy (Health $A B C$ ). Three indicators of SES were used: education, income, and ownership of financial assets. Serum levels of interleukin-6 (IL-6), C-reactive protein (CRP), and tumor necrosis factor- $\alpha$ (TNF- $\alpha$ ) were measured.

Results. LOW SES was associated with significantly elevated levels of IL-6, CRP and TNF-a compared to high SES. Behavioral factors (including smoking, drinking, obesity) explained a substantial part of the inverse association between SES and inflammatory markers. Adjustment for prevalent diseases (including heart diseases, lung disease, and diabetes) associated with inflammation explained for less of the association.

Conclusions. This study suggest that even in old age, interventions to improve health behaviors, especially in low SES groups, may be useful in reducing risks associated with inflammation. 


\section{INTRODUCTION}

Low socioeconomic status (SES) has recently been related to higher levels of inflammatory markers (1-4). This is important, as inflammation - being a biological response of the immune system - has been associated with increased morbidity and mortality across the age span, including in old age (5-7). Two recent studies show that persons with low SES have higher serum levels of C-reactive protein (CRP) than persons with high SES $(1,2)$. Another study found lower levels of interleukin-6 (IL-6) and tumor necrosis factor- $\alpha$ (TNF- $a$ ) in high SES groups, but the effect was nonlinear and found in women only (3). Evidence relating inflammatory markers to SES is, however, limited at present especially regarding to what extent this association might be mediated by other health and behavioral factors commonly associated with low SES.

Increased levels of inflammatory markers, such as IL-6 and CRP, are observed in the presence of acute and chronic conditions including atherosclerosis $(8)$, cerebrovascular disease $(9,10)$, coronary heart disease $(11-14)$, congestive heart failure (15), and arthritis (16). Recent studies also show that depression and cognitive impairment are associated with elevated levels of inflammatory markers $(17,18)$. These health conditions are also more common in low SES groups and may thus contribute to the association between low SES and higher levels of inflammatory markers. Similarly, behavioral factors may also explain an association between low SES and increased inflammatory marker levels. Low SES is related to many adverse behavioral factors, such as smoking, excessive alcohol use, obesity, and physical inactivity (19). These factors are also related to higher levels of inflammatory markers (20-22).

Using data from a large sample of community-dwelling older adults this study examined the association between SES and several markers of inflammation (CRP. IL-6, and TNF-a). In addition, the present study sought to determine whether any association remained after adjusting for biomedical and behavioral factors typically related to elevated serum levels of inflammatory markers.

\section{METHODS}

\section{Study population}

The Health, Aging and Body Composition (Health $A B C$ ) study is a longitudinal cohort study consisting of 3,075 well-functioning, 70- to 79-year old, black and white men and women. Participants were identified from a random sample of White 
Medicare beneficiaries and all age-eligible community-dwelling black residents in designated zip code areas surrounding Memphis, Tennessee, and Pittsburgh, Pennsylvania. Participants were eligible if they reported no difficulty in either walking one quarter of a mile, going up 10 steps without resting or performing any basic activity of daily living. Participants were excluded if they reported a history of active treatment for cancer in the prior three years, planned to move out of the study area in the next three years, or were currently participating in a randomized trial of a lifestyle intervention. Data, collected between April 1997 and June 1998, included an inperson interview and a clinic-based examination, with evaluation of body composition, clinical and sub-clinical diseases, and physical functioning.

Data on inflammatory markers were missing for 30 participants and SES data were missing for one participant, leaving 3,044 participants for the present analyses. All participants signed informed written consent forms approved by the institutional review boards of the clinical sites.

\section{Measures}

Socioeconomic status. Three indicators of SES were used: education, family income, and ownership of financial assets (23). Different SES indiciators were used because these variables represent different dimensions of SES (24). Education is the socio-cultural dimension of SES and represents social class in an early stage of the life course compared to income representing a later life stage. Ownership of financial assets, as a proxy for wealth, describes availability of material resources accumulated over the life course. Categories for education were: less than 12 years, 12 years, and more than 12 years. Family income was defined as: wages, salaries social security or retirement benefits, help from relatives, and rent from property. Five categories of family income from the year prior to interview were distinguished: less than $\$ 10,000$, between $\$ 10,000$ and less than $\$ 25,000$, between $\$ 25,000$ and less than $\$ 50,000$, greater than or equal to $\$ 50,000$, and missing $(n=371,12.2 \%)$. The number of asselts a person reported was used as a third SES measure. Assets included: money market account, savings bonds or treasury bills, home ownership or investment property or housing, a business or farm, stock or stock mutual funds, and IRA or KEOGH account, and other investments. Three categories were created: none, one or two, and three to seven (23).

Inflammatory markers. Measures for the cytokines IL-6 and TNF-a and for CRP were obtained from frozen stored plasma or serum. Fasting blood samples were obtained in the morning, and after processing, the specimens were aliquoted into cryovials, frozen at $-70^{\circ} \mathrm{C}$, and shipped to the Health $\mathrm{ABC}$ Core Laboratory at the University of Vermont. Cytokines were measured in duplicate by enzyme-linked 
immunosorbent assay (ELISA) kits from R\&D Systems (Minneapolis, MN). The detectable limit was $0.10 \mathrm{pg} / \mathrm{mL}$ for $\mathrm{IL}-6$ (by HS600 Quantikine Kit) and $0.18 \mathrm{pg} / \mathrm{mL}$ for TNF-a (by HSTA50 kit). Serum levels of CRP were also measured in duplicate by ELISA based on purified protein and polyclonal anti-CRP antibodies (Caibiochem, San Diego, CA). The CRP assay was standardized according to the World Health Organization First International Reference Standard with a sensitivity of $0.08 \mu \mathrm{g} / \mathrm{mL}$. Assays of blind duplicates collected for 150 participants showed an average interassay coefficient of variation of $10.3 \%$ for IL-6, 8.0\% for CRP and $15.8 \%$ for TNF-a.

Covariates. Sociodemographics included age, sex, race (black or white), study site (Memphis or Pittsburgh), and marital status (never married, previously married, married). For the analyses with family income we also controlled for whether the household included anyone in addition to the participant and his or her spouse. Behavioral factors included smoking (current, former, never smoker), cigarette use in pack-years, alcohol use during the past year $(0,<1,1-7,>7$ drinks per week), physical activity (total kilocalories per kilogram per week), and body mass index (BMI, weight in kilograms divided by height in meters squared $\left(\mathrm{kg} / \mathrm{m}^{2}\right)$ ). Abdominal visceral fat (centimeters squared) was quantified by an analyses of CT scans by General Electric 9800 Advantage in Pittsburgh and a Siemens Somatron and Picker PQ2000S in Memphis. Presence of lung, heart, and cerebrovascular disease, diabetes mellitus, osteoarthritis, and cancer was determined using standardized algorithms considering self-report, use of specific medications, and clinical assessments. Depressed mood was assessed with the Center for Epidemiologic Studies Depression (CES-D) scale. A cutoff score of 16 was used as a criterion for major depressive symptoms (25). Cognitive impairment was defined as a Modified Mini-Mental State Examination (3MS) score less than 78 (26). Medications taken in the previous two weeks were recorded and coded according to the lowa Drug Information System (27). By use of this system, the use of anti-inflammatory drugs and corticosteroids were assessed.

\section{Statistical analyses}

Analyses were performed using SPSS, version 12.0. Characteristics of the study population were stratified by race. Differences in main characteristics between black and white persons were determined using chi-square tests for categorical variables and t-test statistics or nonparametric Mann-Whitney statistics for continuous variables. A non-parametric test for differences in inflammatory marker levels was used because levels of inflammatory markers were not normally distributed. To compare serum levels of inflammatory markers across SES groups a Kruskal-Wallis 
Table 1. Marn characteristics of the study population

\begin{tabular}{|c|c|c|c|c|}
\hline & Overall & Whitie & Blaick & pwalue * \\
\hline & $n=3,044$ & $n=1,760$ & $n=1,264$ & \\
\hline Age, mean (SD) & $74.2(2.8)$ & $74.3(2.9)$ & $74.0(2.9)$ & 0.001 \\
\hline Women, $\%$ & 51.4 & 47.5 & 57.0 & $<0.001$ \\
\hline Memphis site. $\%$ & 50.2 & 52.1 & 47.5 & 0.01 \\
\hline Manried: $\%$ & 56.5 & 67.5 & 42.6 & $\angle 0.001$ \\
\hline \multicolumn{5}{|l|}{ Education, \% } \\
\hline$>12$ years & 42.0 & 53.5 & 26.0 & \multirow{3}{*}{$<0.001$} \\
\hline 12 ygars & 32.7 & 342 & 30.7 & \\
\hline$<12$ years & 25.1 & 123 & 43.4 & \\
\hline \multicolumn{5}{|l|}{ Imcorme $(\$), \%$} \\
\hline$\geq 50,000$ & 14.1 & 21.0 & 4.4 & \multirow[t]{5}{*}{$<0.001$} \\
\hline $25,000-<50,000$ & 27.9 & 35.4 & 17.7 & \\
\hline $10,000-<25,000$ & 342 & 27.8 & 43.3 & \\
\hline$<10,000$ & 11.6 & 3.7 & 22.8 & \\
\hline Missing & 12.2 & 12.5 & 11.8 & \\
\hline \multicolumn{5}{|l|}{ Agsets, \% } \\
\hline $3-7$ & 42.9 & 62.4 & 16.6 & \multirow[t]{3}{*}{$<0.001$} \\
\hline $1-2$ & 39.7 & 288 & 55.8 & \\
\hline None & 16.5 & 8.8 & 27.6 & \\
\hline \multicolumn{5}{|l|}{ Inflammatory markers } \\
\hline IL-6, pg/mL, median (ramge) & $1.83(1.27-2.79)$ & $1.74(1.20-2.62)$ & $1.99(1.33-3.06)$ & $<0.001$ \\
\hline CRP, mg/L imedian (range) & $1.59(0.99-3.14)$ & $1.48(0.93-2.69)$ & $2.08(1,11-3.85)$ & $<0.001$ \\
\hline TNF- $a, p g / m L$, median (range) & $3.16(2.45-4.11)$ & $3.29(2.57-4.22)$ & $2.99(2.28-3.87)$ & $<0.001$ \\
\hline \multicolumn{5}{|l|}{ Smoking $\%$} \\
\hline Newer & 43.7 & 43.0 & 44.8 & \multirow[t]{3}{*}{$<0.001$} \\
\hline Current & 10.3 & 6.2 & 16.1 & \\
\hline Forrtier & 45.9 & 50.7 & 39.1 & \\
\hline Smoking pack-years, mean (SD) & $19.3(27.9)$ & $21.1(30.2)$ & $16.7(24.1)$ & $<0.00$ \\
\hline \multicolumn{5}{|l|}{ Drinking. $\%$} \\
\hline Nome & 50.1 & 41.5 & 62.7 & \multirow[t]{4}{*}{$<0.001$} \\
\hline$<1 /$ wh & 20.7 & 20.9 & 20.7 & \\
\hline 1.7 wh & 21.4 & 28.3 & 11.8 & \\
\hline$>1 / d a y$ & 7.4 & 9.2 & 4.9 & \\
\hline $\mathrm{BMI}, \mathrm{kg} / \mathrm{m}^{2}$, mean $(S D)$ & $27.4(2.9)$ & $26.5(2.9)$ & $28.6(5.4)$ & $<0.001$ \\
\hline Abdomen visceral fat $\mathrm{cm}^{2}$, mean (SD) & $142.8(67.6)$ & $151.9(69.8)$ & $130.0(62.2)$ & $<0.001$ \\
\hline Physical activity $\mathrm{kcal} / \mathrm{kg} /$ week, mean (SD) & $83.1(69.4)$ & $84.9(64.4)$ & $80.6(75.9)$ & $0.10^{\circ}$ \\
\hline \multicolumn{5}{|l|}{ Diseases, \% } \\
\hline Lung disease & 18.6 & 19.8 & 170 & 0.05 \\
\hline Heart disease & 17.3 & 17.7 & 16.9 & 0.55 \\
\hline Canbrovascullar disease & 7.2 & 6.5 & 8.5 & 0.03 \\
\hline Diabetes melitus & 18.9 & 14. & 25.7 & $<0.001$ \\
\hline Osteoporosis & 14.2 & 17.2 & 10.3 & $<0.001$ \\
\hline Cancer & 18.9 & 24.5 & 11.2 & $<0,001$ \\
\hline Depressed mood & 4.8 & 4.9 & 4.7 & 0.75 \\
\hline Cognitive impaired & 7.7 & 2.0 & 15.8 & $<0.001$ \\
\hline \multicolumn{5}{|l|}{ Medication use, \% } \\
\hline Ant-inflammatory drugs & 53.2 & 56.7 & 48.7 & $<0,001$ \\
\hline Corticosteroids & 2.3 & 2.8 & 1.5 & 0,02 \\
\hline
\end{tabular}

* Based on chimsquare test for categorical variables and t-test or nomparametric Mann-Whitney statistics for continuous wariables 
test was used; median values of inflammatory markers with interquartile ranges were reported.

Linear regression analysis was used to test the association between SES and serum levels of inflammatory markers. Log-transformed values of inflammatory markers were used as dependent variables in the regression models. Three models were fitted, the first model adjusted for sociodemographics. The second adjusted for sociodemographics and behavioral factors and the model 3 adjusted for sociodemographics and diseases, anti-inflammatory drugs and corticosteroids.

\section{RESULTS}

Characteristics of the study population are shown in table 1. The mean age of the study sample was $74.2,51.4 \%$ were women, and $41.5 \%$ were black. Of the 3,044 participants, $25.1 \%$ had less than 12 years of education, $11.6 \%$ had an income less than $\$ 10,000$ and $16.5 \%$ had no assets. Because the Health $A B C$ study includes one of the largest samples of older African-Americans, the main characteristics are also shown for blacks and whites separately. Black participants were less well educated, had lower income and had fewer assets compared with white participants. Levels of IL-6 and CRP were higher in blacks than in whites and TNF- $\alpha$ levels were higher in whites than in blacks. The association between SES and inflammatory markers, however, was not different between the two groups (dlata not shown). This was confirmed by the non-significant interactions between each indicator of SES and race; therefore, subsequent results are shown for both together. Interaction terms between SES and sex were also not statistically significant (all $p>0.05$; data not shown). Table 2 presents median values of IL-6, CRP, and TNF-a in each SES group. People with low SES had significantly higher serum levels of IL-6 and CRP than people in high SES groups $(p<0.001)$. Median values of TNF- $\alpha$ were highest in the middle SES groups of education and income and results were not statistically significant for the number of assets.

Regression coefficients for the association of each indicator of SES with serum levels of IL-6, CRP, and TNF- $\alpha$ are shown in tables 3,4 , and 5 respectively. Table 3 shows that low SES was associated with significantly higher levels of IL-6 compared with high SES groups in the model that adjusted for age, sex, race, study site, and marital status (Model 1). When behavioral variables were added to the first model (Model 2), regression coefficients decreased from 42-66\% (without taking into account the missing category for income) and most results did not remain statistically significant. 


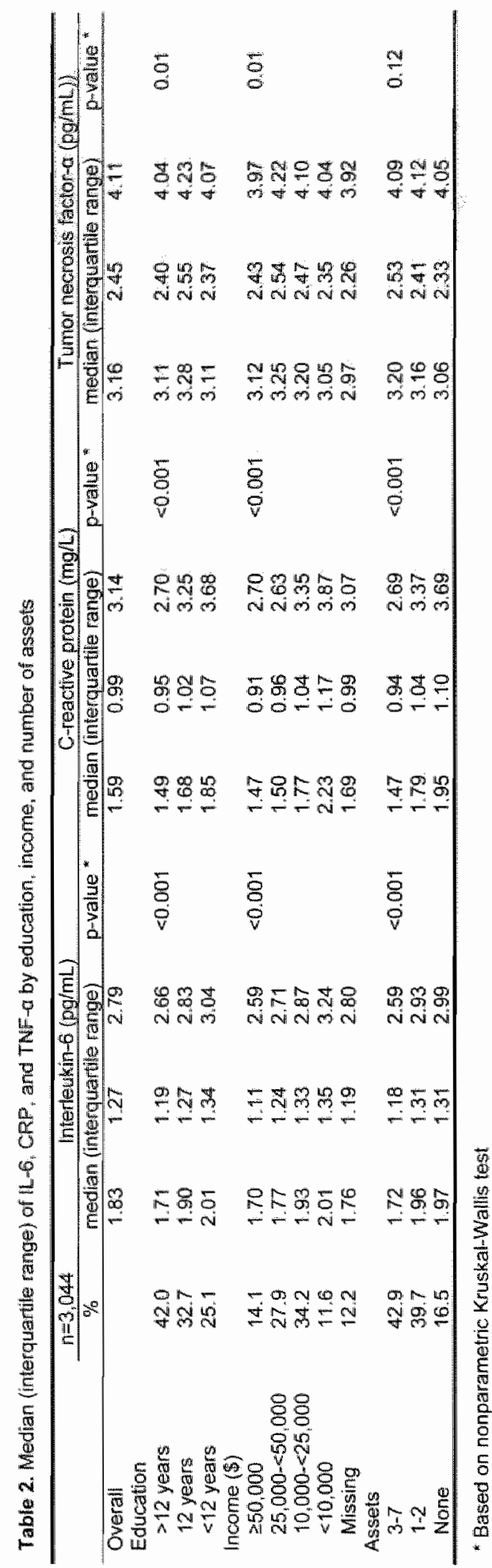


Table 3. Regression coefficients (with SE) of interleukin-6 (log transtomed) by edubaton, income, and number or assets

\begin{tabular}{|c|c|c|c|c|c|c|c|c|}
\hline & \multicolumn{8}{|c|}{ Interleukin-6 } \\
\hline & \multicolumn{2}{|c|}{ Model 1} & \multicolumn{3}{|c|}{ Model 2+ } & \multicolumn{3}{|c|}{ Madel 3 \& } \\
\hline & $\begin{array}{l}\text { Regression } \\
\text { coefficient } \\
\text { (SE) }\end{array}$ & $\begin{array}{c}\text { P } \\
\text { value }\end{array}$ & $\begin{array}{l}\text { Regression } \\
\text { coefficient } \\
\text { (SE) }\end{array}$ & $\begin{array}{c}\text { p- } \\
\text { walue }\end{array}$ & $\%$ & $\begin{array}{l}\text { Regression } \\
\text { coefticient } \\
\text { (SE) }\end{array}$ & para & $f^{20}$ \\
\hline \multicolumn{9}{|l|}{ Education } \\
\hline 12 years & $0.065(0.029)$ & 0.02 & $0.028(0.028)$ & 0.32 & 57 & $0.053(0.028)$ & 0.06 & 18 \\
\hline$<12$ years & $0.075(0.034)$ & 0.03 & $0.033(0.033)$ & 0.31 & 56 & $0.051(0.034)$ & 0.13 & 32 \\
\hline \multicolumn{9}{|l|}{ lincome $(\$)$} \\
\hline$\geq 50,000$ & Ref. & & & & & & & \\
\hline $25,000-<50,000$ & $0.078(0.040)$ & 0.05 & $0.034(0.038)$ & 0.38 & 56 & $0,053(0.039)$ & 0.17 & 32 \\
\hline $10,000-<25,000$ & $0.116(0.041)$ & 0.01 & $0.060<0.040$ & 0.13 & 48 & $0.084(0.040)$ & 0.04 & 28 \\
\hline$<10,000$ & $0.177(0.055)$ & 0.001 & $0.103(0.054)$ & 0.06 & 42 & $0.936(0.055)$ & 0.01 & 23 \\
\hline Missing & $0.060(0.049)$ & 0.22 & $0.017(0.047)$ & 0.72 & 72 & $0.044(0.048)$ & 0.36 & 27 \\
\hline \multicolumn{9}{|l|}{ Assels } \\
\hline $3-7$ & Ref. & & & & & & & \\
\hline $1-2$ & $0.065(0.030)$ & 0.03 & $0.036(0.029)$ & 0.21 & 45 & $0.053(0.029)$ & 0.07 & 18 \\
\hline None & $0.097(0.040)$ & 0.03 & $0.030(0.038)$ & 0.44 & 66 & $0.068(0.039)$ & 0.08 & 22 \\
\hline \multicolumn{9}{|c|}{ 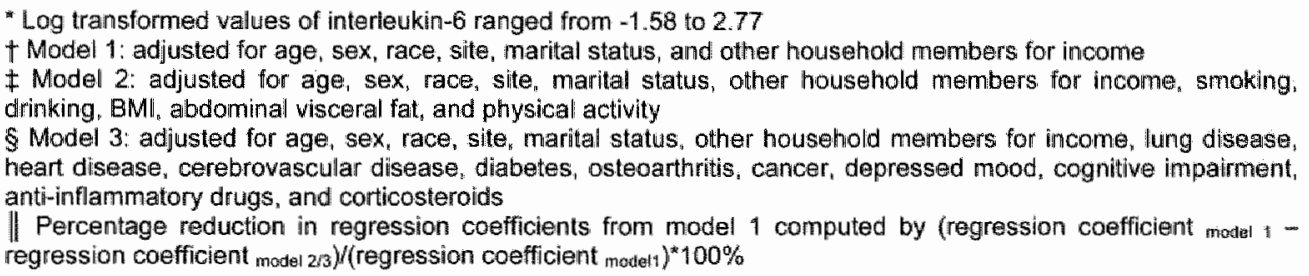 } \\
\hline
\end{tabular}

When prevalent diseases were added to the model with demographic variables only the regression coefficients decreased from $18-32 \%$. There still was a statistically significant association between low income and elevated levels of IL-6 after adjustment. Low SES was also associated with significantly higher levels of CRP, but this was not statistically significant for assets (Table 4). The role of behavioral factors and diseases was similar to that seen for IL-6. Behavioral factors decreased the regression coefficients substantially (56\% on average) while control for diseases decreased the regression coefficients much less (28\% on average). There was a non-linear association of education and assets with TNF-a; the highest levels of TNF-a were found in the middle SES groups compared with the highest SES groups (Table 5). The largest reduction in regression coefficients related to SES was also found in model 2 in which behavioral factors were added. In additional analyses it was determined which behavioral factors reduced the regression coefficient of SES the most (data not shown). BMI and visceral fat reduced the regression coefficients for all three inflammatory markers the most. Smoking and drinking were further able to reduce the regression coefficients; physical activity was least important. 
Table 4; Regression coeficients (with SE) of Crezctive photein (log fransformed) by educaliom, income, and number of assets.

\begin{tabular}{|c|c|c|c|c|c|c|c|c|}
\hline & \multicolumn{8}{|c|}{ C-meactwe protein } \\
\hline & \multicolumn{2}{|c|}{ Modet it } & \multicolumn{3}{|c|}{ Madel 2 t } & \multicolumn{3}{|c|}{ Model 3} \\
\hline & $\begin{array}{l}\text { Regression } \\
\text { coefficient } \\
(\mathrm{SE})\end{array}$ & $\begin{array}{l}\text { p } \\
\text { value }\end{array}$ & $\begin{array}{c}\text { Regression } \\
\text { coefficient } \\
\text { (SE) }\end{array}$ & $\begin{array}{c}p \\
\text { vatue }\end{array}$ & $\begin{array}{c}\% \text { red } \\
1\end{array}$ & $\begin{array}{c}\text { Ptegression } \\
\text { coetlicienti } \\
(\mathrm{SE})\end{array}$ & $\begin{array}{c}\text { pu } \\
\text { value }\end{array}$ & $\begin{array}{c}\text { \%ored } \\
\text { 月 }\end{array}$ \\
\hline \multicolumn{9}{|l|}{ Education } \\
\hline$>12$ years & Fit & & & & & & & \\
\hline 12 years & $0.055(0.037)$ & 0.13 & $0.019(0.036)$ & 0.59 & 65 & $0.048(0.036)$ & 0.19 & 13 \\
\hline$<12$ years & $0.115(0.043)$ & 0.01 & $0.075(0.042)$ & 0.08 & 35 & $0.091(0.044)$ & 10.04 & 21 \\
\hline \multicolumn{9}{|l|}{ Incomine $(3)$} \\
\hline$\geq 50,000$ & Rel. & & & & & & & \\
\hline $25,000-<50,000$ & $0.043(0.051)$ & 0.40 & $0.014(0.049)$ & 0.78 & 67 & $0.016(0.050)$ & 0.76 & 63 \\
\hline $10,000-<25,000$ & $0.109(0.053)$ & 0.04 & $0.066(0.052)$ & 0.20 & 39 & $0.076(0.052)$ & 0.14 & 30 \\
\hline$<10_{\sharp} 000$ & $0.144(0.071)$ & 0,04 & $0.078(0.069)$ & 0.26 & 46 & $0.104(0.070)$ & 0.14 & 28 \\
\hline Nhissing & $0.020(0.062)$ & 0.74 & $-0.021(0.061)$ & 0.73 & $>100$ & $0.005(0.062)$ & 0.94 & 75 \\
\hline \multicolumn{9}{|l|}{ Assets } \\
\hline $3-7$ & Ref & & & & & & & \\
\hline $1-2$ & $0.064(0.038)$ & 0.09 & $0.035(0.037)$ & 0.34 & 45 & $0.051(0.037)$ & 0.17 & 20 \\
\hline None & $0.076(0.051)$ & 0.13 & $0.003(0.049)$ & 0.96 & 96 & $0.061(0.050)$ & 0.23 & 20 \\
\hline
\end{tabular}

* Log lransformed walues of C-reactive protein ranged from -1.90 to 4.44

$\uparrow$ Madel 1: adjusted for age, sex, race, site, marital status, and other household members for income + Model 2: adjusted for age, sax, race, site, imarital status, other household members for income, smoking, drinking. $\mathrm{BMI}_{n}$ abdominal visceral fat, and physical activity

Model 3: adjusted for age, sex, race, silte, marital status, other household members for income, lung disease, heart disease, cerebrovascula disease, diabetes, osteoarthritis, cancer, depressed mood, cognitiwe impairment, anti-inflammatory drugg, and corticosteroids

|| Percentage reduction in regression coefficients from model 1 computed by regression coefficient model ${ }^{-}-$ regression coefficient mated as)/(regression coefficient madew) "100\%

We further excluded 1,437 persons with diseases that were strongly associated with elevated levels of inflammatory markers (heart disease, lung disease, cerebrovascular disease, and diabetes mellitus). The association between SES and all three inflammatory markers remained similar and significant (data not shown). In addition, interaction terms between SES and those diseases were not statistically significant, which confirmed that the association between SES and inflammatory markers was similar for people with and without prevalent disease. 
Table 5. Regression coefficients (with SE) of tumor necrosis factoro (log transformed) by education, incomb; and number of assets

\begin{tabular}{|c|c|c|c|c|c|c|c|c|}
\hline & \multicolumn{8}{|c|}{ Tumor mectosis factor-a } \\
\hline & \multicolumn{2}{|c|}{ Woded $1+$} & \multicolumn{3}{|c|}{ Model 2} & \multicolumn{3}{|c|}{ Model 38} \\
\hline & $\begin{array}{c}\text { Regression } \\
\text { coefficient } \\
\text { (SE) }\end{array}$ & $\begin{array}{c}p^{\infty} \\
\text { value }\end{array}$ & $\begin{array}{l}\text { Regression } \\
\text { coefficient } \\
\text { (SE) }\end{array}$ & $\begin{array}{c}\text { pw } \\
\text { value }\end{array}$ & $\begin{array}{c}\% \text { red } \\
0\end{array}$ & $\begin{array}{l}\text { Regression } \\
\text { coeffucignt } \\
\text { (SE) }\end{array}$ & $\begin{array}{c}\mathrm{p} \\
\text { walue }\end{array}$ & \% red \\
\hline \multicolumn{9}{|l|}{ Education } \\
\hline$>12$ years & Ref & & & & & & & \\
\hline 12 years & $0.070(0.019)$ & $<0,001$ & $0.052(0.019)$ & 0.01 & 26 & $0.064(0.018)$ & 0.001 & 9 \\
\hline$<12$ years & $0.046(0.022)$ & 0.04 & $0.025(0.022)$ & 0.25 & 46 & $0033(0.022)$ & 0.13 & 28 \\
\hline \multicolumn{9}{|l|}{ Income (\$) } \\
\hline$\geq 50,000$ & Ref. & & & & & & & \\
\hline $25,000-<50,000$ & $0.057(0.026)$ & 0.03 & $0.039(0.025)$ & 0.12 & 32 & $0.052(0,025)$ & 0.04 & 9 \\
\hline $10,000-<25_{\mu}, 000$ & $0.076(0.027)$ & 0.004 & $0.053(0.027)$ & 0.05 & 30 & $0.066(0.026)$ & 0.04 & 13 \\
\hline$<10,000$ & $0.093(0.036)$ & 0.01 & $0.068(0.036)$ & 0.06 & 27 & $0.073(0.036)$ & 0,04 & 22 \\
\hline Missing & $0.001(0.031)$ & 0.99 & $-0.018(0.031)$ & 0.55 & $>100$ & $0.004(0.034)$ & 0.90 & $>100$ \\
\hline \multicolumn{9}{|l|}{ Assets } \\
\hline $3-7$ & Ref. & & & & & & & \\
\hline $1-2$ & $0.051(0.019)$ & 0.01 & $0.040(0.019)$ & 0.04 & 22 & $0.046(0.019)$ & 0.02 & 10 \\
\hline None & $0,034(0,026)$ & 0.19 & $0.013(0.025)$ & 0.62 & 62 & $0.016(0.025)$ & 0.53 & 53 \\
\hline
\end{tabular}

* Log transformed values of tumor necrosis factor-a ranged from -0.57 10.3.39

+ Model 1: adjusted for age, sex, race, site, marital status, and other househald members fior income * Model 2: adjusted for age, sex, race, site, marital status, other household members for income, smoking, drinking, BMI, abdominal visceral fat, and physical activity

5. Model 3: adjusted for age, sex, race, site, marital status, other household members for income, lung disease, heart disease, cerebrovascular disease, diabetes, osteoarthritis, cancer, depressed mood, cognitive impairment, antï-inflammatory drwgs, and corkicosteroids

i| Percentage reduction in regression coefficients from model 1 compulted by (regression coefficient mode? 1 regression coefficient model $2 / 3$ )(regression coefficient mode! $)^{*} 100 \%$

\section{DISCUSSION}

In well-functioning older adults, low SES was associated with elevated levels of inflammatory markers, compared with high SES. The most consistent linear associations were found for IL-6 and CRP. Results were less clear and not always linear for TNF-a. A substantial portion of the inverse association between SES and inflammatory markers was explained by behavioral factors. Adjustment for prevalent diseases associated with inflammation explained less of the association. Both behavioral factors and diseases failed to explain the association between SES and inflammatory markers completely.

The prevalence of many diseases including heart disease, diabetes mellitus, cognitive impairment and depression is higher in low SES groups (28-32). However, the results suggest that the inverse association between SES and inflammatory markers is largely independent of prevalent disease despite these diseases being related to increased levels of inflammatory markers $(6,17,18)$. On the other hand, behavioral factors explained a substantial part of the SES differences in inflammatory marker levels. An unhealthy lifestyle, including smoking, drinking and obesity, is more prevalent in low SES groups (19) and also related to higher levels of inflammatory 
markers $(20,21)$. It is not surprising that $\mathrm{BMI}$ and abdominal visceral fat, both of which are inversely related to SES, are important in explaining SES differences in inflammatory marker levels because IL-6 and TNF- $\alpha$ are produced within adipose tissue (33). There is an indirect effect with CRP. Since IL-6 is a primary stimulus of CRP production in the liver, higher levels of IL-6 could result in higher levels of CRP (34).

This study has some limitations. First, this study was cross-sectional. Consequently it is impossible to draw conclusions regarding the causal pathways. It is, however, unlikely that high levels of inflammatory markers could have lowered SES, especially education level, as the latter indicator is less sensitive to change during adulthood. In this study similar results were found across all SES indicators, including education. Second, only limited information on severity of diseases was available. We cannot exclude the possibility that a better measurement of the disease burden would have resulted in a stronger contribution of diseases to the association between SES and inflammatory markers. In particular, sub-clinical cardiovascular disease is extremely common in older adults and is associated with high IL-6 levels (35). Finally, there may be other factors which could also be important in explaining SES differences in inflammatory marker levels. These factors may include psychological stress that are related to both low SES and increased levels of inflammatory markers (perhaps through adverse behavioral factors) $(3,36)$. This study also has several strengths. To our knowledge this is the first study that examined the association between SES and levels of inflammatory markers in a large sample of black and white older adults. Furthermore, a large number of potential confounders and mediators were considered in the association between SES and inflammatory markers.

In conclusion, low SES was associated with elevated levels of inflammatory markers. Rather than by a higher prevalence of diseases in low SES groups, the elevated levels of inflammatory markers in low SES groups were to a larger extent based upon a higher prevalence of unhealthy behaviors (especially obesity, smoking, and drinking) in these groups; visceral fat is, however, less amenable to modification. This suggests that even in old age, interventions to improve health behaviors, especially in low SES groups, may be useful in reducing risks associated with inflammation. 


\section{ACKNOWLEDGMENT}

This study was supported by National Institute on Aging contracts N01-AG-62101, N01-AG-6-2103, and N01-AG-6-2106. 


\section{REFERENCES}

1. Jousilahti $P$, Salomaa $V$, Rast V, Vahtera $E$, Palosuo $T$. Association of markers of systemic inflammation, $C$ reactive protein, serum amyloid $A_{n}$ and fibrinogen, with socioeconomic status. $J$ Epidemiol Community Health 2003;57:730-733.

2. Owen $N_{\text {s }}$ Poulton $T$. Hay FC, Mohamed-All $V$. Steptoe A. Socioeconomic status, C-reactive protein, immune factors, and responses to acute mental stress. Brain Behav Immun $2003 ; 17: 286-295$.

3. Steptoe A, Owen $N$, Kunz Ebrecht $S$, Mohamed Ali W. Inflammatory cytokines, socioeconomic status, and acute stress responsivity. Brain Behav Immun 2002;16:774-784.

4. Panagiotakos DB, Pitsavos CE. Chrysohoou CA, et al. The association between educational status and risk factors related to cardiovascular disease in healthy individuals: The ATTICA study. Ann Epidemiol 2004; $14: 188-94$.

5. Reuben DB, Cheh $A$, , Harris TB, et al. Peripheral blood markers of inflammation predict mortality and functional decline in high-functioning community-dwelling older persons. I Am Geriatr Soc 2002;50:638-44.

6. Cesari $M$, Penninx $B W, N$ ewman $A B$, et al. Inflammatory markers and onset of cardiovascular events: results from the Health $A B C$ study. Circulation 2003;108:2317-2322.

7. Ferrucci L, Harris TB, Guralnik JM, et al. Serum IL-6 level and the development of disability in older persons. J Am Geriatr Soc 1999;47:639-46.

8. Rus HG, Vlaicu R, Niculescu F. Interleukin-6 and interleukin-8 protein and gene expression in human arterial atherosclerotic wall. Atherosclerosis 1996;127:263-271.

9. Kostulas $N$, Kivisakk $P$, Huang $Y$, Matusevicius $D$, Kostulas $V$, Link $H$. Ischemic stroke is associated with a systemic increase of blood mononuclear cells expressing interleukin-8 mRNA. Stroke 1998;29:462-466.

10. Pantoni L, Sarti C, Inzitari D. Cytokines and cell adhesion molecules in cerebral ischemia: experimental bases and therapeutic perspectives. Arterioscler Thromb Vasc Biol 1998;18:503513.

11. Ridker PM, Cushman M, Stampfer MJ, Tracy RP, Hennekens $C H$. Inflammation, aspirin, and the risk of cardiovascular disease in apparently healthy men. N Engl J Med 1997;336:973-979.

12. Torre-Amione $G$, Kapadia S, Benedict $C$, Oral H, Young JB, Mann DL. Proinflammatory cytokine levels in patients with clepressed left ventricular ejection fraction: a report from the Studies of Left Ventricular Dysfunction (SOLVD). J Am Coll Cardiol 1996;27:1201-1206.

13. Biasucci LM, Vitelli A, Liuzzo $G$, et al. Elevated levels of interleukin-6 in unstable angina. Circulation 1996;94:874-877.

14. Tracy RP, Lemaitre RN, Psaty BM, et al. Relationship of C-reactive protein to risk of cardiovascular disease in the elderly. Results from the Cardiovascular Health Study and the Rural Health Promotion Project. Arterioscler Thromb Vasc Biol 1997; 17:1121-1127.

15. Tsutamoto T, Hisanaga T. Wada A, et al. Interleukin-6 spillover in the peripheral circulation increases with the severity of heart fallure, and the high plasma level of interleukin- 6 is an important prognostic predictor in patients with congestive heart failure. J Am Coll Cardiol 1998;31:391-398.

16. Cohen HJ, Pieper CF, Harris T, Rao KM, Currie MS. The association of plasma IL-6 levels with functional disability in community dwelling elderly. J Gerontol A Biol Sci Med Sci $1997 ; 52: 201-8$ 
17. Penninx BW, Kritchevsky SB, Yaffe Kh, et al. Inflammatory markers and depressed mood in older persons: results from the Heaith, Aging and Body Composition study. Biol Psychiatry 2003:54:566-572.

18. Yaffe $K$, Lindquist $K$, Penninx BW, et al. Inflammatory markers and cognition in wellfunctioning African American and white elders. Neurology 2003;61:76-80.

19. Marmot MG, Smith GD, Stansfeld $\mathrm{S}$, et all. Health inequalities among British civil servants: the Whitehall II study. Lancet 1991;337:1387-93.

20. Frohlich $M$, Sund $M$, Lowel $H_{n}$ tmhof $A$, Hoffmeister $A$, Koenig $W$. Independent association of various smoking characteristics with markers of systemic inflammation in men. Results from a representative sample of the general population (MONICA. Augsburg Survey 1994/95). Eur Heart $\mathrm{J} 2003 ; 24: 1365-1372$

21. Imhof A, Froehlich $M$, Brenner $H$, Boeing $H$, Pepys MB, Koenig W. Effect of alcohol consumption on systemic markers of inflammation. Lancet 2001:357:763-767.

22. Colbert LH, Visser M, Simonsick EM, et al. Physical activity, exercise, and inflammatory markers in older adults: findings from the health, aging and body composition study. J Am Geriatr Soc 2004:52:1098-104.

23. Rooks RN, Simonsick EM, Miles $T$, et al. The association of race and socioeconomic status with cardiovascular disease indicators among older adults in the health, aging, and body composition study. J Gerontol B Psychol Sci Soc Sci 2002;57:247-56.

24. Adler NE, Ostrove JM. Socioeconomic status and health: what we know and what we don't. Ann $N$ Y Acad Sci 1999;896:3-15.

25. Beekman AT, Deeg DJ, Van Limbeek J, Braam AW, De Vries MZ, Van Tilburg W. Criterion validity of the Center for Epidemiologic Studies Depression scale (CES-D): results from a community-based sample of older subjects in The Netherlands. Psychol Med 1997;27:231-5.

26. McDowell $\|_{1}$ Kristjansson $B$, Hill GB, Hebert R. Community screening for dementia: the Mini Mental State Exam (MMSE) and Modifjed Mini-Mental State Exam (3MS) compared. J Clin Epidemiol 1997;50:377-383.

27. Pahor M, Chrischilles EA, Guralnik JM, Brown SL, Wallace RB, Carbonin P. Drug data cading and analysis in epidemiologic studies. Eur J Epidemiol 1994;10:405-11.

28. Kaplan GA, Keil JE. Socioeconomic factors and cardiovascular disease: a review of the literature. Circulation 1993,88:1973-1998.

29. Hart CL, Holle DJ, Smith GD. The contribution of risk factors to stroke differentials, by socioeconomic position in adulthood: the Renfrew/Paisley Study. Am J Public Health 2000;90:178:8-1791.

30. Evans JM, Newton RW, Ruta DA, MacDonald TM, Morris AD. Socio-economic status, obesity and prevalence of Type 1 and Type 2 diabetes mellitus. Diabet Med 2000:17:478-80.

31. Lee S, Kawachi I, Berkman LF, Grodstein F. Education, other socioeconomic indicators, and cognitive function. Am J Epidemiol. 2003:157:712-720.

32. Stansfeld $S A$, Head J Fuhrer $R$, Wardle $J$ "Cattell $V$. Social inequalities in depressive symptoms and physical functioning in the Whitehall II study; exploring a common cause explanation. J Epidemiol Community Health 2003:57:361-7.

33. Coppack SW. Pro-inflammatory cytokines and adipose tissue. Proc Nutr Soc 2001:60:349-56.

34. Visser M, Bouter LM, McQuillan GM, Wener MH, Harris TB. Elevated C-reactive protein levels in overweight and obese adulls. JAMA 1999;282:2131-5. 
35. Jenny NS. Tracy RP, Ogg MS, et al. In the elderly, interleukin-6 plasma levels and the $174 \mathrm{G}>\mathrm{C}$ polymorphism are associated with the development of cardiovascular disease. Arterioscler Thromb Vasc Biol 2002:22:2066-71.

36. Brydon L. Edwards S, Mohamed-Ail V, Steptoe A. Socioeconomic status and stress-induced increases in interleukin-6. Brain Behaw Immun 2004:18:281-90. 


\section{Is there a biomedical explanation for socioeconomic differences in incident mobility limitation?}

\section{Published as}

Koster A, Penninx BW, Bosma H, Kempen GI, Harris TB, Newman AB, Rooks RN, Rubin SM. Simonsick EM, van Eijk JT, Kritchevsky SB. Is there a biomedical explanation for socioeconomic differences in incident mobility limitation? J Gerontol A Biol Sci Med Sci 2005;60:1022-7. 


\section{ABSTRACT}

Objective. The association between low socioeconomic status and poor physical functioning has been well described; biomedical factors may play an important role in explaining these differences. This study examines the association between socioeconomic status and incident mobility limitation in well-functioning older adults, and seeks to determine whether this link could be explained by biomedical factors.

Methods. Data were obtained from 3,066 men and women, aged 70-79 from Pittsburgh, Pennsylvania and Memphis, Tennessee participating in the Health, Aging and Body Composition (Health $\mathrm{ABC}$ ) study. Three indicators of socioeconomic status were used: education, income, and ownership of financial assets. Mobility limitation was defined as reporting difficulty walking $1 / 4$ mile or climbing 10 steps during two consecutive semiannual assessments over 4.5 years. Biomedical factors included a wide range of diseases (e.g., heart and cerebrovascular disease) and biological risk factors (e.g. hypertension, poor pulmonary function, and high serum levels of inflammatory markers).

Results. Adjusted hazard ratios of incident mobility limitation were significantly higher in those persons with low education, low income, and few assets. Hazard ratios ranged from 1.66 to 2.80 in the lowest socioeconomic groups. Additional adjustment for biomedical factors reduced the hazard ratios by an average of $41 \%$ for education, $17 \%$ for income, and $29 \%$ for assets.

Conclusions. Biomedical factors can account for some of the association between socioeconomic status and incident mobility limitation. However, to reduce physical disabilities and, in particular, the socioeconomic differences therein, it may not be sufficient to solely intervene upon biological risk factors and risks of diseases. 


\section{INTRODUCTION}

The association between low socioeconomic status (SES) and poor physical functioning has been well described (1-4), and several authors hypothesize that biomedical factors such as diseases and biological risk factors play an important role in explaining these differences (5-7). Low SES is a risk factor for cardiovascular disease and stroke, as well as a variety of other diseases (8-10). Obesity, high blood pressure, glucose intolerance, and reduced lung function are also more prevalent among low SES groups in comparison with high SES groups (11-14). Several of these biomedical factors have been directly related to adverse functional outcomes $(4,15,16)$. As important as disease and established disease risk factors may be in predicting function, data are emerging to suggest that certain inflammatory markers also play an important rolle, independent of prevalent clinical disease (17-20). Two recent studies $(21,22)$ also show that persons with low SES have higher serum levels of inflammatory markers than persons do with high SES.

Despite the knowledge that low SES is related to both poorer function and increased prevalence of many diseases and their risk factors "the extent to which biomedical factors can explain the relationship between low SES and functional decline has not been studied extensively. Knowledge of possible biological pathways underlying the association between SES and poor functional outcomes may give insight into potential ways of reducing SES differentials in physical functioning.

In the present study, we examine the association between SES and incident persistent mobility limitation in a large community-based cohort of well-functioning older adults and seek to determine whether this link can be explained by biomedical factors.

\section{METHODS}

\section{Study population}

The Health, Aging and Body Composition (Health $A B C$ ) study is a longitudinal cohort study consisting of 3,075 well-functioning, 70- to 79-year-old , black and white men and women. Participants were identified from a random sample of white Medicare beneficiaries and all age-eligible community-dwelling black residents in designated ZIP code areas surrounding Memphis, Tennessee, and Pittsburgh, Pennsylvania. Participants were eligible if they reported themselves to be wellfunctioning and free of difficulty with any activity of daily living. 'Well-functioning' was defined as having no difficulty in either walking $1 / 4$ mile or going up 10 steps without 
resting. Participants were excluded if they reported a history of active treatment for cancer in the prior 3 years, planned to move out of the study area within the next 3 years, or were currently participating in a randomized trial of a lifestyle intervention. Baseline data, collected between April 1997 and June 1998, included an in-person interview and a clinic-based examination, with evaluation of body composition, clinical and subclinical diseases, and physical functioning. Four and a half years of foilow-up were used in this study. For nine participants, outcome data or SES data were missing, leaving 3,066 participants for the present analyses. All participants signed informed written consent approved by the institutional review boards of the clinical sites.

\section{Measures}

Socioeconomic status. Three indicators of SES were used: education, family income, and ownership of financial assets. Categories for education were: less than 12 years, 12 years, and more than 12 years. Family income was measured by adding all reported income components of all household members. Income was defined as any source of income including, wages, salaries, social security or retirement benefits, help from relatives, and rent from property. Four categories of family income were distinguished: less than $\$ 10,000$, between $\$ 10,000$ and less than $\$ 25,000$, between $\$ 25,000$ and less than $\$ 50,000$, and greater than or equal to $\$ 50,000$. Because of the large number of participants with missing income data a fifth category was created for this group. Financial assets included: money market account, saving bonds or treasury bills, home ownership or investment property or housing, a business or farm, stock or stock mutual funds, and individual retirement account (IRA) or KEOGH account, and other investments. Three categories were created: none, one or two, and three to seven (23). Rather than use a dichotomous variable of any versus no assets, categories were used because the literature has shown that various SES gradients have significant effect on health outcomes (24).

Incident persistent mobility limitation. The occurrence of mobility limitation over four and a half years of follow-up was determined every 6 months, at study assessment visits $(12,24,36$, and 48 months after baseline), or during telephone follow-up assessments $(6,18,30,42$, and 54 months after baseline). Incident persistent mobility limitation was considered to be present when a person reported any difficulty walking one quarter mile or climbing 10 steps at two semiannual followup assessments. The requirement that mobility limitation needed to be present at two consecutive assessments selected more participants with chronic and severe functional limitation; therefore, this outcome was thought to be a more reliable indicator of a clinically relevant change in functional status. The incidence of mobility 
limitation was adjudicated by a special Health $A B C$ study committee that considered additionally available information such as reason for missing study contact (in nursing home, severe illness) and proxy information for those participants who died.

Biomedical factors. Possible biomedical explanatory variables cover a wide range of clinical and subclinical diseases. Baseline presence of diseases was determined using standardized algorithms considering self-report, use of specific medications, and some clinical assessments. Baseline prevalent cancer was based on self-reports of cancer or malignancy and/or use of anticancer medication. The presence of heart disease was defined as having coronary heart disease and/or congestive heart failure. Cerebrovascular disease was defined as a history of stroke or transient ischemic attack. Peripheral arterial disease was based on self-reports of intermittent claudication or a history of lower extremity bypass or angioplasty. Three categories, using American Diabetes Association criteria, were distinguished for glucose intolerance: not impaired (fasting glucose level $<100 \mathrm{mg} / \mathrm{dll}$ ), impaired fasting glucose (fasting glucose level between $100 \mathrm{mg} / \mathrm{dl}$ and $126 \mathrm{mg} / \mathrm{dl}$ ), and diabetes mellitus (fasting glucose level $>126 \mathrm{mg} / \mathrm{dl}$ ). Hypercholesterolemic persons had high total cholesterol levels ( $2240 \mathrm{mg} / \mathrm{dl})$ and/or high low-density lipoprotein cholesterol levels ( $\geq 130 \mathrm{mg} / \mathrm{dl}$ ) or were being treated with lipid-lowering drugs (25). Triglyceride levels were considered high if $>150 \mathrm{mg} / \mathrm{dl}$, and high-density lipoprotein cholesterol levels were considered low if $<40 \mathrm{mg} / \mathrm{dl}$ in men and $<50 \mathrm{mg} / \mathrm{dl}$ in women (26). For hypertension, four categories were created: normotensive (systolic pressure <140 $\mathrm{mmHg}$ and diastolic pressure $<90 \mathrm{mmHg}$ ); normotensive and treated with blood pressure lowering drugs, hypertension stage 1 (systolic pressure $\geq 140 \mathrm{mmHg}$ or diastolic pressure $\geq 90 \mathrm{mmHg}$ ), and hypertension stage 2 (systolic pressure $\geq 160$ $\mathrm{mmHg}$ or diastolic pressure $\geq 100 \mathrm{mmHg}$ ) (27). Two variables for pulmonary function were used: a poor forced expiratory volume in 1 second/forced vital capacity ratio ( $\left.F E V_{1} / F V C\right)$ of $70 \%$ or lower, and percentage predicted FEV fo $_{1} 80 \%$ or lower (28, 29). Body mass index (BMI) was categorized as lower than $25 \mathrm{~kg} / \mathrm{m}^{2}$, between 25 and $30 \mathrm{~kg} / \mathrm{m}^{2}$, and higher than $30 \mathrm{~kg} / \mathrm{m}^{2}$. Knee pain was considered if reported to be present at least 1 month of the past year. Ankle arm blood pressure index was considered indicative of peripheral arterial disease if lower than 0.9 (30). Finally, serum level of three inflammatory markers were assessed; interleukin-6 (IL-6), Creactive protein (CRP), and tumor necrosis factor- $\alpha$ (TNF- $\alpha$ ) (20). Each biomarker variable was dichotomized, where inflammation was defined as being in the highest tertile of IL-6 ( $\geq 2.40 \mathrm{pg} / \mathrm{ml})$, CRP $(\geq 2.55 \mathrm{mg} / \mathrm{L})$, and TNF-a $(\geq 3.72 \mathrm{pg} / \mathrm{ml})$. In addition, an inflammation index was calculated as the number of inflammatory markers in the highest tertile, which has been shown to be an important predictor of incident mobility limitation (20). 
Sociodemographics. Sociodemographics included age, sex, race (black, white), study site (Memphis, Pittsburgh), and marital status (never married, previously married , married). For the analyses with familly income we also controlled for whether (yes/no) people had household members other than their spouse.

\section{Statistical analyses}

Analyses were performed using SPSS, version 11.5 (SPSS Inc., Chicago, IL). To determine if there were differences in the incidence of mobility limitation between SES groups, unadjusted Cox proportional hazard regression models were fitted. To determine if there were differences in prevalences of the biomedical variables between SES groups, the chi-square test was used. To evaluate the association of biomedical factors with time to incident persistent mobility limitation, Cox proportional hazard regression models were fitted, adjusting for sociodemographics. Cox proportional hazard regression models were also fitted to study the association of SES on time to incident mobility limitation. Persons surviving with no evidence of incident limitation were censored at the last study visit, those dying with no evidence of incident limitation were censored at time of death, and those lost to follow-up were censored at their last interview. Two models were fitted; the first model was adjusted for sociodemographics. The second model contained all variables of the first model as well as the biomedical variables. To determine the role of biomedical factors, a percentage reduction in hazard ratio (HR) from model 1 was computed: (HR model 1 $\left.H R_{\text {model } 2}\right) /(H R \text { model } 1-1)^{\star} 100 \%$.

\section{RESULTS}

Figure 1 shows the incidence rate per 1,000 person years of incident mobility limitation according to SES. A $p$-value for trend was statistically significant $(p<0.001)$ for all three SES indicators. More people with low SES had incident mobility limitation than did those with high SES. Resuits are shown for black and white persons together because interaction terms between any of the SES indicators and race were not statistically significant (all $p>0.10$ ).

In further analyses we used only those biomedical variables that were statistically significant predictors of incident persistent mobility limitation; because of their nonsignificance baseline presence of cancer and hypercholesterolemia were not further considered. All other biomedical factors were significant predictors of incident mobility limitation, adjusted for sociodemographics (not tabulated). 
Incidence rate per 1,000 person years of mobinity limitation according to education

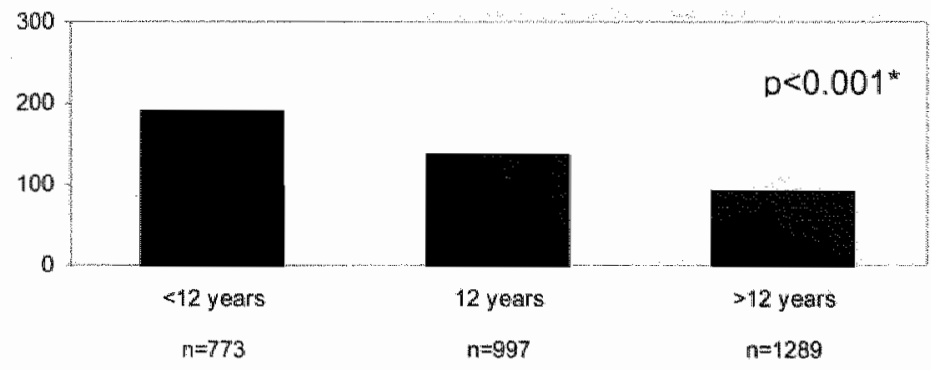

Incidence rate per 1,000 person years of mobility limitation according to income

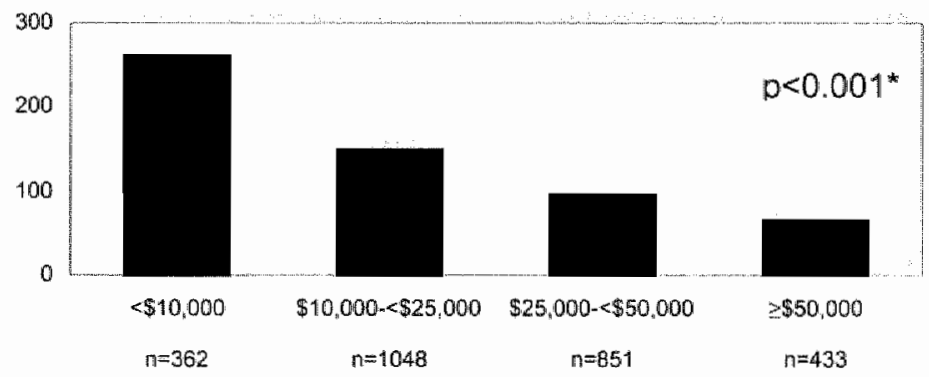

Incidence rate per 1,000 pers on year's of mobility limitation according to number of assets

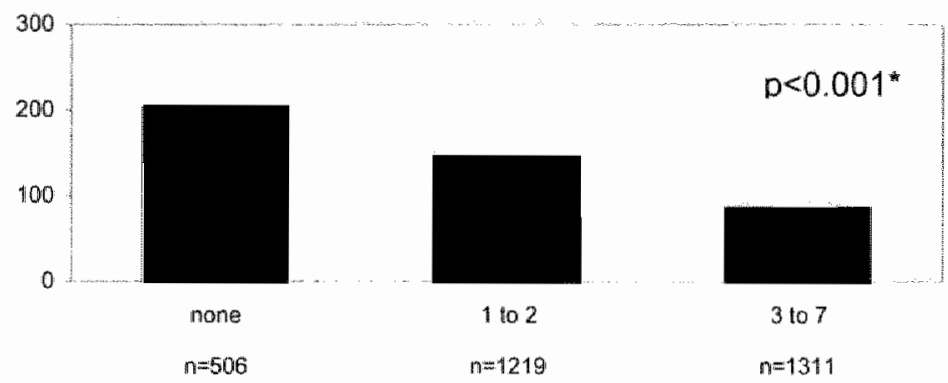

Figure 1. Incidence rate per 1,000 person years of mobility limitation according to socioeconomic status

* $p$-value based on unadjusted survival analyses 
Especially strong predictors were having three inflammatory markers in the highest tertile (HR: $3.21,95 \%$ confidence interval [CI]: $2.65,3.89$ ), peripheral arterial disease (HR: $2.42,95 \% \mathrm{Cl}: 1.97,2.96$ ), and knee pain (HR: $2.20,95 \% \mathrm{Cl}: 1.93,2.50$ ).

Generally, the prevalence of disease and biological risk factors was higher in low SES groups except for high triglycerides levels and low high-density lipoprotein cholesterol levels for which the prevalence was higher in high SES groups. Glucose intolerance, hypertension, low predicted FEV, high BMI, low ankle arm blood pressure index, high serum levels of IL-6 and CRP, and having three inflammatory markers in the highest tertile were statistically significantly associated with low education, low income and few assets (Table 1).

Hazard ratios of incident mobility limitation, adjusted for sociodemographics, were significantly higher in low SES groups compared to the highest SES group (Table 2, Madel 1). Low income showed a particularly increased risk: hazard ratios were $2.80(95 \% \mathrm{Cl}: 2.06,3.81)$ in the income group $<\$ 10,000$, and $1.82(95 \% \mathrm{Cl}$ : $1.40,2.36$ ) in the income group $\$ 10,000-\$ 25,000$ compared to that of those participants with an income higher than $\$ 50,000$. Strong associations were found between SES and incident mobility limitation for all three SES indicators. When all SES indicators were included in one analytic model, all three indicators remained significant predictors of incident mobility limitation. Therefore, education, income, and number of assets all had an independent effect on incident mobility limitation.

Biomedical factors (Model 2) could explain a substantial part of the SES gradient in incident mobility limitation. The largest reduction in hazard ratios was found for education; $48 \%$ for the group with 12 years of education and $33 \%$ for the group with less than 12 years of education ( $41 \%$ on average). Biomedical factors decreased the hazard ratios by an average of $17 \%$ for income and $29 \%$ for the number of assets. Figure 2 shows the biomedical factors that reduced the hazard ratios for the lowest SES group versus the highest SES group by more than $5 \%$, adjusted for sociodemographics. High serum levels of inflammatory markers and high BMI decreased the hazard ratios by more than $5 \%$ for all three SES indicators. 


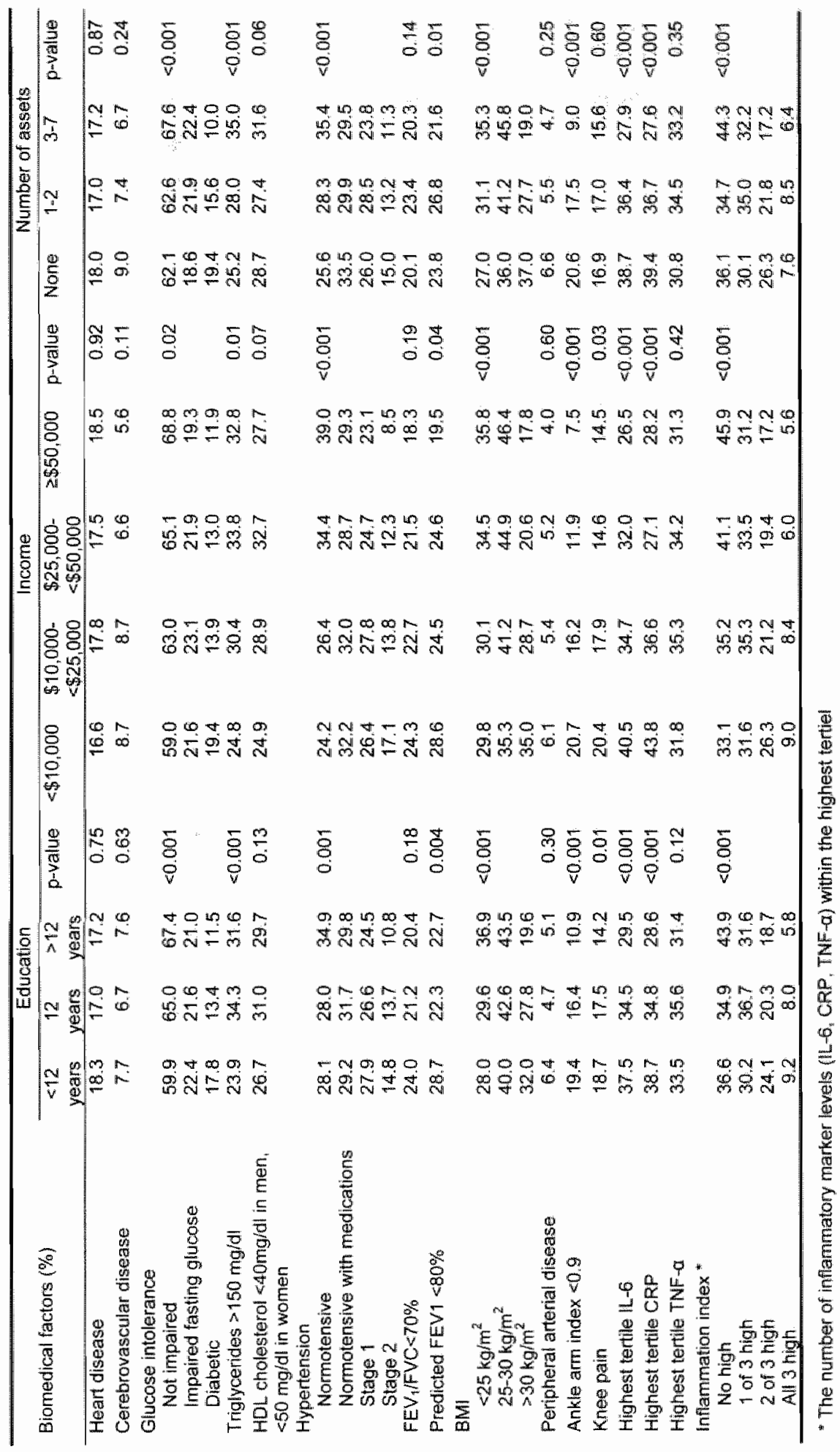


Table 2. Hazard ratios (HR) and $95 \%$ contidence interval (CI) of incident mobitity limilation by aduation, hicome, and number of asseds

\begin{tabular}{|c|c|c|c|c|c|}
\hline \multirow[b]{2}{*}{ Socibeconomic status } & \multicolumn{2}{|c|}{ Model 1} & \multicolumn{3}{|c|}{ Made $2+$} \\
\hline & $\mathrm{HR}$ & $95 \% \mathrm{Cl}$ & $H R$ & $95 \% \mathrm{Cl}$ & $\%$ red. $\ddagger$ \\
\hline \multicolumn{6}{|l|}{ Education } \\
\hline s12 years & $1: 00$ & & 1.00 & & \\
\hline 12 years & 1.33 & $1.13,1.56$ & 11.17 & $1.00,1138$ & 48 \\
\hline 412 years & 1.70 & $1.42,2.04$ & 1.47 & $1.23,1.87$ & 33 \\
\hline \multicolumn{6}{|l|}{ Uncome } \\
\hline$\geq \$ 50,000$ & 1.00 & & 1.00 & & \\
\hline$\$ 25,000-<\$ 50,000$ & 1.39 & $1.07,1.80$ & 1.33 & $1.02,1.73$ & 15 \\
\hline$\$ 10,000-<25,000$ & 1.82 & $1.40,2.36$ & 1.61 & $1.24,209$ & 26 \\
\hline$<\$ 10,000$ & 2.80 & $2.06,3.81$ & 2.64 & $1.93,3.61$ & 9 \\
\hline Missing & 1.55 & $1.15,2,09$ & 1.45 & $1.07,1.96$ & 18 \\
\hline \multicolumn{6}{|l|}{ Number of assets } \\
\hline 3.7 & 1.00 & & 1.00 & & \\
\hline $1-2$ & 1.28 & $1.08,1.51$ & 1.20 & $1.02,1.42$ & 29 \\
\hline None & 1.66 & $1.35,2.04$ & 1.47 & $1.19,1.81$ & 29 \\
\hline
\end{tabular}

" Model 1: adjusted for age, sex "race, study site, other household members for income, and marital status

+ Model 2 adjusted for age, sex, race, study site, other household members for income, marital status, and biomedical factors.

* Percentege reduction im hazard ratio from model 1 computed by (HR model 1 -

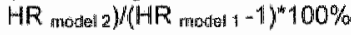

\section{DISCUSSION}

In a well-functioning older population, low SES predicted an increased incidence of mobility limitation during four and a half years of follow-up. Biomedical factors explained a substantial part of the SES differentials in mobility limitation incidence. On average $41 \%$ of the education differences in mobility limitation incidence was explained by biomedical factors; this was $17 \%$ for income and $29 \%$ for the number of assets. However, even after taking into account a wide range of diseases and biological risk factors, persons in the lowest SES group still had a significant increased risk of mobility limitation incidence. Hazard ratios still ranged from 1.47 to 2.64 in the lowest SES groups compared to the highest SES groups. Hazard ratios were more modest in the middle SES groups compared to the highest SES groups. High serum levels of inflammatory markers, high BMI, and hypertension were found to be the most important biomedical variables in reducing the hazard ratios for SES. It is notable that these variables measured biological characteristics rather than diseases. These biological risk factors have in common that they are risk 
Decrease in hazard ratio for $<12$ years versus $>12$ yeers of education

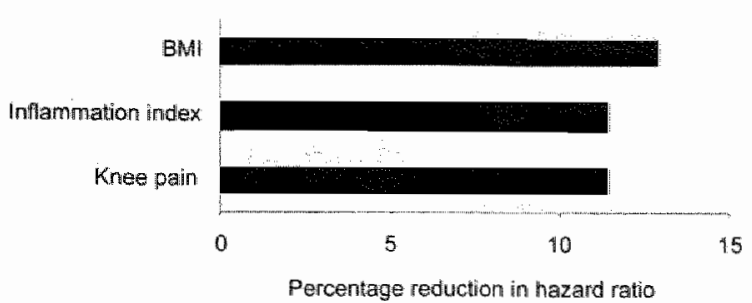

Decrease in hazard ratio for the lowest versus the highest income group

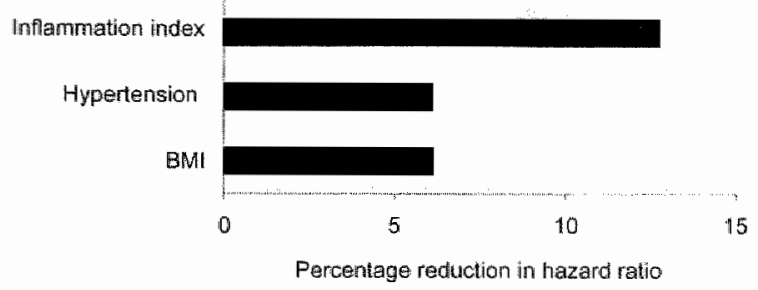

Decrease in hazard ratio fior mo assets versus $3-7$ assels

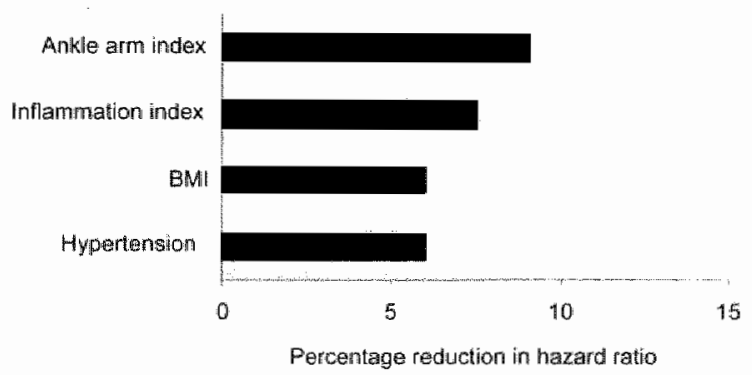

Figure 2. Biomedical factors that reduced the hazard ratio for the lowest wersus the highest socioeconomic group by more than $5 \%$ adjusted for age, sex, race, study site, and marital sta"us 
factors for a wide variety of health outcomes and may represent indicators of disease severity.

Relatively few studies in older people have investigated the relationship between SES and functional outcomes (31-33). Studies have found that the relationship between SES and health outcomes were weaker in people aged 65 or older compared to younger people. In addition; it has been argued that disparities in income diminish after retirement. In our study, the effect of SES on poor functional outcomes in elderly persons was still quite strong.

Besides biomedical factors there may also be other factors that explain the association between SES and mobility limitation. These factors may be related to behavioral or psychosocial factors. Low SES is related to many adverse behavioral factors, such as smoking status and excessive alcohol consumption that in turn are related to poor health outcomes $(3,6,34)$. In this study, the contribution of biomedical factors in explaining SES difference in incident mobility limitation is similar when we adjust for smoking status (current, former, never smoker), alcohol use during the past year $(0,<1,1-7,>7$ drinks per week), and physical activity (total killocalories per kilogram per week) in both models (data not shown). There is also evidence that psychosocial factors, such as control beliefs and stress, play an important role in functional outcomes $(35 \%$, and also in the association between SES and poor functional outcomes (36).

This study has some limitations. First, information on mobility limitation was based on self-report. Second, only limited information was available on the severity of baseline diseases. It must be acknowledged that the approach followed is limited by both the comprehensiveness of the panel of biomedical factors considered and the reliability with which these factors have been assessed. We cannot exclude the possibility that, had the underlying biomedical factors been measured more exactly, the diminution in the strength of the SES effect may have been larger. Third, onlly baseline data on biomedical factors were analyzed, so the association between SES on the one hand and biomedical factors on the other hand might have resulted from reverse causation: therefore, biomedical factors could have partly confounded the link between SES and mobility limitation (37-39). If present, it is likely that this selection effect would have had a larger effect on income and assets than on educational level, as the latter indicator is less sensitive to change during adulthood. However, in this study, the same results were found across all SES indicators (including education) so reversed causation is not very likely.

Our study also has several strengths. First, the study consists of a large cohort of older black and white adults in which loss-to follow-up for our outcome was very limited $(<4 \%)$. Second, because of the longitudinal character of our study we 
establish that SES precedes the development of mobility limitation. Third, we had information on a wide variety of diseases and biological risk factors, that allowed for a more comprehensive assessment than has been possible previously. Fourth, all participants were well-functioning at baseline, so the study was designed to determine incident functional limitation. Mobility limitation is the most important outcome in the Health ABC study because of the need to identify risk factors at a stage of age-related decline that would be amenable to preventive interventions.

In summary, there is a strong association between low SES and incident mobility limitation in older persons. Part of this association could be explained by biomedical factors. This study suggests that biomedical factors are important in the mechanism underlying the association between SES and poor functional outcomes. However, to reduce physical disabilities and, in particular, the SES differences therein, it may not be sufficient to solely intervene on biological risk factors and risks of diseases.

\section{ACKNOWLEDGMENT}

This study was supported by National Institute on Aging contracts N01-AG-62101, N01-AG-6-2103, and N01-AG-6-2106. 


\section{REFERENCES}

1. Gundy E. Glaser K. Socio-demographic differences in the onset and progression of disability in early old age: a longitudinal study. Age Ageing 2000;29:149-57.

2. Hemingway $H$, Nicholson $A$, Stafford $M$, Roberts $R_{n}$ Marmot $M$. The impact of socioeconomic status on health functioning as assessed by the SF-36 questionnaire: the Whitehall III Study. Am J Public Health 1997;87:1484 1490.

3. Martikainen $P$, Stansfeld $\mathrm{S}_{1}$ Hemingway $\mathrm{H}$, Marmot M. Determinants of sociceconomic differences in change in physical and mental functioning. Soc Sci Med 1999;49:499-507.

4. Seemen TE, Charpentier PA, Berkman LF, et al. Predicting changes in physical performance in a high-functioning elderly cohort: MacArthur studies of successful aging. J Gerontol A Biol Sci Med Sci 1994:49:M97-108.

5. Adler NE, Ostrove JM. Socioeconomic status and health: what we know and what we don't. Ann $\mathbb{N}$ Y Acad Sol 1999;896:3-15.

6. Marmot MG, Shipley MJ, Rose G. Inequalities in death-specific explanations of a general pattern? Lancet 1984:1:1003-6.

7. Hemingway H, Stafford M, Stansfeld S, Shipley M, Marmot M. Is the SF-36 a valid measure of change in population health? Results from the Whitehall II Study. BMJ 1997;315:1273-9.

8. Kaplan GA, Keil JE. Socioeconomic factors and cardiovascular disease: a review of the literature. Circulation 1993;88:1973-1998.

9. Hart CL. Hole DJ, Smith GD. The contribution of risk factors to stroke differentials, by socioeconomic position in adulthood: the Renfrew/Paisley Study. Am J Fublic Health 2000;90:1788-1791.

10. Marmot MG. Bosma $H$. Hemingway $H$, Brunner $E$, Stansfeld $S$. Contribution of job control and other risk factors to social variations in coronary heart disease incidence. Lancet 1997;350:235-239.

11. Brunner EJ, Marmot $M G$, Nanchahall $K$, et al. Social inequality in corronary risk: central obesity and the metabolic syndrome. Evidence from the Whitehall II study. Diabetologia 1997:40:1341-1349.

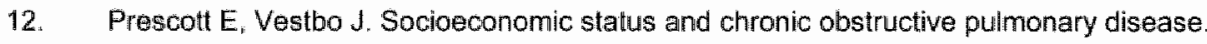
Thorax 1999;54:737-741.

13. Everson SA, Maty SC, Lynch JW, Kaplan GA. Epidemiologic evidence for the relation between socioeconomic status and depression, obesity, and diabetes ، J Psychosom Res $2002,53: 891-895$

14. Galobardes B, Costanza MC, Bernstein MS, Delhumeau C, Morabia A. Trends in risk factors for lifestyle-related diseases by socioeconomic position in Geneva, Switzerland, 1993-2000: health inequalities persist. Am J Public Health 2003:93:1302-1309.

15. Jensen GL, Friedmann JM. Obesity is associated with functional decline in communitydwelling rural alder persons. J Am Geriatr Soc 2002;50:918-923.

16. Boult $\mathrm{C}$, Kane RL, Louis TA, Boult L, McCaffrey D. Chronic conditions that lead to functional limitation in the elderly. J Gerontol 1994;49:M28-M36.

17. Cohen HW. Harris T. Pieper CF. Coagulation and activation of inflammatory pathways in the development of functional decline and mortality in the elderly. Am J Med 2003;114:180-7.

18. Ferrucci L. Harris. TB, Guralnik JM, et al. Serum IL-6 level and the development of disability in older persons. J Am Geriatr Soc 1999;47:639-46. 
19.

Taaffe DR. Harris TB, Ferrucci L Rowe d, Seeman TE. Cross-sectional and prospective relationships of interleukin-6 and C-reactive protein with physical performance in elderly persons: MacArthur studies of successful aging. J Gerontol A Biol Sei Med Sci 2000,55:70915.

20. Penninx $B W$, Kritchevsky $S B, N e w m a n ~ A B$, et al. Inflammatory markers and incident mobility limitation in the elderly. J Am Geriatr Soc 2004:52:1105-13.

21. Jousilahti P, Salomaa V, Rasi V, Vahtera E, Palosuo T. Association of markers of systemic inflammation, $C$ reactive protein, serum amyloid $A$, and fibrinogen, with socioeconomic status. $\checkmark$ Epidemiol Community Health 2003;57:730-733.

22. Steptoe A, Owen N, Kunz Ebrecht S, Mohamed Ali V. Inflammatory cytokines, socioeconomic stalus, and acute stress responsivity. Brain Behav Immun 2002;16:774-784.

23. Rooks $\mathbb{R N}$, Simonsick EM, Miles $T$, et al. The association of race and socioeconomic status with cardiovascular disease indicators among older adults in the health, aging, and body composition study. J Gerontol B Psychol Sci Soc Sci 2002;57:247-56.

24. Adler NE, Boyce T. Chesney MA, et al. Socioeconomic status and health. The challenge of the gradient. Am Psychol 1994:49:15-24.

25. Holvoet P, Harris TB, Tracy RP, et al. Association of High Coronary Heart Disease Risk Status With Circulating Oxidized LDL in the Well-Functioning Elderly: Findings From the Health, Aging, and Body Composition Study. Arterioscler Thromb Vasc Biol 2003;23:1444-1448.

26. Ford ES, Giles WH. Dietz WH. Prevalence of the metabolic syndrome among US adults: findings from the third National Health and Nutrition Examination Survey. JAMA 2002;287:356-359.

27. Chobanian AV, Bakris GL, Black HR, et al. The Seventh Report of the Joint National Committee on Prevention, Detection, Evaluation, and Treatment of High Blood Pressure: the JNC 7 report. JAMA 2003;289:2560-2572.

28. Hankinson $\mathrm{L} L$, Odencrantz $J R, F$ Fedan KB. Spirometric reference values from a sample of the general U.S. population. Am J Respir Crit Care Med 1999;159:179-187.

29. Pauwels RA, Buist AS, Calverley PM, Jenkins CR, Hurd SS. Glabal strategy for the diagnosis, management, and prevention of chronic obstructive pulmonary disease. NHLBINWHO Global Initiative for Chronic Obstructive Lung Disease (GOLD) Warkshop summary. Am J Respir Crit Care Med 2001:163:1256-1276.

30. Newman AB, Shemanski L, Manolio TA, et al. Ankle-arm index as a predictor of cardiovascular disease and mortality in the Cardiovascular Health Study. The Cardiovascular Health Study Group. Arterioscler Thromb Vasc Biol 1999;19:538-545.

31. Amaducci L, Maggi S, Langlois $d$, et al. Education and the risk of physical disability and mortality among men and women aged 65 to 84: the ltalian Longitudinal Study on Aging. I Gerontol A Biol Sci Med Sci 1998;53:M484-90.

32. Broese van Groenou MI, Deeg DJ, Penninx BW. Income differentials in functional disability in old age: relative risks of anset, recovery, decline, attrition and mortality. Aging Clin Exp Res 2003:15:174-183.

33. Melzer $D_{1}$ Izmirlian G, Leveille SG, Guralnik JM. Educational differences in the prevalence of mobility disability in old age: the dynamics of incidence, mortality, and recovery. $\downarrow$ Gerontol B Psychol Sici Soc Sci 2001:56:294-301. 
34. Droomers $M$, Schrijvers CT, Mackenbach JP. Educational level and decreases in leisure time physical activity: predictors from the longitudinal GLOBE study. J Epidemiol Community Health 2001:55:562-8.

35. Kempen GI, van Heuvelen MJ, van Sonderen E, van den Brink RH, Kooilman AC, Ormel J. The rellationship of functional limitations to disability and the moderating effects of psychalogical attributes in community-dwelling older persons. Soc Sol Med 1999;48:1161-72.

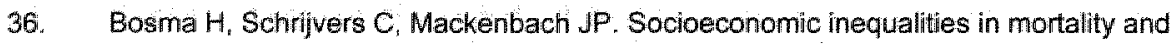
importance of percelved control: cohort study. BWJ 1999;319:1469-70.

37. Blane D, Davey Simith $G_{i}$ Bartley M. Socilal selection: what doe it contribute to social class differences in health? Soc Health lliness 1993;15:1-15.

38. Lundberg O. Causal explanations for class inequality in health--an empirical analysis. Soc Sci Med 1991;:32:385-93

39. West $P$. Rethinking the health selection explanation for health inequalities. Soc Sci Med $1991 ; 32: 373-84$. 


\section{7}

\section{Socioeconomic differences in cognitive decline and the role of biomedical factors}

\section{Published as}

Koster A, Penninx BW, Bosma H, Kempen Gl, Newman AB, Rubin SM, Satterfield $S$, Atkinson $\mathrm{HH}_{4}$, Ayonayon $\mathrm{HN}$, Rosano $\mathrm{C}$, Yaffe $\mathrm{K}$, Harris TB, Rooks RN, van Eijk JT, Kritchevsky SB. Socioeconomic differences in cognitive dectine and the role of biomedical factors. Ann Epidemiol 2005;15:564-571. 


\section{ABSTRACT}

Objective. This study examines the association between socioeconomic status and cognitive decline in a community-based cohort of well-functioning older adults and seeks to determine whether this link could be explained by biomedical factors.

Methods. Data are from 2,574 men and women, aged 70-79 from Pittsburgh, PA and Memphis, TN participating in the Health, Aging and Body Composition study (Health $A B C$ ). Three indicators of socioeconomic status were used: education, income, and ownership of financial assets. Cognitive decline over four years was defined as a decrease of five points or more in the Modified Mini-Mental State Examination (3MS) score. Biomedical factors measured at baseline, included heart disease, cerebrovascular disease, diabetes, hypertension, poor pulmonary function, and high serum levels of intlammatory markers.

Results. Adjusted odds ratios were significantly higher in those with low education, low income, and few assets. Odds ratios ranged from 1.51 to 2.16 in the lowest socioeconomic groups. Additional adjustment for biomedical factors reduced the odds ratios of cognitive decline by an average of $2 \%$ for education, $5 \%$ for income, and $8 \%$ for the number of assets.

Conclusions. Low socioeconomic status predicts a decline in cognitive function in older adults and this relationship is not mediated by biomedical factors. 


\section{INTRODUCTION}

Accumulating evidence shows that low socioeconomic status (SES) is related to poor mental and physical functioning (1-5). However, longitudinal research on its association with decline in cognitive functioning remains scarce. Several studies have examined the association between educational level and cognitive change (68). Only few researchers have examined the association of other SES indicators, like occupational level and income, with cognitive function (9-12).

Biomedical factors, including common diseases and their biological risk factors, are likely to be an important mechanism that may help to explain a potential association between low SES and cognitive decline. Low SES is a risk factor for cardiovascular disease and stroke, as well as a variety of other diseases (13-15). Obesity, high blood pressure, glucose intolerance, and reduced lung function are also more prevalent among low SES groups in comparison to high SES groups (1619). Several of these biomedical factors have also been associated with poor cognitive function (20-23). Two recent studies show that persons with low SES have higher serum levels of inflammatory markers than persons with high SES $(24,25)$. It is plausible to assume that SES differentials in inflammatory markers may also be important, as there is accumulating evidence that these markers are related to cognitive decline $(26,27)$.

To our knowledge the role of biomedical factors in the relation between SES and cognitive decline has not been studied extensively before. Insight into possible biological pathways underiying the association between SES and poor cognitive function may provide a better undlerstanding of potential ways of reducing SES differentials in cognitive decline. This may be especially important in an aging population, given that maintaining good cognitive function is an essential part of successful aging (28).

The present study examines the association between low SES and cognitive decline and potential mediation effects of biomedical factors in a large communitybased cohort study of older adults.

\section{METHODS}

\section{Study population}

The Health, Aging and Body Composition (Health $A B C$ ) study is a longitudinal cohort study consisting of 3,075 well-functioning, 70 to 79 -year old, black and white men and women. Participants were identified from a random sample of White 
Medicare beneficiaries and all age-eligible community-dwelling black residents in designated zip code areas surrounding Memphis, Tennessee, and Pittsburgh, Pennsylvania. Participants were eligible if they reported themselves to be wellfunctioning and free of difficulty with any activity of daily living. "Well-functioning" was defined as having no difficulty in either walking one quarter of a mile or going up 10 steps without resting. Participants were excluded if they reported a history of active treatment for cancer in the prior three years, planned to move out of the study area in the next three years, or were currently participating in a randomized trial of a lifestyle intervention. Baseline data included an in-person interview and a clinic-based examination, with evaluation of body composition, clinical and sub-clinical diseases, and physical functioning. These data were collected between April 1997 and June 1998. The present study utilized four years of follow-up. For our analyses, individuals with missing data for SES or cognition at baseline or follow-up and those who died during the follow-up were excluded. Data on all SES measures were missing for one participant, 14 had missing baseline cognitive data, 204 people had missing follow-up cognitive data, and 282 people died during the follow-up, leaving 2,574 participants for the current analyses. All participants signed informed written consent forms approved by the institutional review boards of the clinical sites.

\section{Measures}

Socioeconomic status. Three indicators of SES, measured at baseline, were used: education, family income, and ownership of financial assets (29). Categories for education were: less than 12 years, 12 years, and more than 12 years. Family income was defined as: wages, salaries, social security or retirement benefits, heip from relatives, and rent from property. Five categories were distinguished: less than $\$ 10,000$, between $\$ 10,000$ and less than $\$ 25,000$, between $\$ 25,000$ and less than $\$ 50,000$, greater than or equal to $\$ 50,000$, and missing $(n=316,12.3 \%$ ). The number of financial assets a person reported was used as a third SES measure. Assets included: money market account, savings bonds or treasury bills, home ownership or investment property or housing, a business or farm, stock or stock mutual funds, and individual retirement account (IRA) or KEOGH account, and other investments. Three categories were created: none, one or two, and three to seven (29). Rather than use a dichotomous variable of any versus no assets, categories were used because the literature has shown that various SES gradients have significant effect on health outcomes (30).

Cognitive function. The Modified Mini-Mental State Examination (3MS) was used as an indicator of general cognitive status. This test includes orientation to time and place, recall, simple language, and construction (31). The $3 \mathrm{MS}$ has a minimum 
score of zero and maximum score of 100 (best) and may be more sensitive for mild cognitive change than the traditional Mini-Mental State Examination (31). A dedine in cognitive function between baseline and the fourth year of follow up was defined as a decrease of five points or more in 3MS score, as previously used and recommended in other studies $(26,32,33)$. For $292(11.3 \%)$ participants, 3MS data in the fourth year of follow-up were based on a shortened $3 M S$ used in a telephone interview. A decline in cognitive function was also considered to be present if a participant was using specific medications for Alzheimer's disease, was hospitalized because of dementia as either the primary or concurrent diagnosis on a discharge summary during the four year follow-up $(n=44,1.71 \%)(26)$.

Biomedical factors. Possible biomedical explanatory variables covered a wide range of clinical and sub-clinical diseases. Baseline presence of diseases was adjudicated using standardized algorithms considering self-report, use of specific medications, and clinical assessments. The presence of heart disease was defined as having coronary heart disease and/or congestive heart failure. Cerebrovascular disease was defined as a history of stroke or transient ischemic attack. Peripheral arterial disease was based on self-reports of intermittent claudication or a history of lower extremity bypass or angioplasty. Three categories, using American Diabetes Association criteria, were distinguished for glucose intolerance: not impaired (fasting glucose level $<100 \mathrm{mg} / \mathrm{dl}$ ), impaired fasting glucose (fasting glucose level between $100 \mathrm{mg} / \mathrm{dl}$ and $126 \mathrm{mg} / \mathrm{dl}$ ), and diabetes mellitus (fasting glucose level $>126 \mathrm{mg} / \mathrm{dl}$ ). Hypercholesterolemic persons had high total cholesterol levels ( $\geq 240 \mathrm{mg} / \mathrm{dl}$ ) and/or high LDL cholesterol levels $(\geq 130 \mathrm{mg} / \mathrm{dl})$ or were being treated with lipid-lowering drugs (34). Dyslipidemic persons had high triglycerides ( $>150 \mathrm{mg} / \mathrm{dl}$ ) and/or low HDL cholesterol levels ( $<40 \mathrm{mg} / \mathrm{dl}$ in men and $<50 \mathrm{mg} / \mathrm{dl}$ in women) (35). For hypertension, four categories were created: normotensive (systolic pressure $<140$ $\mathrm{mmHg}$ and diastolic pressure $<90 \mathrm{mmHg}$ ), normotensive and treated with blood pressure lowering drugs, hypertension stage 1 (systolic pressure $\geq 140 \mathrm{mmHg}$ or diastolic pressure $\geq 90 \mathrm{mmHg}$ ), and hypertension stage 2 (systolic pressure $\geq 160$ $\mathrm{mmHg}$ or diastolic pressure $\geq 100 \mathrm{mmHg}$ ) (36). Two indicators of poor pulmonary function were used. A poor forced expiratory volume in one second/forced vital capacity ratio ( $\mathrm{FEV}_{1} / \mathrm{FVC}$ ) of $70 \%$ or lower, and percentage predicted $\mathrm{FEV} \mathrm{V}_{1}$ of $80 \%$ or lower based on predicted values derived by Hankinson et al. $(37,38)$. Body mass index (BMI) was categorized as lower than $25 \mathrm{~kg} / \mathrm{m}^{2}$, between 25 and $30 \mathrm{~kg} / \mathrm{m}^{2}$, and higher than $30 \mathrm{~kg} / \mathrm{m}^{2}$. Ankle arm blood pressure index was considered indicative of peripheral arterial disease if lower than 0.9 (39). Finally, serum level of three inflammatory markers were assessed; interleukin-6 (IL-6), C-reactive protein (CRP), and tumor necrosis factor-a (TNF-a) (40). Each biomarker variable was 
dichotomized, and inflammation was defined as being in the top tertile level of IL-6 $(\geq 2.40 \mathrm{pg} / \mathrm{ml}), \mathrm{CRP}(\geq 2.55 \mathrm{mg} / \mathrm{l})$; and TNF-a $(\geq 3.72 \mathrm{pg} / \mathrm{ml})$. In addition, a summary inflammation index was calculated as the number of inflammatory markers in the highest tertile (41).

Sociodemographics. Sociodemographics included age, sex, race (black, white), study site (Memphis, Pittsburgh), and marital status (never married, previously married, married). For the analyses with family income we also controlled for whether the household included anyone in addition to the participant and his or her spouse.

\section{Statistical analyses}

Analyses were performed using SPSS, version 11.5. Mean 3MS scores at baseline were compared across SES groups using analyses of variance. A chisquare test was conducted to assess the distribution of cognitive decline by SES. To determine if there were differences in the prevalence of biomedical variables between SES groups and to evaluate the association between biomedical factors and cognitive decline, chi-square tests were used. Logistic regression models were fitted to study the association between SES and cognitive decline. Two models were fitted, the first model adjusted for sociodemographics, other household members for income, and baseline 3MS score. The second model contained all variables of the first model as well as biomedical variables. To determine the role of biomedical factors a percentage reduction in odds ratio (OR) from model 1 was computed: (OR model 1 - OR model 2$) /\left(O R_{\text {model } 1}-1\right)^{*} 100 \%$.

\section{RESULTS}

Table 1 shows baseline 3MS scores and the distribution of cognitive decline by SES. People with low education, low income or few assets had statistically significantly lower baseline 3MS scores than people in the high SES groups $(p<0.001)$. The percentage of people with a cognitive decline over four years was also significantly higher in low SES groups in comparison to higher SES groups $(p=0.01$ to $p<0.001$ ).

Generally, the prevalence of disease and biological risk factors were higher in low SES groups, except for dyslipidemia for which the prevalence was significantly higher in high SES groups (Table 2). Glucose intolerance, hypercholesterolemia, hypertension, high BMI, low ankle arm index, high serum levels of IL-6 and CRP, and having three inflammatory markers in the highest tertile were significantly associated with low education, low income, and few assets. The prevalence of heart disease, 
cerebrovascular disease, low FEV, $/ F V C$, peripheral arteral disease, and high TMF-o levels were not significantly associated with any of the SES indicators.

The prevalence of cerebrovascular disease, glucose intolerance, low predicted FEV1, low ankle arm index, high serum levels of $1 L-6$, and having one or more inflammatory markers in the highest tertile were significantly associated with a four year decline in cognitive function (all $p<0.03$ ) (Table 3).

Table 1. Baseline 3MS score (mean and standard dewation (SD)) and percentage of four year cognitive decline according to socioeconomic status

\begin{tabular}{|c|c|c|c|c|c|}
\hline \multirow[b]{2}{*}{ Socioeconamic status } & \multirow{2}{*}{$\frac{n=2,574}{\%}$} & \multicolumn{2}{|c|}{ 3MS score at baseline } & \multicolumn{2}{|c|}{4 year deciline } \\
\hline & & Mean (SO) & p-value & $\%$ & p-trend \\
\hline \multicolumn{6}{|l|}{ Education } \\
\hline$>12$ years & 43.8 & $93.8(5.1)$ & \multirow[t]{3}{*}{$<0.001$} & 16.7 & \multirow[t]{3}{*}{$<0.001$} \\
\hline 12 years & 32.8 & $90.9(6.3)$ & & 23.4 & \\
\hline$<12$ years & 23.2 & $84.1(10.0)$ & & 37.0 & \\
\hline \multicolumn{6}{|l|}{ Income } \\
\hline$\geq \$ 50,000$ & 15.0 & $94.2(5.0)$ & \multirow[t]{5}{*}{$<0.001$} & 14.2 & \multirow[t]{5}{*}{0.01} \\
\hline$\$ 25,000-<\$ 50,000$ & 28.7 & $92.7(5.8)$ & & 210 & \\
\hline$\$ 10,000-<25,000$ & 33.4 & $89.1(8.2)$ & & 25.1 & \\
\hline$<\$ 10,000$ & 10.6 & $85.4(10.3)$ & & 35.9 & \\
\hline Missing & 12.3 & $90.1(8.3)$ & & 27.2 & \\
\hline \multicolumn{6}{|l|}{ Assets } \\
\hline $3-7$ & 45.5 & $93.2(5.7)$ & \multirow[t]{3}{*}{$<0.001$} & 17.1 & \multirow[t]{3}{*}{$<0.001$} \\
\hline $1-2$ & 38.5 & $88.7(8.4)$ & & 28.3 & \\
\hline None & 15.1 & $87.6(9.6)$ & & 31.4 & \\
\hline
\end{tabular}

Further analyses were done using only those biomedical variables that were significantly associated with both a four year cognitive decline and SES. Glucose intolerance, low predicted FEV1, low ankle arm index, high serum levels of IL-6, and having one or more inflammatory markers in the highest tertile were significantly associated with low SES and a decline in cognitive function. Odds ratios for cognitive decline in four years, adjusted for sociodemographics, other household members for income, and baseline 3MS score were significantly higher in low SES groups compared with high SES groups (Table 4, Model 1). Low education showed a particularly increased risk: odds ratios were 2.16 (95\% confidence interval (CI): 1.59 2.94) for less than 12 years of education, and 1.42 ( $95 \% \mathrm{Cl}: 1.10-1.83)$ for 12 years of education compared with those with more than 12 years of education. Statistically significant associations between low SES and cognitive decline were found for all three SES indicators. Additional adjustment for biomedical factors (Model 2) decreased the odds ratios by an average of $2 \%$ for education, $5 \%$ for income, and $8 \%$ for the number of assets. 


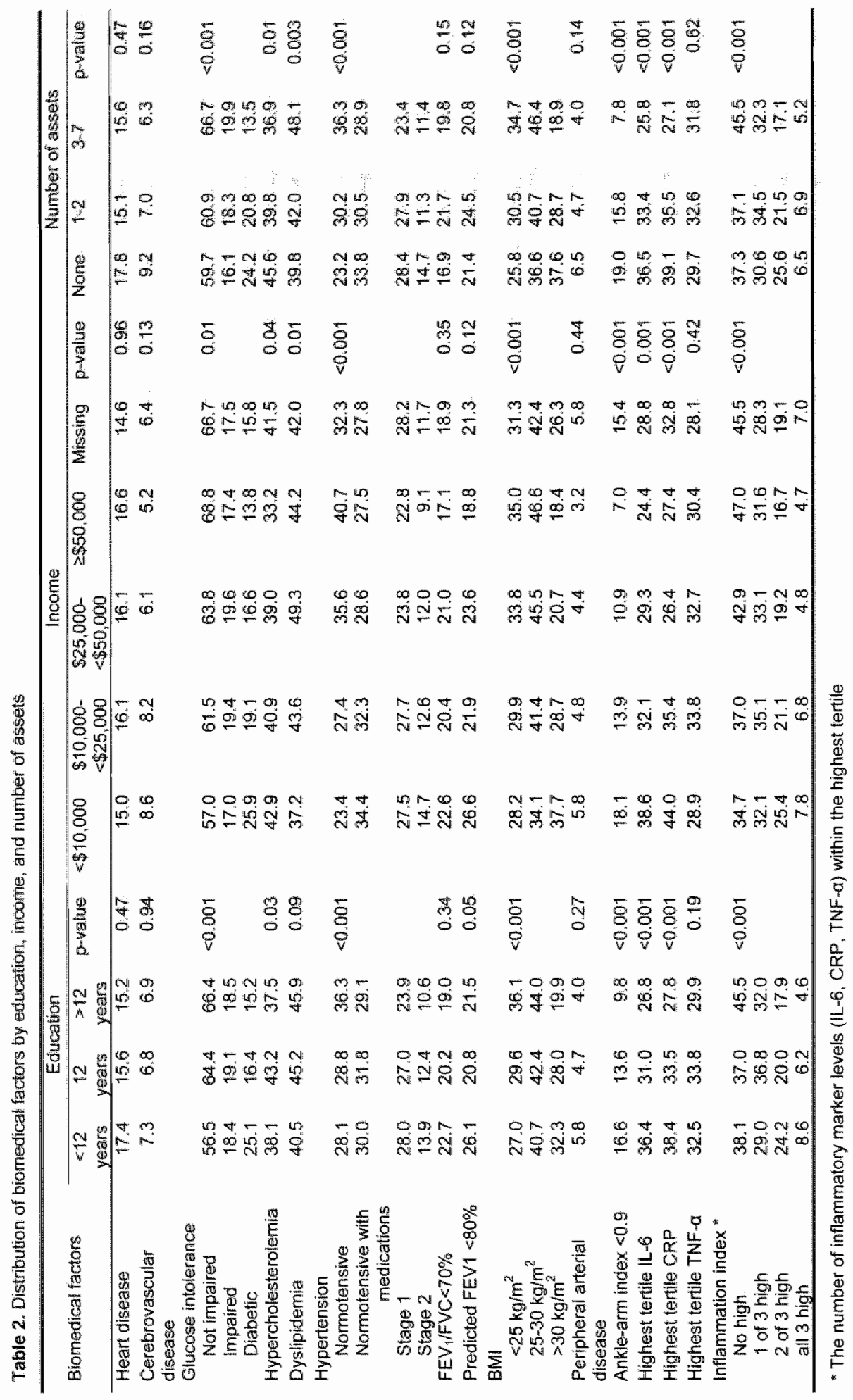


Table 3. Percentage of fotir year cognitive decline according to the presence of diseases and biological risik factors

\begin{tabular}{|c|c|c|}
\hline Blomedical factors & $\%$ & p-value \\
\hline \multicolumn{3}{|l|}{ Heart disease } \\
\hline No & 23.8 & 0.94 \\
\hline Yers & 23.6 & \\
\hline \multicolumn{3}{|l|}{ Cerebrovascullar disease } \\
\hline No & 23.1 & 0.03 \\
\hline Yes & 30.3 & \\
\hline \multicolumn{3}{|l|}{ Glucose intolerance } \\
\hline Not impaired & 22.7 & 0.02 \\
\hline Impaired fasting glucose & 23.0 & \\
\hline Diabetĭc & 29.8 & \\
\hline \multicolumn{3}{|l|}{ Hypercholesterolemia } \\
\hline No & 24.2 & 0.47 \\
\hline yes & 23.0 & \\
\hline \multicolumn{3}{|l|}{ Dyslipidemia } \\
\hline No & 23.8 & 0.96 \\
\hline Yes & 23.7 & \\
\hline \multicolumn{3}{|l|}{ Hypertension } \\
\hline Normotensive & 22.1 & 0.56 \\
\hline Normotensive with medications & 25.0 & \\
\hline Stage 1 & 23.6 & \\
\hline Stage 2 & 24.9 & \\
\hline \multicolumn{3}{|l|}{ FEVI/FVC< $<70 \%$} \\
\hline No & 23.0 & 0.42 \\
\hline Yes & 24.7 & \\
\hline \multicolumn{3}{|l|}{ Predicted FEV $1<80 \%$} \\
\hline No & 22.3 & 0.03 \\
\hline Yes & 27.0 & \\
\hline \multicolumn{3}{|l|}{ BMi } \\
\hline$<25 \mathrm{~kg} / \mathrm{m}^{2}$ & 23.8 & 0.97 \\
\hline $25-30 \mathrm{~kg} / \mathrm{m}^{2}$ & 23.5 & \\
\hline$>30 \mathrm{~kg} / \mathrm{m}^{2}$ & 23.9 & \\
\hline \multicolumn{3}{|l|}{ Peripheral arterial disease } \\
\hline No & 23.5 & 0.11 \\
\hline Yes & 29.9 & \\
\hline \multicolumn{3}{|l|}{ Ankle-arm index $<0.9$} \\
\hline No & 21.8 & $<0.001$ \\
\hline Yes: & 30.6 & \\
\hline \multicolumn{3}{|l|}{$\| \operatorname{Lin} 6$} \\
\hline Not in highest lertile & 21.9 & $<0.001$ \\
\hline In highest tertile & 27.6 & \\
\hline \multicolumn{3}{|l|}{ CRP } \\
\hline Not in highest tertile & 22.8 & 0.15 \\
\hline In highest tertite & 25.4 & \\
\hline \multicolumn{3}{|l|}{ TNF-a } \\
\hline Not in highest tertille & 22.6 & 0.14 \\
\hline In highest tertile & 25.4 & \\
\hline \multicolumn{3}{|l|}{ Intammation index } \\
\hline No high & 21.6 & 0.02 \\
\hline 1 of 3 high & 23.4 & \\
\hline 2 of 3 high & 25.7 & \\
\hline All 3 high & 31.8 & \\
\hline
\end{tabular}

* The number of inflammatory marker levels (IL-6. CRP', TNF- $\alpha$ ) within the highest tertile 
Results are shown for black and white, men and women, and all ages together because interaction terms between SES and race, SES and sex, and SES and age were not statistically significant (all p>0 05). Interactions between SES and biomedical factors were also not statistically significant. In additional analyses we also determined the association between SES and cognitive change as a continuous variable. Results were very similar and the role of biomedical factors also was the same.

Table 4. Odds ratios (OR) and 95\% confidence interval (Cl) for dedine in cognitwe function over four years by socioeconomic status.

\begin{tabular}{|c|c|c|c|c|c|}
\hline \multirow[b]{2}{*}{ Socioeconomic statuss } & \multicolumn{2}{|c|}{ Model $1^{*}$} & \multicolumn{3}{|c|}{ Model 2 I } \\
\hline & $\mathrm{OR}$ & $95 \% \mathrm{C}$ & OR & $95 \% \mathrm{Cl}$ & \% red 1 \\
\hline \multicolumn{6}{|l|}{ Education } \\
\hline$>12$ years & 1.00 & & 1.00 & & \\
\hline 12 years & 1.42 & $1.10-1.83$ & 1.41 & $1.09-1.83$ & 2 \\
\hline 12 years & 2.16 & $1.59 \cdot 2.94$ & 2.14 & $1.57-2.91$ & 2 \\
\hline \multicolumn{6}{|l|}{ Income } \\
\hline 2550,000 & 1.00 & & 1.00 & & \\
\hline$\$ 25,000-450,000$ & 1.72 & $1.17 \cdot 2.53$ & 1.70 & $1.15-2.50$ & 3 \\
\hline$\$ 10,000 \cdots \$ 25,000$ & 1.65 & $1.11 \cdot 2.47$ & 1.64 & $1.10-2.45$ & 2 \\
\hline$<10,000$ & 1.67 & $1.00-2.77$ & 1.61 & $0.97-2.68$ & 9 \\
\hline Missing & 2.05 & $1.31-3.21$ & 1.99 & $1.27-3.13$ & 6 \\
\hline \multicolumn{6}{|l|}{ Assets } \\
\hline $3-7$ & 1.00 & & 1.00 & & \\
\hline $1-2$ & 1.27 & $0.98 \cdot 1.64$ & 1.25 & $0.97 \times 1.62$ & 7 \\
\hline None & 1.51 & $1.07-2.12$ & 1.47 & $1.04-2.07$ & 8 \\
\hline
\end{tabular}

* Model 1: adjusted for age, sex, race, study sile, marital status household members for income, baseline cognitive function † Model 2: adjusted for age, sex, race, study site, marital status, other household members for income, baseline cogniltive function, and biamedical factors (glucose intolerance, predicted FEV1, ankle arm index, $\| L-6$, inflammation index)

\# Percentage reduction in odds ratio from model 1 compulted by

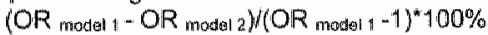

\section{DISCUSSION}

In an older population, people with low SES had an increased risk of a decline in cognitive function in comparison to people with high SES. Baseline presence of glucose intolerance, low predicted FEV1, low ankle arm index, high serum levels of IL-6, and having one or more inflammatory markers in the highest tertile were significantly associated with low SES and a decline in cognitive function. In spite of these associations, biomedical variables explained only very little of the SES differentials in cognitive decline.

The association between low SES and cognitive decline was found across all SES indicators. Strongest associations were found with education. Besides a SES indicator, education may also be a proxy for general intellectual abilities. Higher 
levels of education may also improve an individual's ability to perform on tests of cognitive function (test-taking skills) or can even mask mild cognitive deficits. Our study has a longitudinal design and therefore the potential for this effect is minimized because this differential ability in performing tests would be present at baseline as well as follow-up and we adjusted for baseline cognitive score (4).

Statistically significant associations with poor cognitive function were also found for low income and few assets; this shows the importance of SES as a predictor of cognitive decline. This corroborates a recent study by Mehta et al (12). In this study "literacy was used as a proxy for SES; this measure was also associated with cognitive test performance. Because of the longitudinal character of this study and because we controlled for cognitive score at baseline, it is clear that SES precedes the decline in cognitive function. To our knowledge the association between income, as SES indicator, and cognitive function has not been studied extensively before. A recent study by Lee et al. (9) showed no statistically significant associations between income and cognitive decline after adjusting for age, in 70-79 year old community-dwelling women. Another study by Evens et al. (6) showed weak associations with income and a decline in cognitive function in a community population of persons over the age of 65 years. Turrell et al. found a significant association between SES, including income, and levels of cognitive function in men aged between 58 and 64 years; this was, however, a cross-sectional study (42).

Biomedical factors explained only $5 \%$ of the association between SES and cognitive decline in this study, which does not support the hypothesis that high SES may simply represent better health that effects cognitive function (4). It is plausible that high SES is associated with greater exposure to more cognitively stimulating environments resulting in more extensive brain development or activation that has a positive effect on cognitive function $(4,43)$. The 'use it or lose it' theory suggests that neurological activation, such as participation in cognitively challenging activities, keeps persons mentally fit until old age (44). Childhood SES, early life conditions, and whether childhood disadvantages persist, are also important in cognitive development and abilities in adulthood $(42,45)$. A recent study, however, indicates that a higher SES during childhood or more exposure to a cognitively stimulating environment are not associated with a less rapid decline in cognitive function in old age (46). Genetic factors and environmental differences may also be important in cognitive development. A study by Hendrie et al. found lower incidence rates of dementia and Alzheimer disease in Yoruba residents of Nigeria in comparison with African-American residents (all aged 65 years or older), despite the higher SES in the African-American population. It was hypothesized that this was partly explained by different genetic or environmental factors (47). Future research should also take into 
account behavioral factors, such as physical activity, smoking, alcohol use, and diet $(48-51)$.

In this study, we had information on a wide variety of diseases and biological risk factors, allowing for a more comprehensive assessment than has been possible previously. Biomedical factors were measured at baseline and we did not have information on childhood health that could also have affected cognitive function. It must also be acknowledged that the approach followed is limited both by the comprehensiveness of the panel of biomedical factors considered, and the reliability with which these factors have been assessed. We cannot exclude the possibility that had the biomedical factors been measured more exactly, the diminution in the strength of the SES effect may have been larger.

Loss to follow-up for our outcome was a limitation in this study. Four hundred eighty-six people, of whom 282 people died, had no cognitive data in the fourth year of follow-up. Those who did not take the $3 \mathrm{MS}$ at follow-up had less education, lower income, and fewer assets compared with the study population $(p<0.001)$. Furthermore, they had significantly worse 3MS scores at baseline compared with those who remained in the study $(p<0.001)$. In a decedent proxy interview it was determined whether a person had memory problems prior to death. Of the 282 people who died during the follow-up, 60 persons had memory problems. The association between SES and cognitive decline may have therefore been underestimated. Furthermore, income data were missing for 316 participants, these persons had the highest risk of a cognitive decline and had more often a lower educational level compared with persons with full data. This may have led to an underestimation of the effect of income on a decline in cognitive function. Whether the relative contribution of the biomedical factors is equally underestimated remains unknowri.

In summary, low SES predicts a decline in cognitive function in older adults. Besides the evidence that higher prevalence of diseases and their risk factors are related to both low SES and poor cognitive function, in this study "biomedical factors could explain only $5 \%$ of the SES differentials in cognitive decline. We therefore could not support the hypotheses that biomedical factors are important in the mechanism underlying the association between SES and cognitive function.

\section{ACKNOWLEDGMENT}

This study was supported by National Institute on Aging contracts N01-AG-62101. N01-AG-6-2103, and N01-AG-6-2106. 


\section{REFERENCES}

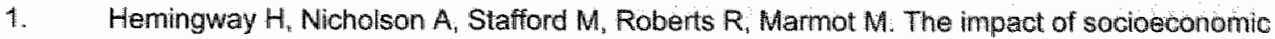
status on health functioning as assessed by the SF-36 questionnaire: the Whitehall II Study. Am J Public Health 1997:87: 1484-1490.

2. Martikainen $P$, Stansfeld $S_{*}$ Hemingway $H$, Marmat M. Determinants of socioeconomic differences in change in physical and mental functioning. Soc Sci Med 1999;49:499-507.

3. Seeman TE, Charpentier PA, Berkman LF, et al. Predicting changes in physical performance in a high-functioning elderly cohort: MacArthur studies of successful aging. $J$ Gerontol A Biol Sci Med Sci 1994;49:M97-108.

4. Albert MS. How does education affect cognitive function? Ann of Epidemiol 4995; 5:76-78.

5. Leibovici D, Ritchie K, Ledesert B, Touchon J. Does education level determine the course of cognitive decline? Age Ageing 1996;25:392-397.

6. Evans DA, Beckett LA, Albert MS, et all. Level of education and change in cognitive function in a community population of older persons. Ann Epidemiol 1993;3:71-77.

7. Farmer MIE, Kittner SJ, Rae DS, Bartko JJ, Regier DA. Education and change in cognitive function. The Epidemiologic Catchment Area Study. Ann Epidemiol 1995;5:1-7.

8. Colsher PL, Wallace RB. Longitudinal application of cognitive function measures in a defined population of community-dwelling elders. Ann Epidemiol 1991:1:215-230.

9. Lee S, Kawachi ll, Berkman LF, Grodstein F. Education, other socioeconomic indicators, and cognitive function. Am J Epidemiol. 2003:157:712-720.

10. Dartigues JF, Gagnon M, Mazaux JM, et al. Occupation during life and memory performance in nondemented French elderly community residents. Neurology 1992:42:1697-1701.

11. Jorm AF. Rodgers $B$, Henderson $A S_{n}$ et al. Occupation type as a predictor of cognitive decline and dementia in old age. Age Ageing 1998;27:477-483.

12. Mehta $K M$, Simonsick $E M$, Rooks $R$, et al. Black and white differences in cognitive function test scores: what explains the difference? J Am Geriatr Soc 2004;52:2120-2127.

13. Kaplan GA, Kell JE. Socioeconomic factors and cardiovascular disease: a review of the literature. Circulation 1993;88:1973-1998.

14. Hart CL, Hole DJ, Smith GD. The contribution of risk factors to stroke differentials, by socioeconomic position in adulthood: the Renfrew/Paisley Study. Am J Public Health 2000;90:1788-1791.

15. Marmot MG, Bosma H. Hemingway H, Brunner $\mathrm{E}$, Stansfeld S. Contribution of job control and other risk factors to social variations in coronary heart disease incidence. Lancet 1997:350:235-239

16. Brunner $E \downarrow$, Marmot MG, Nanchahal $K$, et al. Social inequality in coronary risk: central obesity and the metabolic syndrome. Evidence from the Whitehall II study. Diabetologia 1997:40:1341-1349.

17. Prescott $E$, Vestbo J. Socioeconomic status and chronic obstructive pulmonary disease. Thorax 1999;54:737-741.

18. Everson SA, Maty SC, Lynch JW, Kaplan GA. Epidemiologic evidence for the relation between socioeconomic status and depression, obesity, and diabetes. J Psychosom Res. $2002 ; 53: 891-895$. 
19. Gabbardes $B$, Costenza MC, Bernstein MS, Delhumeau C, Morabia A. Trends in risk factors for lifestyle-related diseases by socioeconomic position in Geneva, Switzerland, 1993-2000: health inequalities persist. Arn J Public Health 2003;93:1302-1309.

20. Elias MF, Elias PK, Sullivan LM, Wolf PA, D'Agostino RB. Lower cognitive function in the presence of obesity and hypertension: the Framingham heart study. Int I Obes Relat Metab Disord 2003;27:260-268.

21. Bennett SJ, Sauve MJ. Cognitive deficits in patients with heart falure: a review of the literature. J.Cardiovasc Nurs. 2003;18:219-242.

22. Grodstein F, Chen J, Wilson RS, Manson JE. Type 2 diabeles and cognitive function in community-dwelling elderly women. Diabetes Care 2001;24:1060-1065.

23. Teunissen CE, de Vente $\mathbb{J}$, won Bergmann $K$, et al. Serum cholesterol, precursors and metabolites and cognitive performance in an aging population. Neurobiol Aging 2003;24:147155

24. Jousilahti P, Salomaa V, Rasi V, Vahtera E, Palasuo T. Association of markers of systemic

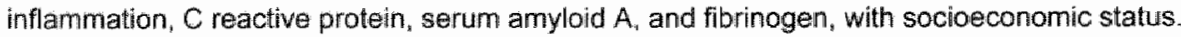
J Epidemiol Community Health 2003,57:730 733.

25. Steptoe A, Owen N, Kunz Ebrecht S, Mohamed Ali V. Inflammatory cytokines, socioeconomic status, and acute stress responsivity. Brain Behav Immun 2002;16:774-784.

26. Yaffe $K$, Lindquist $K_{*}$ Pennin $\times B W$, et all. Inflammatory markers and cognition in wellfunctioning African-American and white elders. Neurology 2003;61:76-80.

27. Weaver JD, Huang MH, Albert M. Harris T, Rowe JW, Seeman TE. Interleukin-6 and risk of cognitive decline: MacArthur studies of successful aging. Neurology 2002;59:371-378.

28. Rowe JW, Kahn RL. Successfull aging. Gerontologist 1997;37:433-440.

29. Rooks RIN, Simonsick EM, Miles $T$, et al. The association of race and socioeconomic status with cardiovascular disease indicators among older adults in the health, aging, and body composition study J Gerontol B Psychol Sci Sac Sci 2002;57:247-56.

30. Adler NE, Boyce T, Chesney MA, et al. Socioeconomic status and health. The challenge of the gradient. Am Psychol 1994:49:15-24.

31. Teng EL, Chui HC. The Modified Mini-Mlental State (3MS) examination. J Clin Psychiatry $1987: 48: 314-318$.

32. Lopez OL, Kuller LH, Fitzpatrick A, Ives D, Becker JT, Beauchamp N. Evaluation of dementia in the cardiovascular health cognition study. Neuroepidemiology 2003:22:1-12.

33. Yaffe $K$, Kanaya $A$, Lindquist $K$, et al. The metabolic syndrome, inflammation, and risk of cognitive decline. JAMA 2004:292:2237-42.

34. Holvoet P, Harris TB, Tracy RP, et al. Association of High Coronary Heart Disease Risk Status With Circulating Oxidized LDL in the Well-Functioning Elderly: Findings From the Health, Aging, and Bady Composition Study. Arterioscler Thromb Vasc Biol 2003;23:1444-1448.

35. Ford ES, Giles WH, Dietz WH. Prevalence of the metabolic syndrome among US adults: findings from the third National Health and Nutrition Examination Survey. JAMA 2002:287:356-359.

36. Chobanian AV, Bakris GL, Black HR et al. The Seventh Report of the Joint National Committee on Prevention, Detection. Evaluation, and Treatment of High Blood Pressure: the JNC 7 report. JAMA 2003;289:2560-2572.

37. Hankinson $\mathrm{JL}$, Odencrantz JR, Fedan KB. Spirometric reference values from a sample of the general U.S. population. Am J Respir Crit Care Med 1999;159:179-187. 
38. Pauwels RA, Buist AS, Calverley PM, Jenkins CR, Hurd SS. Global strategy for the diagnosis, management, and prevention of chronic obstructive pumonary disease. NHLBIWHO Global Initiative for Chronic Obstructive Lumg Disease (GOLD) Workshop summary. Am J Respir Crit Care Med 2001;163:1256-1276.

39. Newman AB, Shemanski L, Manolio TA, el al. Ankle-arm index as a predictor of cardiovascular disease and mortality in the Cardiovascular Health Study. The Cardiovascular Health Study Group. Arterioscler Thromb Vasc Biol 1999;19:538-545.

40. Penninx BW, Kritchevsky SB, Newman $A B$, et al. Inflammatory markers and incident mobility limitation in the elderly. J Am Geriatr Soc 2004:52:1105-13.

41. Harris TB, Ferrucci L, Tracy RP, et al. Associations of elevated interleukin-6 and C-reactive protein levels with mortality in the elderly. Am J Med 1999;106:506-12.

42. Turrell $G$, Lynch JW, Kaplan GA, et all. Socioeconomic position across the lifecourse and cognitive function in late middle age. J Gerontol B Psychol Sci Soc Sci 2002;57:S43-S51.

43. Bosma $H$, van Boxtel MP. Ponds RW, et al. Engaged lifestyle and cognitive function in middle and old-aged, non-demented persons: a reciprocal association? Z. Gerontol Geriatr. 2002;35:575-581.

44. Swaab DF. Brain aging and Alzheimer"s disease, "wear and lear" versus "use it or lose it". Neurobiol Aging 1991:12:317-324.

45. Kaplan GA, Turrell G, Lynch JW, Everson SA, Helkala EL, Salonen JT. Childhood socioeconomic position and cognitive function in adulthood. Int J Epidemiol 2001;30:256-263.

46. Everson-Rose SA, Mendes de Leon CF, Bienias JL, Wilson RS, Evans DA. Early life conditions and cognitive functioning in later life. Am J Epidemiol 2003;158:1083-1089.

47. Hendrie HC, Ogunniyi A, Hall KS, et al, lncidence of dementia and Alzheimer disease in 2 communities: Yoruba residing in Ibadan. Nigeria, and African Americans residing in Indianapolis, Indiana. JAMA 2001;285:739-47.

48. Weuve J, Kang JH, Manson JE, Breteler MM, Ware JH, Grodstein F. Physical activity, including walking, and cognitive function in older women. JAMA 2004,292:1454-61.

49. Engelhart MJ, Geerlings MI, Ruitenberg $A$, at al. Dietary intake of antioxidants and risk of Alzheimer disease. JAMA 2002;287:3223-9.

50. Kalmijn S. Fatty acid intake and the risk of dementia and cognitive decline: a review of clinical and epidemiological studies. J Nutr Health Aging 2000;4:202-7.

51. Kalmijn $S_{3}$, van Boxtei MP, Verschuren MW, Jolles J, Launer LJ. Cigarette smoking and alcohol consumption in relation to cognitive performance in middle age. Am J Epidemiol 2002;156:936-44. 
8

\section{Explaining socioeconomic differences in incident depression in older adults}

\section{Submitted as}

Koster A, Bosma $H_{1}$ Kempen Gl, Penninx BW, Beekman AT, Deeg DJ, van Eijk JT Explaining socioeconomic differences in incident depression ün older adults. 


\section{ABSTRACT}

Objective. The objective of this study was to examine the association between socioeconomic status and the onset of depression in older adults and to determine the relative contribution of psychosocial factors, physical health status, and behavioral factors in explaining this link.

Methods. Data were from 2,593 men and women, aged 55-85 years, participating in the Longitudinal Aging Study Amsterdam (LASA). Two indicators of socioeconomic status were used: education and income. The onset of depression was measured over nine years of follow-up with the Center for Epidemiologic Studies on Depression (CES-D) scale. Cox proportional hazard regression models were fitted to study the association of SES on time to onset of depression.

Results. Adjusted hazard ratios of incident depression were significantly higher in those with low education (hazard ratio (HR):1.52, 95\% confidence interval ( $\mathrm{Cl}$ ): 1.17 1.99) and low income (HR:1.48, $95 \%$ Cl: 1.13-1.94). Psychosocial factors, explained on average $16 \%$ socioeconomic differences in incident depression. Physical health status reduced the effect of socioeconomic status on depression incidence with on average $7 \%$, and behavioral factors with less than $5 \%$. A small network size, low selfefficacy, and poor physical function had the largest individual contribution in reducing the effect of socioeconomic status on incident depression in this study.

Conclusions. In older adults, low socioeconomic status predicted the incidence of depression. Part of this association was explained by psychosocial factors and physical health status. The SES differences in incident depression remain, however, to a large extent unexplained. 


\section{INTRODUCTION}

Generally, low socioeconomic status (SES) is related to higher rates of morbidity and mortality and has been shown to be an important predictor of poor functioning $(1,2)$. SES differences have also been found in mental disorders, including depression (2-5). Low SES is related to a higher prevalence and incidence of depression (3-5). Depression is a common disorder in late life with negative consequences for well-being and daily functioning (6-8) and is also associated with higher mortality rates (9). In order to reduce depression in older persons and the SES differences therein, it is important to understand the underlying mechanisms that may mediate the association between SES and depression. This may help to provide tools for prevention and intervention strategies. Psychosocial factors as well as physical health status and behavioral factors may be important in explaining SES inequalities in depressive symptoms $(4,10,11)$.

People with low SES generally have fewer psychosocial resources than people with high SES. Low SES is related to low control beliefs, negative coping styles, poor social support, and more stressfull life events (12-14). The association between psychosocial factors and depression has been studied extensively. Several studies have found a favorable effect of social support on mental health (15-17). Stressful life events have a negative impact on depressive symptoms $(10,18)$.

Physical health status may also be important in the explanation of SES differences in depressive symptoms. Low SES is a risk factor for many diseases, including cardiovascular disease, stroke, and diabetes $(5,19-22)$. The prevalence of chronic diseases is associated with increased depressive symptoms (23-25). Physical limitations should also be taken into account in the explanation of SES differences in depressive symptoms. LOw SES is a strong predictor of poor physical function in older adults $(26,27)$, which is in turn a predictor of depression $(16,28)$.

Finally, behavioral factors may play a role in the explanation of SES inequalities in depressive symptoms. Low SES is related to many adverse behavioral factors, such as smoking, excessive alcohol consumption and decreasing physical activity $(29,30)$. There is also some evidence that adverse behavioral factors are associated with depressive symptoms $(11,31,32)$.

The aim of the present study is to examine whether low SES predicts the onset of depression over nine years of follow-up in a representative sample of Dutch older adults, who participated in the Longitudinal Aging Study Amsterdam. The contribution of a number of potentially explanatory factors to explain SES differences in depression has been studied before. In this study, however, several explanatory factors including psychosocial factors, physical health status, and behavioral factors, 
Chapter 8

will be simultaneously examined in the explanation of SES inequalities in depression incliderice.

\section{METHODS}

\section{Study population}

Data for this study were collected in the Longitudinal Aging Study Amsterdam (LASA), an ongoing cohort study on predictors and consequences of changes in wellbeing and autonomy in older persons in the Netherlands (33). A random sample of persons, 55-85 years of age, was drawn from the population registers of 11 municipalities. This sample was originally recruited for the NESTOR study on Living Arrangements and Social Networks of alder adults (LSN) in 1992 (34). The response rate was $62.3 \%(n=3,805)$. About eleven months after the LSN interview, 3,107 $(81.7 \%)$ subjects were enrolled in the main baseline interview of LASA conducted between September 1992 and September 1993. Since then three follow-up measurements took place, the first in 1995/1996, the second in 1998/1999, and the third in 2001/2002. At the first follow-up in 1995/1996, 2,545 participants took part in the study; $416(13.4 \%)$ had died and $146(4.7 \%)$ were lost to follow-up for other reasons (refusal, too frail, could not be contacted). In 1998/1999, at the second follow-up measurement, 2,076 persons participated in the study; $343(13.5 \%)$ had died and $126(5.0 \%)$ were lost to follow-up for other reasons. At the third follow-up measurement, 1,691 persons took part in the study; $289(13.9 \%)$ had died and 96 $(4.6 \%)$ were lost to follow-up for other reasons. In order to study the onset of depression, respondents with depression at baseline $(n=448)$ were excluded (CES-D score $\geq 16$ ). Furthermore, 66 persons were excluded because of incomplete data, resulting in 2,593 participants. For 80 participants, income data were missing resulting in 2,513 participants for the analyses with income.

\section{Measures}

Socioeconomic status. Two indicators of SES, measured at baseline, were used: level of education and household income. Categories for level of education were: high (university, college, higher vocational, general secondary, and intermediate vocational education); medium (general intermediate, and lower vocational education); and low (elementary education or less). For monthly net household income three categories (tertiles), in euros, were distinguished: high (greater or equal to 1,035); medium (between 625 and less than 1,035); low (less 
than 625) (35). For participants with a partner living in the household, household income was multiplied by 0.7 to make them comparable to the incomes in a oneperson household. Income data at baseline were missing for 370 respondents. For 290 respondents, imputations were made using income data collected at the LSN measurement in 1992 or follow-up measurements (35). For 80 persons income data at all measurements were missing. They were excluded from the analyses with income.

Depression. Depressive symptoms were assessed at each measurement cycle with the Center for Epidemiologic Studies on Depression (CES-D) scale, a 20 item self-report scale designed to measure depressive symptoms during the previous week (36). Scores ranged from 0 to 60 , with higher scores indicating more depressive symptoms. A cut-off score of 16 was used as a criterion for clinically significant depressive symptoms, here called depression (37). In addition to this cutoff score, subjects were classified with incident depression when they also had a relevant increase in depressive symptoms which was determined as an increase of $0.5^{*}$ standard deviation ( $=4$ points) in CES-D score between baseline and follow-up measurement $(38,39)$. First incident depression was defined as an increase of 4 points or more in CES-D score and thereby crossing the cut-off score of 16.

Mediators. Psychosocial factors, measured at baseline, included partner status (presence of a partner, yes or no), network size, instrumental and emotional social support, mastery, and self-efficacy. The size of the personal network was determined by asking the respondent to identify the persons, other than their partner, whom they had frequent contact with and who were important to them (range is 0-75) (40). For a maximum of nine network members with whom contact was most frequent, information was collected regarding the intensity of received instrumental and emotional support (range is 0 (no social support)-36). Mastery was measured by an abbreviated version (5-item) of the Pearlin Mastery Scale (range is 5 (lowest)-25) (41). Self-efficacy was measured with a 12-item version of the General Self-efficacy Scale of Sherer et al. (range is 12 (lowest)-60) $(42,43$ ). Missing values for network size ( $n=126)$, instrumental support $(n=133)$, emotional support $(n=135)$, mastery $(n=74)$, and self-efficacy $(n=115)$ were replaced by group means in order to maintain an optimal sample size for the analyses.

Physical health status covered diseases and physical functioning. Baseline presence of diseases was determined by asking the participants whether they had any of the following chronic diseases: cardiac disease, peripheral arterial disease, stroke, diabetes mellitus, lung disease, cancer, and arthritis (44). Physical functioning was measured by the degree to which the respondent had difficulty performing six daily activities: walking up and down a 15-step staircase without resting, getting 
(un)dressed, getting up from and sitting down in a chair, cutting own toenails, walking 5 minutes outdoors without resting, and using own or public transport (45). The sum score of the six items ranged from 0 to 24 , with lower scores indicating more limitation in physical function.

Behavioral factors included smoking, alcohol use, physical activity, and body mass index (BMI). Four categories of smoking were created: current, former, never and missing. Categories of alcohol use were: not drinking, moderate drinking, excessive drinking (at least three glasses daily), and missing. Physical activity was defined as the total number of physical activities performed in the past two weeks including walking, cycling, gardening, performing light and heavy household tasks, and two sports activities. Four categories were created: $1-3,4-5,6-7$, and missing. BMI (weight in kilograms divided by height in meters squared) was categorized as lower than $25 \mathrm{~kg} / \mathrm{m}^{2}$, between 25 and $30 \mathrm{~kg} / \mathrm{m}^{2}$, greater of equal to $30 \mathrm{~kg} / \mathrm{m}^{2}$, and missing. Data on behavioral factors were missing because these data were collected in a medical interview in which $86 \%$ of the study sample took part.

Sociodemographics that were included as covariates were age and sex.

\section{Statistical analyses}

Differences in baseline characteristics between SES groups were determined using chi-square tests for categorical variables and analyses of variance for continuous variables. To determine if there were differences in time to incidence of depression between SES groups, unadjusted Cox proportional hazard regression models were fitted. If a person developed depression, person time was set at the midpoint between the previous interview and the interview during which the person reported a depression. Persons surviving with no evidence of incident depression were censored at the last follow-up measurement. Those who died with no evidence of incident depression were censored at time of death, and those lost to follow-up were censored at their last follow-up measurement.

To evaluate the association of psychosocial factors, physical health status, and behavioral factors with time to incident depression, Cox proportional hazard regression models were fitted, adjusting for sociodemographics. To study the association of SES with time to incident depression and the role of the mediators therein, five models were fitted. The first model adjusted for age and sex. In model 2 , 3 , and 4, psychosocial factors, physical health status, and behavioral factors, were separately introduced into the first model. The fifth model included all variables of the previous models. A percentage reduction in hazard ratio from model 1 was computed: (HR model $1-\mathrm{HR}$ model $x) /(\mathrm{HR} \text { model } 1-1)^{*} 100 \%$. The proportional hazards assumption was investigated by testing the constancy of the log hazard ratio over 
time by means of log-minus-log survival plots and interactions with time (log transformed). According to the tests, the proportional hazard assumption was not violated. All analyses were performed using SPSS version 12.0 .

\section{RESULTS}

Table 1 shows baseline characteristics of the study population by education and income. There were significantly more women in low SES groups and respondents were older in low SES groups. People with low education or income had significantly higher baseline CES-D scores, indicating more depressive symptoms, compared with low SES groups $(p<0.01)$. People with a low education or income level less often had a partner $(p<0.01)$. Low SES was also associated with a smaller network, less emotional support, lower feelings of mastery, and lower self-efficacy compared with high SES people $(p<0.01)$. Generally, the prevalence of diseases was higher in low SES groups. Only the prevalence of diabetes mellitus and arthritis was significantly higher in both the lowest education and income group $(p<0.01)$. People with low education or income had significantly lower baseline physical function scores, indicating worse function, compared with high SES groups $(p<0.01)$. In low SES groups, there were more non-smokers and less people drank alcohol $(p<0.01)$. Furthermore, people in low SES groups were less physically active and had a higher BMI than those in high SES groups.

Results are shown for men and women, and all ages together because interaction terms between SES and sex, and SES and age were not statistically significant. The incident rate per 1,000 person years of depression according to SES is shown in figure 1. People with low SES had a two times higher incidence rate of depression than those with high SES ( $p<0.01)$.

Table 2 shows the association between psychosocial factors, physical health status, behavioral factors and incident depression. Of the psychosocial factors, a small network (HR: $1.51,95 \% \mathrm{Cl}: 1.19-1.92$ ), low mastery (HR: $2.01,95 \% \mathrm{Cl}: 1.59$ 2.53) and low self-efficacy (HR: $1.64,95 \% \mathrm{Cl}: 1.30-2.07$ ) were significant predictors of incident depression. The prevalence of peripheral arteriosclerosis (hazard ratio (HR): $1.50,95 \%$ confidence interval (Cl): 1.09-2.05), lung disease (HR: $1.44,95 \% \mathrm{Cl}$ : 1.06-1.94), cancer (HR: $1.72,95 \% \mathrm{Cl}: 1.28-2.31$ ), and arthritis (HR: $1.48,95 \% \mathrm{Cl}$ : 1.21-1.81) were also significant predictors of incident depression. Furthermore, poor physical function was a strong predictor of incident depression with a hazard ratio of $1.84(95 \% \mathrm{Cll}: 1.39-2.43)$ in the group with the lowest physical function scores. Of the behavioral factors, only low physical activity was significantly associated with the 
Table 1. Baseline waracterstios of the study population by SES

\begin{tabular}{|c|c|c|c|c|c|c|c|c|}
\hline \multirow[b]{2}{*}{ Baseline characteristics } & \multicolumn{4}{|c|}{ Education $5: 2,5913$} & \multicolumn{4}{|c|}{ Income $n=2,513$} \\
\hline & $\begin{array}{c}\text { High } \\
n=706\end{array}$ & $\begin{array}{c}\text { Medium } \\
n=803\end{array}$ & $\begin{array}{c}\text { Low } \\
n=1084\end{array}$ & $p$ & $\begin{array}{l}\text { High } \\
n=845\end{array}$ & $\begin{array}{c}\text { Nedium } \\
n=850\end{array}$ & $\begin{array}{c}\text { Low } \\
n=848\end{array}$ & $\mathrm{p}$ \\
\hline Women, $\%$ & 33.7 & 46.8 & 618 & $<0.01$ & 38.9 & 44.8 & 64.2 & $<0.01$ \\
\hline Agje, mean (SD) & $\begin{array}{l}68.8 \\
(8.7)\end{array}$ & $\begin{array}{l}69.1 \\
(8.5)\end{array}$ & $\begin{array}{l}722 \\
(8: 6)\end{array}$ & $<0.01$ & $\begin{array}{l}66.8 \\
(18.6)\end{array}$ & $\begin{array}{l}69.6 \\
(8.3)\end{array}$ & $\begin{array}{l}74.1 \\
(7.5)\end{array}$ & $<0.01$ \\
\hline \multicolumn{9}{|l|}{ Depressive symptoms } \\
\hline $\begin{array}{l}\text { CES-D }(0-60) \text {, mean } \\
\text { (SD) }\end{array}$ & $\begin{array}{l}4.8 \\
(4.0)\end{array}$ & $\begin{array}{c}5.2 \\
(4.1)\end{array}$ & $\begin{array}{l}5.8 \\
(4.2)\end{array}$ & $<0.01$ & $\begin{array}{l}4.9 \\
(4.1)\end{array}$ & $\begin{array}{c}5.4 \\
(4.2)\end{array}$ & $\begin{array}{c}5.6 \\
(4.2)\end{array}$ & $<0,01$ \\
\hline \multicolumn{9}{|l|}{ Psychosocial faciors } \\
\hline With partner: & 76.3 & 77.8 & 61.4 & $<0.01$ & 79.2 & 79.8 & 54.3 & $<0,01$ \\
\hline $\begin{array}{l}\text { Wetwork size }(0-75) \\
\text { mean }(S D)\end{array}$ & $\begin{array}{l}15.6 \\
(9.0)\end{array}$ & $\begin{array}{l}14.4 \\
(8.1)\end{array}$ & $\begin{array}{l}13.2 \\
(7.5)\end{array}$ & $<0.01$ & $\begin{array}{l}16.0 \\
(9.0)\end{array}$ & $\begin{array}{l}14.2 \\
(7.8)\end{array}$ & $\begin{array}{l}12.6 \\
(7.6)\end{array}$ & $<0.01$ \\
\hline $\begin{array}{l}\text { Instrumental support } \\
(0-36) \text {, mean }(\mathrm{SD})\end{array}$ & $\begin{array}{r}14.1 \\
(B .5)\end{array}$ & $\begin{array}{r}13.9 \\
(6.4)\end{array}$ & $\begin{array}{l}14.3 \\
(6 i 7)\end{array}$ & 0.43 & $\begin{array}{r}14.1 \\
(6.2)\end{array}$ & $\begin{array}{l}14.1 \\
(6.5)\end{array}$ & $\begin{array}{l}14.3 \\
(7.1)\end{array}$ & 0.83 \\
\hline $\begin{array}{l}\text { Emotional support } \\
(0-36) \text { mean }(\mathrm{SD})\end{array}$ & $\begin{array}{l}22.9 \\
(7.7)\end{array}$ & $\begin{array}{l}21.9 \\
(7.7)\end{array}$ & $\begin{array}{l}20.7 \\
(8.0)\end{array}$ & $<0.04$ & $\begin{array}{l}22.8 \\
(7.5)\end{array}$ & $\begin{array}{l}21.9 \\
(7.9)\end{array}$ & $\begin{array}{l}20.6 \\
(8.3)\end{array}$ & $<0.01$ \\
\hline $\begin{array}{l}\text { Mastery }(5-25) \text {, mean } \\
\text { (SD) }\end{array}$ & $\begin{array}{r}17.9 \\
(3.0)\end{array}$ & $\begin{array}{l}17.8 \\
(2.9)\end{array}$ & $\begin{array}{l}17.4 \\
(3.1)\end{array}$ & $<0.01$ & $\begin{array}{l}18.0 \\
(3.0)\end{array}$ & $\begin{array}{r}17.8 \\
(3.0)\end{array}$ & $\begin{array}{l}17.4 \\
(2.9)\end{array}$ & $<0.01$ \\
\hline $\begin{array}{l}\text { Self-elficudy }(12-60) \\
\text { mean }(S D)\end{array}$ & $\begin{array}{l}43.8 \\
(4.9)\end{array}$ & $\begin{array}{l}42.5 \\
(4.7)\end{array}$ & $\begin{array}{l}41.2 \\
(5.0)\end{array}$ & $<0.01$ & $\begin{array}{l}43.4 \\
(4.9)\end{array}$ & $\begin{array}{l}42.4 \\
(5.0)\end{array}$ & $\begin{array}{l}41.2 \\
(5.0)\end{array}$ & $<0.01$ \\
\hline \multicolumn{9}{|l|}{ Physical Health status } \\
\hline $\begin{array}{l}\text { Cardiac disease, \% } \\
\text { Peripheral }\end{array}$ & 18.0 & 18.3 & 19.3 & 0.75 & 16.8 & 18.2 & 21.8 & 0.03 \\
\hline atherosclerosig, \% & 7.4 & 7.9 & 10.2 & 0.07 & 5.3 & 10.0 & 11.1 & $<0.01$ \\
\hline Stroke, \% & 3.3 & 5.9 & 5.5 & 0.08 & 2.5 & 3.9 & 7.7 & $<0.01$ \\
\hline Diabetes mellit Ls: & 5.0 & 5.7 & $\# 0.0$ & $<0.01$ & 4.4 & 7.3 & $9: 7$ & $<0.01$ \\
\hline Lung disease, $\%$ & 9.5 & 10.2 & 10.8 & 0.66 & 8.6 & 11.0 & 11.3 & 0.15 \\
\hline Cancer, $\%$ & 6.7 & 8,4 & 9.8 & 0.07 & 7.0 & 8.5 & 10.6 & 0.03 \\
\hline Arthritis, $\%$ & 27.6 & 28.9 & 34.4 & $<0.0$ & 26.7 & 30.5 & 36.4 & $<0.01$ \\
\hline $\begin{array}{l}\text { Physical function } \\
(0-24) \text { mean (SD) }\end{array}$ & $\begin{array}{l}22.5 \\
(3.4)\end{array}$ & $\begin{array}{l}22.1 \\
(4.0)\end{array}$ & $\begin{array}{l}20.7 \\
(5.0)\end{array}$ & $<0.01$ & $\begin{array}{l}22.7 \\
(3.11)\end{array}$ & $\begin{array}{l}22.2 \\
(3.7)\end{array}$ & $\begin{array}{l}20.1 \\
(5.4)\end{array}$ & $<0.01$ \\
\hline \multicolumn{9}{|l|}{$\begin{array}{l}\text { Behavioral factors } \\
\text { Smoking, } \%\end{array}$} \\
\hline Non-smoker & 18.4 & 26.2 & 32.3 & $<0.01$ & 19.4 & 23.4 & 37.3 & $<0.01$ \\
\hline Former & 46.9 & 43.3 & 31.9 & & 46.9 & 42.4 & 30.7 & \\
\hline Smoker & 24.4 & 20.2 & 19.9 & & 24.3 & 22.5 & 17.4 & \\
\hline Missing & 10.3 & 10.3 & 15.9 & & 9.5 & 11.8 & 14.9 & \\
\hline \multicolumn{9}{|l|}{ Drinking. $\%$} \\
\hline Non-drinker & 11.2 & 17.3 & 23.2 & $<0.01$ & $11 \times 4$ & 17.1 & 25.4 & $<0.01$ \\
\hline Moderate & 72.4 & 67.2 & 58.4 & & 72.3 & 66.4 & 58.2 & \\
\hline Excessive & 5.8 & 4.6 & 2.1 & & 6.3 & 4.5 & 1.1 & \\
\hline Missing & 10.6 & 10.8 & 16.3 & & 40.4 & 12.1 & 15.3 & \\
\hline \multicolumn{9}{|l|}{ Physical activity, \% } \\
\hline $6-7$ & 21.5 & 19.7 & 14.2 & $<0.01$ & 23,0 & 17.4 & 14.3 & $<0.01$ \\
\hline $4-6$ & 42.8 & 44.8 & 41.1 & & 45,1 & 45.6 & 39.6 & \\
\hline $0-3$ & 32.4 & 28.9 & 36.2 & & $28: 9$ & 31.4 & 39.7 & \\
\hline Missing & 3.3 & 6.6 & 8.6 & & 3.1 & 5.5 & 6.4 & \\
\hline \multicolumn{9}{|l|}{$\mathrm{BM}, \%$} \\
\hline$<25$ & 38.2 & 30.6 & 22.5 & $<0.01$ & 35.9 & 28.9 & 23.5 & $<0.01$ \\
\hline $25-<30$ & 39.1 & 43.5 & 38.7 & & 41.8 & 41.5 & 39.1 & \\
\hline 230 & 9.5 & 14.4 & 19.8 & & 10.8 & 15.3 & 20.0 & \\
\hline Missing & 13.2 & 11.5 & 190 & & 11.6 & 14.2 & 17.4 & \\
\hline
\end{tabular}


Table 2. Hazard ratios ( $H R$ ) and $95 \%$ confidenoe intenwa (C) for incident depression by physical health stiatus, behavioral factors, and psychosocial factors *

\begin{tabular}{|c|c|c|}
\hline & \multicolumn{2}{|c|}{ Incident depression } \\
\hline & $\mathrm{HR}$ & $95 \% \mathrm{Cl}$ \\
\hline \multicolumn{3}{|l|}{ Psychosocial Factors } \\
\hline Without partner & 1.23 & $0.97-1.54$ \\
\hline \multicolumn{3}{|l|}{ Network size } \\
\hline Highest tertile & 1.00 & \\
\hline Middle tertile & $\# .09$ & $0.85-1.40$ \\
\hline Lowest tertile & 4.51 & $1.19-1.92$ \\
\hline \multicolumn{3}{|l|}{ Instrumentall support } \\
\hline Highest tertile & 1.00 & \\
\hline Middle tertile & 0.98 & $0.77-1.25$ \\
\hline Lowest tertile & 0.96 & $0,76-1.20$ \\
\hline \multicolumn{3}{|l|}{ Emolional support } \\
\hline Highest tertilie & $\sharp .00$ & \\
\hline Middle tertile & 1.03 & $0.81-1.30$ \\
\hline Lowest tertile & 1.11 & $0.87-1.41$ \\
\hline \multicolumn{3}{|l|}{ Mastery } \\
\hline Highest tertile & 1.00 & \\
\hline Middle tertile & 1.22 & $0.94-1.59$ \\
\hline Lowest tertile & 2.01 & $1.59-2.53$ \\
\hline \multicolumn{3}{|l|}{ Self-efficacy } \\
\hline Highest tertile & 1.00 & \\
\hline Middle tertile & 1.24 & $0.95-1.61$ \\
\hline Lowest tertile & 1.64 & $1.30-2.07$ \\
\hline \multicolumn{3}{|l|}{ Physical Health Status } \\
\hline Cardiac disease & 1.22 & $0.95-1.56$ \\
\hline Peripheral atherosclerosis & 1.50 & $1.09-2.05$ \\
\hline Stroke & 1.22 & $0.75-1.99$ \\
\hline Difabetes mellatus & 0.89 & $0.57-1.38$ \\
\hline Lung disease & 1.44 & $1.06-1.94$ \\
\hline Cancer & 1.72 & $1.28-2.31$ \\
\hline Arthritis & 1.48 & $1.21-1.81$ \\
\hline \multicolumn{3}{|l|}{ Physical turiction } \\
\hline Highest tertile & 1.00 & \\
\hline Middle tertille & 1.80 & $1.40-2.32$ \\
\hline Lowest tertille & 1.84 & $1.39-2.43$ \\
\hline \multicolumn{3}{|l|}{ Behavioral Factors } \\
\hline \multicolumn{3}{|l|}{ Smoking } \\
\hline Non-smoker & 1.00 & \\
\hline Former & 0.93 & $0.72-1.20$ \\
\hline Smoker & 1.27 & $0.95-1.69$ \\
\hline Missing & 0.64 & 0.43 .0 .95 \\
\hline \multicolumn{3}{|l|}{ Drinking } \\
\hline Non-drinker & 1.00 & \\
\hline Moderate & 0.95 & 0.741 .21 \\
\hline Excessive & 1.15 & $0.65-2.02$ \\
\hline Missing & 0.62 & $0.41-0.93$ \\
\hline \multicolumn{3}{|l|}{ Physical activity" } \\
\hline 67 & 1.00 & \\
\hline $4-5$ & 1.16 & $0.87-1.55$ \\
\hline $0-3$ & 1.37 & $1.01-1.86$ \\
\hline Missing & 1.20 & $0.73-1.95$ \\
\hline \multicolumn{3}{|l|}{ BMI } \\
\hline$<25$ & 1.00 & \\
\hline $25-<30$ & 1.13 & $0.89-11.44$ \\
\hline 230 & 1.10 & $0.87-1.56$ \\
\hline Missing & 0.77 & $0.53-1.11$ \\
\hline
\end{tabular}

* Adjusted for age and sex 
incidence of depression. Subjects with missing data on smoking and drinking, had a significantly lower risk for incident depression compared with non-smokers and nondrinkers.

Hazard ratios of incident depression, adjusted for age and sex, were significantly higher in low SES groups compared with the highest SES group (Table 3: Model 1). Hazard ratios were 1.52 (95\% confidence interval (Cl): 1.17-1.99) in the lowest education group and $1.48(95 \% \mathrm{Cl}: 1.13-1.94)$ in the lowest income group. Additional adjustment for psychosocial factors in model 2 reduced the hazard ratios by $7 \%$ in the medium education group and $19 \%$ in the lowest education group (13\% on average) and by $14 \%$ in the medium income group and $25 \%$ in the lowest income group (20\% on average). Network size and self-efficacy had the largest individual contribution in reducing the hazard ratios for SES (not tabulated). Physical health status, mainly due to physical function, decreased the hazard ratios by an average of $6 \%$ for education and $8 \%$ for income. The reduction in hazard ratios due to behavioral factors was on average less than $5 \%$ (Model 4). In the full model (Model 5) that included all variables of the previous models, low education and low income still significantly predicted the incidence of depression.

Incidence rate per 1,000 person years of depression according to education

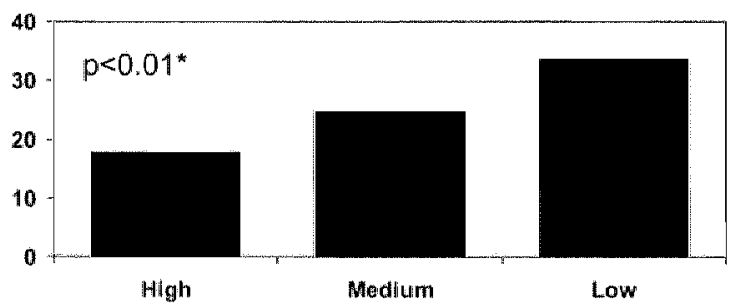

Incidence rate per 1,000 person years of depression according to income

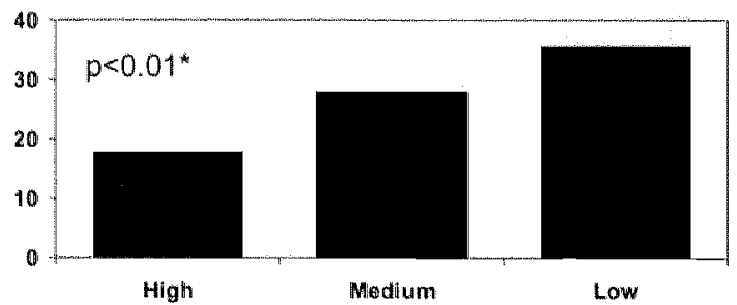

Figure 1. Incidence rate per 1,000 person years of depression acoording to socioeconomic status

"p-value based om unadjusted survival analyses 


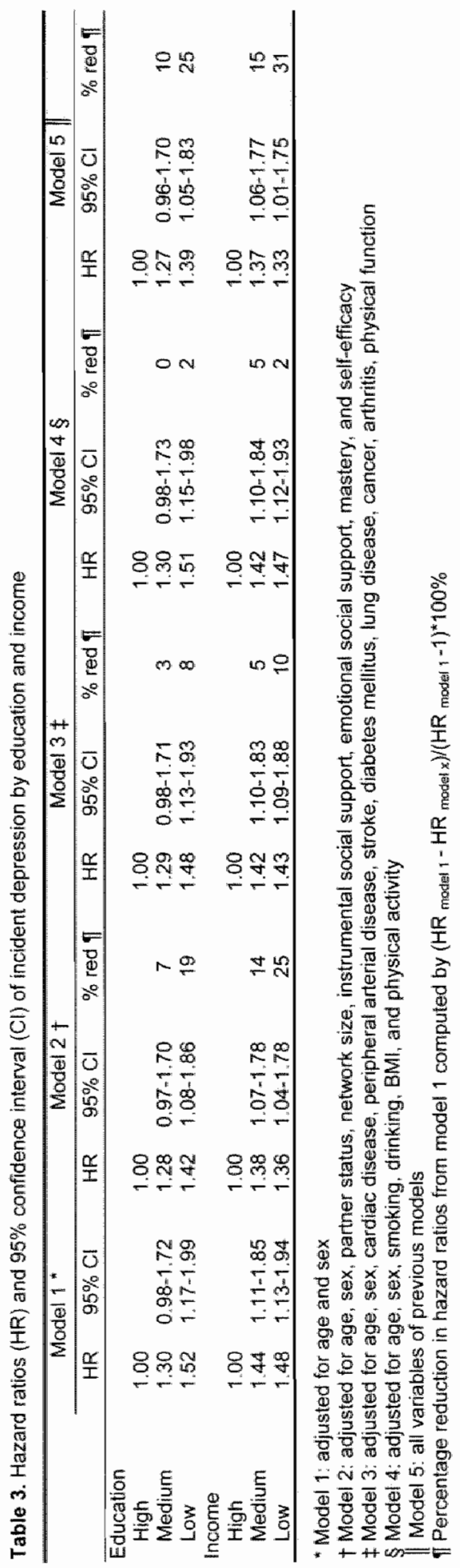




\section{DISCUSSION}

In our study among older adults, low SES predicted an increased incidence of depression during nine years of follow-up. Those with the lowest education or income level had a $50 \%$ higher risk of incident depression compared to those in the highest SES groups. The largest reduction in SES differences in incident depression was found after adjustment for psychosocial factors. Psychosocial factors, mainly network size and self-efficacy, explained on average $13 \%$ of the educational differences in incident depression and $20 \%$ of the income differences in incident depression. Physical health status had less impact in reducing the effect of SES on depression incidence. Finally, behavioral factors explained less than $5 \%$ of the association between SES and incident depression. Even after taking into account psychosocial factors, physical health status, and behavioral factors, low education and low income remained significant predictors of depression incidence.

A small network size, low self-efficacy, and poor physical function had the largest individual contribution in reducing the effect of SES on incident depression in this study. People with a low SES had a smaller network of persons who where important to them, which in turn was also associated with a higher incidence of depression. It is unclear why both emotional and instrumental support - important predictors of depression in other studies $(15,17)$ - were not related to incident depression in our study. Self-efficacy, the extent to which people believe that they can perform a certain behavior, was significantly lower in low SES groups and can be seen as a personal resource to buffer the impact of stress on depression (46). Poorer physical function also contributed to the explanation of SES differences in depression incidence, while diseases were less important. Behavioral factors were only weakly associated with the incidence of depression. This explains the minor role of these factors in reducing the SES gradients in incident depression, which was also found in other studies $(4,47)$.

Together, psychosocial factors, physical health status, and behavioral factors explained on average less than a quarter of the SES differences in incident depression. Low education and low income remained significant predictors of depression incidence. Only baseline data on explanatory factors were analyzed. The contribution of the explanatory factors in reducing the SES differences in depression incidence may have been larger if these factors had also been considered longitudinally. However, there is evidence that behavioral factors, mainly smoking and alcohol consumption remain rather stable over time; physical activity showed greater variability over time. These changes in health behavior were, however, not related to SES (48). Psychosocial factors, such as network size and social support, 
probably also remained rather stable during the follow-up $(49,50)$. The prevalence of physical diseases, however, is more likely to have changed during the nine years of follow-up which may have led to an underestimation of the contribution of these factors.

Although access to a large representative sample of elderly which could be followed up for a relatively long period, using identical methods and including a wide range of potential explanatory variables are methodological assets of the studies, some limitations must be considered. First, information on physical health status was based on self-report, which may have led to an under- or overestimation of these factors in the explanation of SES differences in depression incidence. Second, missing values for psychosocial factors were replaced by group means, which could have led to an attenuation of the effect of these factors in explaining the SES differentials. In additional analyses (data not shown), however, in which subjects with missing values on psychosocial factors were excluded, the contribution of these factors in the explanation of SES differences in incident depression was very similar. Third, because of a large number of missing data on behavioral factors, a missing category was created and included in the main analyses. Persons with missing behavioral data had significantly lower education and lower income (data not shown). Subjects with missing data on smoking and drinking, however, had a significantly lower risk for depression compared with non-smokers and non-drinkers. It remains unclear how this may have affected our findings. Finally, other factors that were not taken into account in this study could also have been important. In the Whitehall II Study, work characteristics, low job control in particular, explained much of the social inequalities in depressive symptoms $(4,10)$. That study consists of white-collar middle-aged men and women, while our study consists of people of 55 years and older of whom the largest part (83\%) had no paid job anymore and work characteristics in the current of previous job were not measured. Furthermore, material factors, e.g. deprivation, as well as life events have been shown important in the explanation of SES differences in depression (10).

To our knowledge, this is one of the few langitudinal studies specifically studying the association between SES and the incidence of depression in older adults as well as taking into account a broad range of possible explanatory factors. Subjects with depression at baseline were excluded from this study in order to determine the association of SES on time to incident depression during the follow-up. Persons with depression at baseline had a significantly lower educational level and income compared with non-depressed persons (data not shown). To the extent that the baseline association is based on causation rather than selection (depression influences SES), we may have underestimated the association between SES and 
depression incidence. Furthermore, people who were lost to follow-up had a significantly lower SES compared to our study population. This may also have led to an underestimation of the association between SES and incident depression.

This study shows that older people with a low level of education or low income are especially at risk of developing depression. In primary care services, special attention is needed for persons with low SES, not only for early recognition but also for care and treatment. Furthermore, a recent study shows that people with depression with low education less often receive specialized mental health services (51).

In summary, low SES predicted the incidence of depression in older adults. Part of this association was explained by psychosocial factors and physical health status. Intervention upon psychosocial characteristics and improving physical function may lower the SES differences and reduce the risk for depression and its consequences for well-being. The SES differences in incident depression remain, however, to a large extent unexplained. Thus, further study is needed to unravel in even more detail the pathways through which low SES leads to depression in older adults.

\section{ACKNOWLEDGMENT}

The Longitudinal Aging Study Amsterdam is largely funded by the Ministry of Health, Welfare and Sports of the Netherlands. 


\section{REFERENCES}

1. Mackenbach JP, Kunst AE, Cavelaars AE, Groenhof F, Geurts JJ. Socioeconomic inequalities in morbidity and mortality in western Europe. The EU Working Group on Socioeconomic Inequalities in Health. Lancet 1997;349:1655-9.

2. Martikainen $P$, Stansfeld $S$. Hemingway $H$, Marmot M. Determinants of socioeconomic differences in change in physical and mental functioning. Soc Sci Med 1999;49:499-507.

3. Larant V, Deliege D. Eaton W. Robert A. Philippot P. Ansseau M. Socioeconomic inequalities in depression: a meta-analysis. Am J Epidemiol 2003;157:98-112.

4. Stansfeld $S A$, Head $J$ Fuhrer $R$, Wardle J, Cattell V. Social inequalities in depressive symptoms and physical functioning in the Whitehall II study: exploring a common cause explanation. J Epidemiol Community Health 2003;57:361-7.

5. Everson SA, Maty SC, Lynch JW, Kaplan GA. Epidemiologic evidence for the relation between socioeconomic status and depression, obesity, and diabetes, J Psychosom Res 2002;53:891-895.

6. Beekman AT, Deeg DJ, Braam AW, Smit JH, Van Tilburg W. Consequences of major and minor depression in later life: a study of disability, well-being and service utilization. Psychol Med 1997:27:1397-409.

7. Ormel J, Kempen GI, Deeg DJ, Brilman El, van Sonderen E, Relyveld J. Functioning, wellbeing, and health perception in llate middle-aged and alder people: comparing the effects of depressive symptoms and chronic medical conditions. J Am Geriatr Soc 1998:46:39-48.

8. Hays $\mathrm{RD}$, Wells $\mathrm{KB}$, Sherbourne $\mathrm{CD}$, Rogers $W$, Spritzer $K$. Functioning and well-being outcomes of patients with depression compared with chronic general medical illnesses. Arch Gen Psychiatry 1995;52:11-9.

9. Schulz $R$, Beach SR, Ives DG, Martire LM, Ariyo AA, Kop WJ. Association between depression and mortality in older adults: the Cardiovascular Health Study. Arch Intern Med 2000;160:1761-8.

10. Stansfeld SA, Head J, Marmot MG. Explaining sociall class differences in depression and well being. Soc Psychiatry Psychiatr Epidemiol 1998;33:1-9.

11. Gazmararian J, Baker D, Parker $R$, Blazer DG. A multivariate analysis of factors associated with depression: evaluating the role of health literacy as a potential contributor. Arch Intern Med 2000;160:3307-14.

12. Bosma $H$, Van Jaarsveld $\mathrm{CH}$, Tuinstra J, et al. Low control beliefs, classicall coronary risk factors, and socio-economic differences in heart disease in older persons. Soc Sci Med $2005 ; 60: 737-45$.

13. Kristenson M, Eriksen HR, Sluiter JK, Starke D, Ursin H. Psychobiological mechanisms of socioeconomic differences in health. Soc Sci Med 2004;58:1511-22.

14. Taylor SE, Seeman TE. Psychosocial resources and the SES-health relationship. Ann N $Y$ Acad Scil 1999;896:210-25.

15. Oxman TE, Berkman LF: KasI S, Freeman DH, Jr., Barrett J. Social support and depressive symptoms in the elderly. Am J Epidemiol 1992;135:356-68.

16. Harris $T_{\text {n }}$ Cook DG, Victor $C$, et al. Predictors of depressive symptoms in older people-a survey of two general practice populations. Age Ageing 2003,32:510 8. 
17. Stansfield SA, Fuhrer $R$, shipley MJ. Types of social support as predictors of psychiatric morbidity in a cohort of British Civil Servants (Whitehall II Study). Psychol Med 1998:28:88192 .

18. Glass TA, Kasi SV, Berkman LF. Stressful life events and depressive symptoms among the elderly. Evidence from a prospective community study. J Aging Health 1997;9:70-89.

19. Brumner $E J$, Marmot MG, Nanchahal $K$, et al Social inequality in coronary risk: central obesity and the metabolic syndrome. Evidence from the Whitehall li study. Diabetologia $1997: 40: 1341-1349$

20. Kaplan GA, Keil JE. Socioeconomic factors and cardiovascular disease: a review of the litterature. Circulation 1993;8:1973-1998.

21. Hart CL, Hole DJ, Smith GD. The contribution of risk factors to stroke differentials, by socioeconomic position in adulthood: the Renfrew/Paisley Study. Am J Public Health 2000;90:1788-1791.

22. Dalstra JA, Kunst AE, Borrell $C_{b}$ et al. Sacioeconomic differences in the prevalence of common chronic diseases: an overview of eight European countries. Int $J$ Epidemiol 2005;34:316-26.

23. Black SA, Goodwin JS, Markides KS , The assaciation between chronic diseases and depressive symptomatology in older Mexican Americans. J Gerontol A Biol Sci Med Sci 1998;53:M188-94.

24. Palinkas LA, Wingard DL, Barrett-Connor E. Chronic illness and depressive symptoms in the elderly: a population-based study. J Clin Epidemiol 1990;43:1131-41.

25. Bisschop Ml, Kriegsman DM, Deeg DJ, Beekman AT, van Tilburg W. The longitudinal relation between chronic diseases and depression in older persons in the community: the Longitudinal Aging Study Amsterdam. J Clin Epidemiol 2004;57:187-94.

26. Melzer $D$, Izmirlian $G$, Leveille SG, Guralnik. JM. Educational differences in the prevalence of mobility disability in old age: the dynamics of incidence, mortality and recovery. $₫$ Gerontol B Psychol Sci Soc Sci 2001;56:294-301.

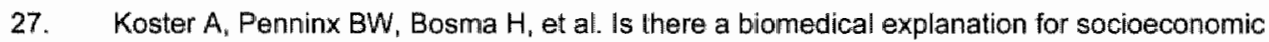
differences in incident mobility limitation? J Gerontol A Biol Sci Med Sci 2005;60:1022-7.

28. Ormel J, Rijsdijk FV, Sullivan $M$, van Sonderen $E$, Kempen GI. Temporal and reciprocal relationship between $I A D L A D L$ disability and depressive symptoms in late life. J Gerontol B Psychol Sci Soc Sci 2002;57:P338-47.

29. van Lenthe FJ" Schrijvers CT, Droomers M, Joung IM, Louwman MJ, Mackenbach JP. Investigating explanations of socio-economic inequalities in health: the Dutch GLOBE study. Eur J Public Health 2004; 14:63-70.

30. Adler NE, Ostrove JM. Socioeconomic status and health: what we know and what we don"t. Ann N Y Acad Sci 1999;896:3-15.

31. Paperwalla $K N$, Levin TT, Weiner $J$, Saravay SM. Smoking and depression. Med Clin North Am 2004:88: 1483-94, $x-x i$.

32. Strawbridge WJ, Deleger S, Roberts RE, Kaplan GA. Physical activity reduces the risk of subsequent depression for older adults. Am J Epidemiol 2002;156:328-34.

33. Deeg DJH, Knipscheer CPM, Van Tilburg W. Autonomy and well-being in the aging population. Concepts and design of the Longitudinal Aging Study Amsterdlam. Bunnik: Netherlands Institute of Gerontology, 1993 
34. Knipscheer CPM, de Jong-Gierveld J, Van Tilburg TG, Dykstra PA. Living arrangements and social networks of older adults. Amsterdam: WU University Press, 1995.

35. Broese van Groenou MI, Deeg DJ, Penninx BW. Income differentials in functional disability in old age: relative risks of onset, recovery, decline, attrition and mortality. Aging Clin Exp Res 2003;15:174-183.

36. Radloff LS. The CES-D scale: a self-report depression scale for research in the general population. Apll Psychol Meas 1977;1:385-401.

37. Beekman AT, Deeg DJ, Van Limbeek J, Braam AW, De Vries MZ, Van Tilburg W. Criterion validity of the Center for Epidemiologic Studies Depression scale (CES-D): results from a community-based sample of older subjects in The Netherlands. Psychol Med 1997:27:23,1-5.

38. Penninx BW, Deeg DJ, wan Eijk JT, Beekman AT, Guralnik JM. Changes in depression and physical decine in older adults: a longitudinal perspective. J Affect Disord 2000;61:1-12.

39. Kennedy $G J$ " Kelman HR, Thomas $C$. Persistence and remission of depressive symptoms in late life. Am J Psychiatry 1991:148:174-8.

40. van Tilburg TG. Delineation of the social network and differences in network size. In: Knipscheer CPM, de Jong-Gierveld J, van Tilburg TG, Dykstra PA, eds. Living arrangements and social networks of older adults. Amsterdam: VU University Press, 1995:83-96.

41. Pearlin LI, Schooler C. The structure of coping. Journal of Health and Social Behavior $1978: 19: 2-21$.

42. Sherer M, Maddux. JE, Mercadente B, Prentice-Dunn S, Jacobs B, Rogers RW. The selfefficacy scale: Construction and validation. Psychol Rep 1982:51:663-671.

43. Bosscher RJ, Smit JH. Confirmatory factor analysis of the General Self-Efficacy Scale. Behav Res Ther 1998; 36:339-43.

44. Kriegsman DM, Penninx BW, van Eijk JT, Boeke AJ, Deeg DJ. Self-reports and general practitioner information on the presence of chronic diseases in community dwelling elderly. A study on the accuracy of patients' self-reports and on determinants of inaccuracy. J Clin Epidemiol 1996;49:1407- 17.

45. van Sonsbeek $J$. Methodological and substantial aspects of the OECD indicator of chronic functional limitations. Maandbericht Gezondheid (CBS) 1988;88:4-17

46. Wheaton $B$. The sociogenesis of psychological disorder: an attributional theory. $J$ Health Soc Behaw $1980 ; 21: 100-24$.

47. West CG, Reed DM, Gildengorin GL. Can money buy happiness? Depressive symptoms in an affluent older population. J Am Geriatr Soc 1998;46:49-57.

48. Mulder M, Ranchor AV, Sanderman R, Bouma J, van den Heuvel W.J. The stability of lifestyle behaviour. Int J Epidemiol 1998;27:199-207.

49. van Tilburg $T$. Losing and gaining in old age: changes in personal network size and social support in a four-year longitudinal study. J Gerontol B Psychol Sci Soc Sci 1998;53:S313-23.

50. Broese van Groenou M, Van Tilburg T. Changes in the support networks of older adults in the Netherlands. J Cross Cult Gerontol 1997:12:23-44.

51. ten Have $M$, de Graaf $R$, Vollebergh $W$, Beekman A. What depressive symptoms are associated with the use of care services? Results from the Netherlands Mental Health Survey and Incidence Study (NEMESIS). J Affect Disord 2004:80:239-48. 

9

General discussion 
This thesis described the associations between socioeconomic status (SES) and longitudinal changes in physical, cognitive, and mental function, particularly in late middle-aged and older adults. Additionally, the role of biomedical, behavioral, and psychosocial factors in explaining these differences was explored. This chapter summarizes and discusses the main findings and some conceptual and methodological considerations are made. Furthermore, implications for public health and recommendations for future research are given.

\section{MAIN FINDINGS}

\section{Describing socioeconomic differences in health}

The first objective of this thesis was to describe the associations between SES and physical, cognitive, and mental function. Strong and consistent associations between SES indicators and functional outcomes were found. Table 1 shows an overview of the associations that were found in the different chapters of this thesis.

Table 1. Overview of the associations between SES and changes in physical, cognitive, and mental function

\begin{tabular}{lccccc}
\hline & Chapter & Education & Income & Occupation & Assets * $^{*}$ \\
\hline Physical function & & & & & + \\
Mobility decline (GLOBE) & $2 \& 3$ & $N S$ & + & + \\
$\begin{array}{l}\text { Physical function decline (LASA) } \\
\text { Incident mobility limitation (Heallh ABC) }\end{array}$ & 6 & + & + & + \\
$\begin{array}{l}\text { Cognitive function } \\
\text { Cognitive decline (Health ABC) }\end{array}$ & 7 & + & + & + \\
$\begin{array}{l}\text { Mental function (depression) } \\
\text { Incident depression (LASA) }\end{array}$ & & & & + \\
\hline
\end{tabular}

* = significant association; NS = not significant association; blank = not investigated

* Assets included money market accounts, saving bonds or treasury bills, home ownership or investment properly or housing, a business or farm, stock or stack mutual funds, and IRA or KEOGH account, and other investments.

Low SES predicted a decline in physical function as well as the onset of physical limitations. SES differences in physical function were found in both younger and older adults of the GLOBE study. In people who were between 55 and 85 years old (LASA), low SES was associated with poor physical function during nine years of follow-up. SES differences in physical function even significantly increased over nine years of follow-up in people who were younger than 70 years. SES differences in physical function did not further widen in people of 70 years and older. This may be due to a healthy survivor effect. In the oldest old, the lowest SES group probably 
consists of "healthy survivors", because of selection prior to baseline and attrition due to mortality during the follow-up. For the Health $A B C$ study, a fairly healthy group of older persons, aged between 70 and 79 years old, was selected. All participants were well-functioning at baseline. In this cohort, a strong association between SES and the onset of mobility limitation during four and a half years of follow-up was found. Altogether, our studies show that SES differences in physical function still exist in old age. Low SES is an important predictor of poor physical function.

In an older population (Health ABC), low SES also predicted a decline in cognitive function. The association between low SES and cognitive decline was found across different SES indicators. Many previous studies investigated the association between educational level and cognitive function in which education is treated as a proxy for intellectual abilities rather than as an indicator for SES (1-3). In our study, significant associations with poor cognitive function were also found for low income and few assets. This shows the importance of SES as a predictor of cognitive decline. This study is an important contribution to the existing literature as the assaciation between SES and cognitive function had not been studied extensively before (especially the number of longitudinal studies is limited).

Among older adults of LASA, low SES predicted the onset of depression during nine years of follow-up. This is one of the few longitudinal studies that specifically studied the association between SES and the incidence of depression in older adults.

In sum, low SES was strongly associated with poor physical, cognitive, and mental function over time. This was found across different indicators of SES and these health inequalities persist in old age. An important strength of our studies is that we studied the associations between SES and function longitudinally. Therefore we may conclude that there probably is a causal relationship between SES and changes in function.

Are socioeconomic differences in health still important in old age?

SES differences in physical function were found in both younger and older adults. In the GLOBE study, which consisted of both younger and older adults (aged 15 to 74 years), the association between SES and mobility decline was similar in a group of 55 years or older $(n=736)$ compared to those younger than 55 years ald $(n=647)$. Additionally, interaction terms between any of the SES indicators and age were not statistically significant which confirmed that the association between SES and mobility decline was similar for all ages. In LASA, SES differences in physical function were found in both younger-old ( 55 to 70 years) and older-old ( 70 to 85 years) adults. SES differences in physical function even increased over time in the 
youngest-old. Low SES also predicted a decline in cognitive function and the onset of depression in older adults. Overall, our studies indicate that SES differences are still important in old age.

\section{Explaining socioeconomic differences in health}

The second objective of this thesis was to gain more insight into the mechanisms underlying the associations between SES and the three functional outcomes, specifically the role of biomedical, behavioral, and psychosocial factors. Table 2 shows an overview of the contributions of biomedical, behavioral, and psychosocial factors in explaining SES differences function.

Table 2. Overview of the contributions of biomedical, behavioral, and psychosocial factors in explaining SES differences in physical, cognitive, and mental function

\begin{tabular}{|c|c|c|c|}
\hline & $\begin{array}{l}\text { Biomedical } \\
\text { factors }\end{array}$ & $\begin{array}{l}\text { Behaviorall } \\
\text { fiactors }\end{array}$ & $\begin{array}{l}\text { Psychosocial } \\
\text { factors }\end{array}$ \\
\hline \multicolumn{4}{|l|}{ Physicial function } \\
\hline Mobillity decline (GLOBE) & 0 & & 0 \\
\hline \multicolumn{4}{|l|}{ Physical function decline (LASA) } \\
\hline$<70$ years old & + & + & + \\
\hline$\geq 70$ years old & + & 0 & + \\
\hline Incident mobility limitation (Health $A B C$ ) & + & & \\
\hline \multicolumn{4}{|l|}{ Cognitive function } \\
\hline Cognitive decline (Health $A B C$ ) & 0 & & \\
\hline \multicolumn{4}{|l|}{ Mental function (depression) } \\
\hline Incident depression (LASA) & D & 0 & + \\
\hline
\end{tabular}

SES differences in mobility decline could hardly be explained by biomedical factors (disease severity and comorbidity) in the GLOBE study even though low SES was associated with a higher prevalence of severe disease and comorbidities. This shows the cumulative adversities of people with a low SES. People with a low SES had increased risk of mobility decline, which was independent of their more severe disease and the more comorbid diseases they had, compared to people with a higher SES. Psychosocial factors did not further explain the SES differences in mobility decline. Especially low income remained a strong predictor of mobility decline in this chronically ill population. In LASA, biomedical, behavioral, and psychosocial factors were simultaneously examined in the explanation of SES differences in changes in physical function. Behavioral factors largely explained the SES differences in baseline physical function in the 55 to 70 year old age group; psychosocial factors contributed most strongly in the group of 70 years and older. The significant SES 
differential decline in physical function that was found in the youngest age group could not be explained by any of the explanatory factors (not tabulated).

In an attempt to explore a possible biomedical mechanism in more detail, the association between SES and serum levels of inflammatory markers, one of the biomedical factors, was studied among 70 to 79 year old well-functioning adults (Health ABC) (not tabulated). Low SES was associated with elevated serum levels of interleukin-6 (IL6), C-reactive protein (CRP), and tumor necrosis factor-a (TNF-a) compared to high SES. This is an important finding, because in the literature high serum levels of inflammatory markers thave been prospectively associated with poor functional outcomes and increased mortality (4-7). Given that serum levels of inflammatory markers and other biomedical factors were strongly related to incident mobility limitation, these factors explained a substantial part of the SES differences in incident mobility limitation in the same study population (Health $A B C$ ). However, even after taking into account a wide range of diseases and biological risk factors, persons in the lowest SES group still had a significant increased risk of mobility limitation incidence. High serum levels of inflammatory markers, high BMI, and hypertension had the largest contribution in reducing the SES differences in mobility limitation. It is notable that these variables measured biological characteristics rather than diseases. In GLOBE and LASA, biomedical factors included a range of (chronic) diseases rather than biological risk factors.

The biomedical factors that explained a substantial part of the SES differences in incident mobility limitation, explained only very little of the SES differentials in cognitive decline. The hypotheses that biomedical factors are important in the mechanism underlying the association between SES and cognitive function could not be supported.

Part of the SES differences in depression incidence was explained by psychosocial factors. Biomedical factors and mainly behavioral factors were less important. A small network size, low self-efficacy, and poor physical function had the largest individual contribution in reducing the effect of SES on incident depression. SES differences in incident depression remained " however, to a large extent unexplained.

In sum, biomedical, behavioral, and psychosocial factors explained only part of SES differences in health and could not fully explain SES differences in physical, cognitive, and mental function. Hence, SES differences in function to some extent remained unexplained. 


\section{CONCEPTUAL AND METHODOLOGICAL CONSIDERATIONS}

There are several conceptual and methodological issues that should be considered when interpreting the results of our studies. These issues concern the use of self-reported data, the selection of explanatory factors and outcomes, selection bias, and generalizability of our findings (8).

\section{Neglected interrelations of explanatory factors}

Our research model as presented in the first chapter is rather simplified. First, there will be other explanatory factors that were not included in any of our studies; these will be discussed in the section on 'selection of explanatory factors and outcomes:. Second, we assumed that the three groups of explanatory variables have an independent contribution to the explanation of SES differences in function. The mechanisms probably are interrelated, indicating that some mechanisms work through others rather than work independently from each other. For example, psychosocial factors and biomedical factors are causally interrelated, as well as psychosocial factors and behavioral factors.

Generally, lower SES persons live and work in more stressful environments (9-11). Stress may derive from daily problems, life events, job demands or financial problems. Additionally, people with a low SES are less participating in social networks and receive less social support which has negative consequences for physical and mental health $(10,12,13)$. Lower SES groups have less buffering resources avallable to cope with stressful situations. Low SES is, for example, related to lower self-efficacy; this refers to the extent to which people believe that they can perform a certain behavior and can be seen as personal resource to buffer the impact of stress. Chronic stress elevates activities of different physiological systems, such as the immune system, which may lead to diseases $(10,14,15)$. The concept of "allostatic load" has been proposed as the wear and tear in the body and brain resulting from chronic overactivity or inactivity of physiological systems (16). Chronic stress and low control may eventually result in vital exhaustion (10). A higher vulnerability to stress may also lead to unhealthy behavior such as smoking or excessive alcohol consumption (10). The contribution of behavioral and psychosocial factors in explaining SES differences in function will partly be through biomedical factors. Adverse behavioral factors, such as smoking or excessive alcohol consumption in the past, may have resulted in diseases in later life. In chapter 5, we studied the association between SES and inflammatory markers, a biomedical factor, in more detail. Low SES was associated with significantly elevated serum levels of inflammatory markers. A substantial part of the inverse association between SES and 
serum levels of inflammatory markers was explained by behavioral factors (including smoking, drinking, and obesity). This study shows that adverse behavioral factors may result in higher serum levels of inflammatory markers.

The above-mentioned considerations have consequences for the estimation of the exact (direct and indirect) contribution of each group of explanatory factors in the explanation of SES differences in function. However, the contribution of biomedical, behavioral, and psychosocial factors together is not affected by whether these factors are interrelated or not.

\section{Self-reported data}

The use of self-reported data may have introduced a potential source of bias. Our outcomes, physical function, cognitive function, and depression, were entirely based on self-reports. This could have led to an under- or overestimation of function $(17,18)$. However, the potential for an under- or overestimation of changes in function is minimized when this is due to a stable characteristic of a person, such as negative affectivity (complaining attitude towards health), because this would be present at baseline as well as at follow-up.

Information about biomedical, behavioral, and psychosocial factors was largely based on self-reported data as well. Bias due to social desirability and not knowing or remembering, possibly leads to underestimated contributions of these factors in the explanation of SES differences in function. Bias due to negative affectivity may, however, lead to an overestimation of, for example, the prevalence of diseases (19). Regarding diseases, misreporting differs between conditions (20-22). Moreover, this type of bias may also be related to SES which may lead to differential misclassification (20). More objective information about biomedical factors was available in the Health $A B C$ study. Information about a wide variety of diseases and biological risk factors was partly based on use of specific medications, some clinical assessments, and self-report.

Imprecision of the measurements is a possible bias that may have led to an underestimation of the contribution of the explanatory factors. For example, in LASA and Health $A B C$ only limited information was available about the severity of diseases. Furthermore, the measurements are not a perfect marker for life-time exposure to risk factors $(23,24)$.

\section{Selection of explanatory factors and outcomes}

Three important groups of explanatory variables were included in our studies. Although we selected a comprehensive selection of variables as possible in each study, this set of variables was not exactly the same in GLOBE, LASA, and Health 
$A B C$. Furthermore, we must acknowledge that there were factors that were not measured or that we did not include. First biomedical factors. In the Health $A B C$ study, a wide variety of diseases and biologicall risk factors were included in the study, allowing for a more comprehensive assessment than has been previously possible. In GLOBE and LASA, a range of (chronic) diseases was included in the study. Less information, however, was available about biological risk factors. This may explain the small contribution of the biomedical factors in explaining SES differences in physical function in GLOBE and LASA. In Health $A B C$, we show that particularly the biological risk factors, such as high serum levels of inflammatory markers and hypertension, had the largest contribution in reducing the SES differences in mobility limitation. In LASA and GLOBE, we therefore may have underestimated the role of biomedical factors. Second, a potentially important behavioral factor that was not included in our studies is diet. Generally, low SES is related to unhealthier diets $(25,26)$. Since an unhealthier diet is also associated with poor function $(27,28)$, the estimation of the role of behavioral factors might have been underestimated. Third, important psychosocial factors that were not included in our studies are job related stressors, for example job control. These factors are known to be related to low SES and poor health outcomes, such as physical function and depression $(10,29-31)$. In older populations, these factors are probably less important as a large part has no paid job anymore. Finally, we did not examine the role of material factors in the explanation of SES differences in function. Income, being a strong predictor of function in our studies, suggests that the direct availability of financial resources might be important (32). Low SES is related to adverse material factors, such as financial problems (lack of money), housing problems, and adverse physical working conditions $(31,32)$. Previous studies showed that material factors explained part of SES health inequalities (33-37). Part of the contribution of material factors was, however, through behavioral and psychosocial factors $(33,34$, 36). In future research, the factors that were mentioned above should be included to obtain a more detailed picture of the background of SES differences in function.

Besides adult socioeconomic circumstances, childhood socioeconomic circumstances also play a part in the explanation of SES differences in health. From a life-course perspective, the onset of SES health inequalities is a continual process. Studies have shown that childhood SES and early life factors have an independent effect on adult health (38-42). Although we used different indicators of SES that represent different dimensions of SES in different life stages, life course indicators were not incorporated in our studies.

In all our studies, we determined whether SES differences in changes in function could be explained by explanatory variables measured at baseline. The 
contribution of explanatory factors in reducing the SES differences in function may have been larger if these factors had also been considered longitudinally. The severity of a disease and comorbidity, for example, is likely to have changed during the follow-up which may have led to an underestimation of the contribution of these factors. Additionally, information about life time exposure to risk factors was not available which may also have led to an underestimation of these factors (43).

Because only baseline data on explanatory factors were analyzed, the association between SES on the one hand and explanatory factors on the other hand might have resulted from reverse causation (explanatory factors influence SES) (4446). It is likely that this selection effect has a larger effect on income than on educational level, as the latter indicator is less sensitive to change during adulthood. In our studies, simlar results were found across all SES indicators, including education.

Our model consisted of three types of function that covered health status: physical, cognitive, and mental function. Social function, another dimension of health and well-being was, however, not included. Social health is perceived as essential and an important condition for well-being and successful aging $(47,48)$. Studies have shown that low SES is associated with poor social function $(49,50)$. It has not been studied extensively how SES differences in social function can be explained. Some studies treat social function as a separate subscale of function while other studies incorporate social function in a summary measure for mental function $(35,51)$. Depression was used as an indicator for mental function. Anxiety, as another common mental disorder, was however not included. Anxiety disorders are also more common among low SES groups $(52,53)$.

\section{Attrition}

Data from three longitudinal cohort studies were used. Especially for the studies that involve older persons, attrition due to morbidity and mortality is a disadvantage. Generally, attrition was thigher among low SES groups. Furthermore, people who were lost to follow-up often had poorer function compared to those who remained in the study. Consequently, the remaining study sample is no longer representative of the original study population. This selection may have led to an underestimation of the association between SES and function. However, attrition may not always be a serious problem when associations between variables are the focus of study $(54,55)$. It remains unknown whether the relative contribution of explanatory variables in the explanation of SES differences in function was equally underestimated. 


\section{Generalizability}

The sample of the GLOBE study consisted of $15-74$ year old men and women with a chronic disease (asthma/COPD, heart disease, diabetes mellitus, and low back pain). Because all participants had a chronic disease we cannot generalize our findings to a healthy population. It is likely that chronically ill persons experience more mobility problems because of their chronic disease than healthy people do. Whether SES differences and the contribution of explanatory variables are different between healthy and chronically ill persons remains unknown.

The LASA study was originally based on randomly selected population-based sample. Attrition, however, has resulted in a relatively healthy study sample; therefore, our result may not be generalizable to more frail older persons or institutionalized persons. The Health $A B C$ study is based on an even healthier older population; all participants were well-functioning at baseline. The latter study is conducted in the United States and therefore may not be comparable to studies in the Netherlands. SES differences in health have found to be larger in the United States than in the Netherlands $(56,57)$. If we measure the gap between the $5 \%$ richest and the $5 \%$ poorest in the Health $A B C$ study, the 5\% richest had incomes about 10 times those of the poorest $5 \%$. In GLOBE and LASA this ratio was about 5 (data not shown). This may explain the particularly large income differences in physical function in Health $A B C$ compared to GLOBE and LASA. SES differences in function may be larger in the Health $A B C$ study, whether the contribution of explanatory variables is different remains unclear.

\section{IMPLICATIONS}

The primary aim of the studies presented in this thesis was to provide a better understanding of the factors that contribute to SES health differences. However, this may also provide more guidance to policy recommendations to reduce these inequalities. Over the past 15 years, the Dutch ministry of health has followed a systematic research based approach to reduce SES differences in health $(58,59)$. The main focus of the program was on developing and evaluating interventions and policies. The strategy covered four intervention and policy measures: (1) reducing inequalities in socioeconomic goods; (2) diminishing the effect of health on SES; (3) changing the distribution of specific risk factors across SES groups; (4) offer extra health care for people in low SES groups.

Despite the efforts to reduce SES differences in health, our studies show that SES differences are still a major public health problem. SES differences in physical 
function even significantly increased over time in younger-old adults ( 55 to 70 years): Our findings have implications for the third type of policy measures as mentioned above in order to reduce SES inequalities in health. We showed that a low SES was associated with a higher prevalence of diseases and their risk factors, adverse behavioral factors, and fewer psychosocial resources compared to high SES. The unequal distribution of these risk factors explained part of the SES differences in function. Policy measures that focus on a change in the distribution of risk factors might therefore help to reduce the SES inequalities. Programs to promote, for example, healthy behavior may be most beneficial in early age (58). However, also in an older population it may be useful to improve health behaviors, especially in low SES groups. In one of our studies we showed that elevated serum levels of inflammatory markers in low SES groups were to a large extent mediated by unhealthy behaviors (especially obesity, smoking and drinking) in these groups (Chapter 5). Improving health behaviors may reduce risks associated with inflammation and indirectly reduce SES differences in health. Unhealthy behavior is not simply a lifestyle choice, it is shaped and constrained by social and physical environments linked to SES (9). Interventions should therefore be directed to both the individual and the environment (such as improving housing and neighborhood conditions). Intervention upon psychosocial characteristics might also be possible to reduce SES differences in health. For example, improving control beliefs in low SES groups by self-management skills $(60,61)$. In general, interventions should be directed to specific target populations with a specific approach for each group. It might be useful to identify and focus on groups that are especially at risk to develop health problems (62). For example, people with a low SES, who also smoke and have low self-efficacy, might be at higher risk than other low SES people.

Several interventions have proven to be effective and a few have been implemented on a larger scale, such as programs to prevent school children from starting smoking (58). Whether it is possible to substantially reduce SES differences in health among older persons remains unknown. Policy developments on health inequalities in different European countries between 1990 and 2001 were analyzed (63). The UK, the Netherlands, and Sweden have proposed comprehensive approaches to reduce health inequalities. Strategies differed between countries, which suggest that policymaking in this area is still in a growth stage and more accurate evidence-based approaches are needed. International exchange of experiences with developing, implementing, and evaluating interventions and policies is desirable to increase the development in this field (63). 


\section{FUTURE RESEARCH}

Our studies indicate that SES differences in health are an important issue in ald age. SES differences existed in different dimensions of health in older persons. As there is particularly still limited research on SES differences in cognitive function, more longitudinal studies on this subject are required that particularly examine the underlying mechanism. We only studied the role of biomedical factors that could hardly explain the SES difterences in cognitive decline; the role of behavioral factors and psychosocial factors is still unknown. This research may be especially important because within an aging population and the increasing life expectancy, the number of people with cognitive impairment and dementia will substantially increase.

The Dutch government advisory committee that developed intervention and policy strategies to reduce SES differences in health recommended that continuing explanatory research is necessary because this may lead to new entry points for interventions $(58,59)$. The studies presented in this thesis contribute to this by unraveling the contribution of biomedical "behavioral, and psychosocial factors. None of these factors could, however, fully explain the SES differences in health. Studies in which health and exposure to risk factors are measured during the entire life-course are needed to study SES differences in health and the explanation in more detail. Further study is also needed to examine how these factors are interrelated in order to determine the exact (direct and indirect) contribution of these factors.

\section{IN CONCLUSION}

LOW SES was strongly associated with poor physical, cognitive, and mental function over time and these health inequalities persist in old age. Biomedical behavioral, and psychosocial factors explained part of the SES health differences, but could not fully explain SES differences in physical cognitive, and mental function. Hence, SES differences in function to some extent remained unexplained.

Further study in unraveling the mechanisms underlying SES differences in health is needed, followed by interventions, in both younger and older persons, to decrease SES health differences. Older people with a low SES are especially at risk to develop problems regarding physical, cognitive, and mental function. In health care, special attention is needed for persons with low SES for early recognition of functional problems, care, and treatment. Especially low SES persons are worse off as they have a shorter life expectancy and also live a greater proportion of their lives in poor health. A decrease in SES differences in function will also decrease SES differences in (healthy) life expectancy. 


\section{REFERENCES}

1. Albert MS. How does education affect cognitive function? Ann of Epidemiol 1995,5:76-78.

2. Evans DA, Beckett LA, Albert MS, et al. Level of education and change in cognitive function in a community population of older persons. Ann Epidemiol 1993;3:71-77.

3. Colsher PL, Wallace RB. Longitudinal application of cognitive function measures in a defined population of community-dwelling elders. Ann Epideniol 1991;1:215-230.

4. Yaffe $K$, Lindquist $K$, Penninx $B W$, et al. Inflammatory markers and cognition in wellfunctioning African-American and white elders. Neurology 2003;61:76-80.

5. Penninx BW, Kritchevsky SB, Yaffe K, et al. Inflammatory markers and depressed moodin older persons: results from the Health, Aging and Body Composition study. Biol Psychiatry 2003:54:566-572.

6. Penninx $\mathrm{BW}$, Kritchevsky $\mathrm{SB}, \mathrm{Newman} \mathrm{AB}$, et al. Inflammatory markers and incident mobility limitation in the elderly. I Am Geriatr Soc 2004;52:1105-13.

7. Reuben DB, Cheh Al, Harris TB, et all. Peripheral blood markers of inflammation predict mortality and functional decline in high-functioning community-dwelling older persons. J Am Geriatr Soc 2002;50:638-44.

8. Bouter LM, van Dongen MCJM. Epidemiologisch onderzoek. Opzet en interpretatie. Derde, herziene druk. Houten/Diegem: Bohn Stafleu van Loghum, 1995.

9. Adler NE, Newman K. Socioeconomic disparities in health: pathways and policies. Inequality in education, income, and occupation exacerbates the gaps between the health "haves" and "have-nots." Health Aff (Millwood) 2002;21:60-76.

10. Kristensan $M$, Eriksen HR, Sluiter JK, Starke D, Ursin H. Psychobiolagical mechanisms of socioeconomic differences in health. Soc Sci Med 2004;58:1511-22.

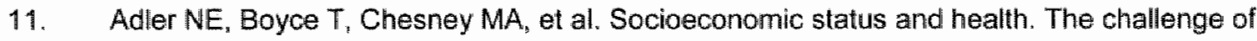
the gradient. Am Psychol 1994;49:15-24.

12. Berkman LF, Glass T, Brissette I, Seeman TE. From social integration to health: Durkheim in the new millennium. Soc Sci Med 2000;51:843-57.

13. Marmot M. Epidemiology of socioeconomic status and health: are determinants within countries the same as between countries? Ann N Y Acad Sci 1999;896:16-29.

14. McEwen BS, Seeman T. Protective and damaging effects of mediators of stress. Elaborating and testing the concepts of allostasis and allostatic load. Ann N Y Acad Sci 1999;896:30-47.

15. Seeman TE, MCEwen BS, Rowe JW. Singer BH. Allostatic laad as a marker of cumulative biological risk: MacArthur studies of successful aging. Proc Natl Acad Sci USA 2001;98:4770-5.

16. McEwen BS. Protective and damaging effects of stress mediators. $N$ Engl $J$ Med 1998;338:171-9.

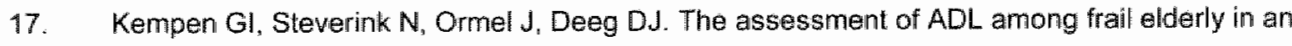
interview survey: self-report versus performance-lbased tests and determinants of discrepancies. J Gerontol B Psychol Sci Soc Sci 1996;51:P254-60.

18. Kempen $\mathrm{Gl}$, van Heuvelen M.d, van den Birink RH, et al. Factors affecting contrasting results between self-reported and performance-based levels of physical limitation. Age Ageing 1996;25:458-64.

19. Watson D, Pennebaker JW. Health complaints, stress, and distress: exploring the central role of negative affectivity. Psychol Rev 1989;96:234-54. 
20. Mackenbach $\mathrm{JP}$, Looman CW, van der Meer $\mathrm{HB}$. Differences in the misreporting of chronic conditions, by level of education: the effect on inequalities in prevalence rates. Am I Public Health $1996 ; 86: 706-11$.

21. Kriegsiman DM, Penninx BW, van Eijk JT, Boeke AJ, Deeg DJ. Self-reports and general practitioner information on the presence of chronic diseases in community dwelling elderly. $A$ study on the accuracy of patients' self-reports and on determinants of inaccuracy. $\mathrm{J}$ Clin Epidemiol 1996;49:1407-17.

22. Goldinan $N, \operatorname{Lin} \| F_{*}$, Weinstein $M, L$ in $Y H$. Evaluating the quality of self-reports of hypertension and diabetes. J Clin Epidemiol 2003;56:148-54.

23. Magnus $P$. Beaglehole $R$. The real contribution of the major risk factors to the coronary epidemics: time to end the "only-50\%" myth. Arch Intern Med 2001:161:2657-60.

24. Smith GD. Phillips AN. Confounding in epidemiological studies: why "independent" effects may not be all they seem. BMJ 1992;305:757-9.

25. Martikainen $\mathrm{P}$. Brunner $\mathrm{E}_{1}$ Marmot $M$. Socioeconomic differences in dietary patierns among middle-aged men and women. Soc Sci Med 2003;56:1397-410.

26. Hulshof KF, Brussaard $\mathrm{JH}_{\text {z }}$ Kruizinga AG, Telman J, Lowik MR. Socio-economic status, dlietary intake and 10 y trends: the Dutch National Food Consumption Survey. Eur J Clin Nutr 2003;57:128-37.

27. Stuck AE, Walthert JM, Nikalaus T, Bula CJ, Hohmann $C_{i}$ Beck. JC. Risk factors for functional status decline in community-living elderly people: a systematic literature review. Soc Sci Med 1999;48:445-69.

28. Kalmijn S. Fatty acid intake and the risk of dementia and cognitive decline: a review of clinical and epidemiological studies. I Nutr Health Aging 2000;4:202-7.

29. Stansfeld SA, Head J, Fuhrer $\mathbb{R}$, Wardle J, Cattell $V$. Social inequalities in depressive symptoms and physical functioning in the Whitehall II study: exploring a common cause explanation. J Epidemiol Community Health 2003;57:361-7.

30. Bosma $H$, Marmot MG, Hemingway $H$, Nicholson AC, Brunner $E$, Stansfeld SA. Low job control and risk of coronary heart disease in Whittehall II (prospective cohort) study. BMJ 1997;314:558-65.

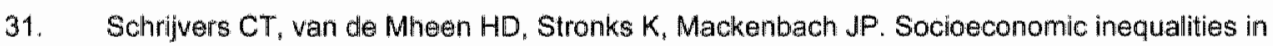
health in the working population: the contribution of working conditions. Int J Epidemiol $1998 ; 27: 1011-8$.

32. Lymch JW, Smith GD, Kaplan GA, House JS. Income inequality and mortality: importance to health of individual income, psychosocial emvironment, or material conditions. BMJ 2000;320:1200\%4.

33. van Oort FV, van Lenthe $F J$, Mackenbach JP. Materiall, psychosocial, and behavioural factors in the explanation of educational inequalities in mortality in The Netherlands. J Epidemiol Community Health $2005 ; 59: 214-20$.

34. van Lenthe FJ Gevers E, Joung IM, Bosma H, Mackenbach JP. Material and behavioral factors in the explanation of educational differences in incidence of acute myocardial infarction: the Globe study. Ann Epidemial 2002;12:535-42.

35. Martikainen $P$. Stansfeld $S$, Hemingway $H$, Marmot $M$. Determinants of socioeconomic differences in change in physical and mental functioning. Soc Soi Med 1999;49:499-507. 
36. Sacker A, Bartley M, Firth D. Fitzpatrick R. Dimensions of social iriequality in the health of women in England: occupational, material and behavioural pathways. Soc Soi Med 2001;52:763-81.

37. Macleod J. Davey SG. Psychosocial factors and public health a suitable case for treatment? J Epidemiol Community Health 2003;57:565-570.

38. Peck MN. The importance of childhood socio-economic group for adult health. Sac Sci Med $1994 ; 39: 553-62$.

39. Smith $G D$, Hart $C$, Blane $\mathbb{D}$. Gillis $C$. Hawthorne $V$. Lifetime socioeconomic position and mortality: prospective observational study. BM $\checkmark 1997 ; 314: 547-52$.

40. van de Mheen $H$, Stronks K, Looman CW, Mackenbach JP. Does childhood socioeconomic status influence adult health through behavioural factors? int J Epidemiol 1998;27:431-7.

41. Bosma $H$, van de Mheen HD, Mackenbach JP. Social class in childhood and general health in adulthood: questionnaire study of contribution of psychological attributes. BMJ $1999,318: 18$ 22 .

42. Kuh D, Ben-Shlomo Y, Lynch J, Hallqwist J, Power C. Life course epidemiology. J Epidemiol Community Health 2003;57:778-83.

43. Ben-Shlomo $Y$, Kuh D. A life course approach to chronic disease epidemiology: conceptual models, empirical challenges and interdisciplinary perspectives. Int $J$ Epidemiol 2002;31:28593.

44. Blane D, Davey Smith G, Bartley M. Social selection: what does it contribute to social class. differences in health? Soc Health IIIness 1993;15:1-15.

45. Lundberg O. Causial explanations for class inequality in health-an empirical analysis. Soc Sci Med 1991;32:385-93.

46. West $P$. Rethinking the health selection explanation for health inequalities. Soc Sci Med 1991;32:373-84.

47. Phelan EA, Anderson LA, LaCroix AZ, Larson EB. Older adults" views of "successfull aging"-... how do they compare with researchers" definitions? J Am Geriatr Soc 2004;52:211-6.

48. Rowe JW, Kahn RL. Successful aging. Gerontologist 1997;37:433-440.

49. Hemingway $\mathrm{H}$, Nicholson $A$, Stafford $M$, Roberts $R$, Marmot $M$. The impact of socioeconomic status on health functioning as assessed by the SF-36 questionnaire: the Whitehall II Study. Am J Public Heatth 1997;87:1484-1490.

50. Mishra GD, Ball $K_{*}$ Dobson $A_{d}$, Byles JE. Do socioeconomic gradients in women's health widen over time and with age? Soc Sci Med 2004;58:1585-95.

51. Kumari M. Seeman T, Marmot M. Biological predictors of change in functioning in the Whitehall II study. Ann Epidemilol 2004:14:250-7.

52. Weich S, Lewis G. Material standard of living. social class, and the prevalence of the common mental disorders in Great Britain. J Epidemiol Community Health 1998;52:8-14.

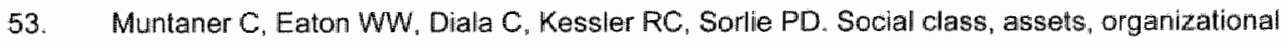
control and the prevalence of common groups of psychiatric disorders. Soc Sici Med $1998 ; 47: 2043-53$.

54. Deeg DJ, van Tilburg T, Smit JH, de Leeuw ED. Attrition in the Longitudinal Aging Study Amsterdam. The effect of differential inclusion in side studies. J Clin Epidemiol 2002;55:319.. 28.

55. Kempen $\mathrm{Gl}$, van Sonderen E. Psychological attributes and changes in disability among lowfunctioning older persons: does attrition affect the outcomes? J Clin Epidemiol 2002;55:224-9. 
56. Kunst AE, Mackenbach JP. The size of mortality differences associated with educational level in nine industralized countries. Am J Public Health 1994:84:932-7.

57. Kunst $A E$, Geurts $J J$, van den Berg J. International variation in socioeconomic inequalities in self reported health. J Epidemiol Community Health 1995:49:117-23.

58. Mackenbach JP, Stronks $\mathrm{K}$. The development of a strategy for tackling health inequalities in the Netherlands: Int J Equity Health $2004: 3: 11$.

59. Mackenbach JP, Stronks K. A strategy for tackling health inequalities in the Netherlands. BMJ 2002;325:1029-32.

60. Lorig $\mathrm{KR}, \mathrm{Holman} \mathrm{H}$. Self-management education: history, definition, outcomes, and mechanisms. Ann Behav Med 2003;26:1-7:

61. van Eijk JT, Diederiks JP, Kempen GI, Honig A, van der Meer K, Brenninkmeijer WJ. Development and feasibility of a nurse administered strategy on depression in communitydwelling patients with a chronic physical disease. Patient Educ Couns 2004;54:87-94.

62. Kaplan GA. Where do shared pathways lead? Some reflections on a research agenda. Psychosom Med 1995;57:208-12.

63. Mackenbach JP, Bakker MJ. Tackling sociaeconomic inequalities in health: anallysis of European experiences. Lancet 2003;362:1409-14. 
Summary 
Chapter 1 outlines the background of the studies in this thesis and presents the objectives of this thesis. LOw socioeconomic status (SES) has been shown to be an important predictor of different functional health outcomes. Particularly the association between low SES and poor physical function has been well described in the literature. There is also evidence that low SES is related to poor cognitive function, although longitudinal studies are limited. Furthermore, SES differences have been found in mental disorders, such as depression. In generall, relatively few studies have investigated the association between SES and functional outcomes in older persons and longitudinal studies are limited. In order to prevent the negative consequences of poor function and the SES differences therein, understanding the pathways underlying these associations is important. Biomedical factors (such as diseases), behavioral factors (such as smoking and drinking), and psychosocial factors (such as long term difficulties and social support) possibly play an important role herein.

The first objective of this thesis is to describe the associations between SES and changes in physical, cognitive, and mental function. The second objective of this thesis is to explore the role of biomedicall, behavioral, and psychosocial factors in the explanation of SES differences in the three functional outcomes. The studies that are presented in this thesis have important strengths. First, the associations between SES and three different types of function, that represent different aspects of a person's health status, are studied. Second, the role of three different groups of explanatory factors is studied. Third, the associations between SES and function are studied longitudinally. Fourth, it will be determined whether SES differences in function still exist in old agle. Finally, different indicators of SES, including education and income, that represent different dimensions of SES, will be used. Including these strengths, the studies will contribute to a better understanding of the mechanism underlying SES health differences.

Data from three different large longitudinal cohort studies were used; the GLOBE (Dutch acronym for Health and Living conditions of the population of the city of Eindhoven and surroundings in the Netherlands) study, LASA (Longitudinal Aging Study Amsterdam), and the Health ABC (Health, Aging and Body Composition) study.

Chapter 2 describes the association between SES and mobility decline and whether this could be explained by disease severity and comorbidity in four different chronic disease groups (asthma/COPD, heart disease, diabetes mellitus, and low back pain), using data from the GLOBE study. This study shows that in 15 to 74 year old persons, low occupational level and low income predicted an increased risk of 
mobility decline during six years of follow-up. Only little of this association could be explained by the higher disease severity and comorbidity in these patients. Findings were similar for patients with asthma/COPD, heart disease, diabetes mellitus, and chronic low back pain.

Chapter 3 elaborates - using data from the GLOBE study - on the previous chapter by examining the role of psychosocial factors, independent of disease severity, comorbidity, and health-related behavior, in the further explanation of SES differences in mobility decline in chronically ill persons. Although IOw SES was associated with a more negative psychosocial profile, psychosocial factors could not explain the SES differences in mobility decline.

In Chapter 4 the association between SES and changes in physical function is investigated in younger-old (55 to 70 years) and older-old ( 70 to 85 years) adults. Additionally, several explanatory factors, including diseases, behavioral, and psychosocial factors are simultaneously examined in the explanation of SES differences in physical function. Using data from LASA, we reported that in older adults, low SES was related to a poorer llevel of physical function during nine years of follow-up. In persons aged 55 to 70 years, the SES differentials in physical function became larger during nine years of follow-up, while SES differentials did not further widen over time in subjects 70 years and older. Behavioral factors largely explained the SES differences in physical function, whereas psychosocial factors reduced SES differences most in the oldest age group. These findings indicate age-specificity of both the pattern of SES differences in function and the mechanisms underlying these associations.

Chapter 5 reports on the association between SES and different markers of inflammation and whether any association remains significant after adjusting for diseases and behavioral factors typically related to elevated serum levels of inflammatory markers. In well-functioning older adults, participating in the Health ABC study, low SES was associated with elevated serum levels of interleukin-6 (IL6), C-reactive protein (CRP), and tumor necrosis factor-a (TNF-a) compared to high SES. This is an important finding, as high serum levels of inflammatory markers have been associated with increased mortality. Elevated serum levels of inflammatory markers in low SES groups were to a large extent mediated by unhealthy behaviors (especially obesity, smoking, and drinking), rather that by a higher prevalence of diseases in low SES groups. 
Chapter 6 describes the association between SES and incident mobility limitation in 70 to 79 year old persons who were well-functioning at baseline (Health ABC study). Furthermore, the role of biomedical factors in explaining these differences is examined. LOW SES strongly predicted an increased incidence of mobility limitation during four and a half years of follow-up. Biomedical factors, including a wide range of diseases and biological risk factors, explained part of this association. On average $41 \%$ of the educational differences was explained by biomedical factors; this was $17 \%$ for income and $29 \%$ for the number of financial assets (such as saving bonds, home ownership, and investments) that a person owned. High serum levels of inflammatory markers, high body mass index, and hypertension were found most important in reducing the SES differences in mobility limitation incidence. This study suggests that biomedical factors are important in the mechanism underlying the association between SES and functional outcomes. However in order to reduce physical disability and particularly the SES differences therein, it may not be sufficient to solely intervene upon biollogical risk factors and risks of diseases.

Chapter 7 shows that in a well-functioning older population (Health $A B C$ study), people with low SES also had an increased risk of a decline in cognitive function in comparison to people with high SES. Although a higher prevalence of diseases and their risk factors were related to both low SES and poor cognitive function, in this study, biomedical factors could explain only $5 \%$ of the SES differences in cognitive decline. The hypothesis that biomedilcal factors are important in the mechanism underlying the association between SES and cognitive function could not be supported.

In Chapter 8, it is examined whether low SES predicts the onset of depression in older adults who participated in LASA. The contribution of several explanatory variables, including psychosocial factors, physical health status, and behavioral factors is simultaneously examined in the explanation of SES inequalities in depression incidence. Low SES predicted an increased incidence of depression during nine years of follow-up. The largest reduction in SES differences in incident depression was found after adjustment for psychosocial factors. A small network size, low self-efficacy, and poor physical function had the largest individual contribution in reducing the effect of SES on depression incidence in this study. The SES differences in incident depression remained, however, to a large extent unexplained. 
Chapter 9 summarizes and discusses the main findings. Furthermore, conceptual and methodological issues are considered. Despite some limitations, we conclude that low SES was strongly associated with poor physical, cognitive, and mental function over time and that these health inequalities persist in old age. Biomedical, behavioral, and psychosocial factors could not fully explain SES differences in physical, cognitive, and mental function. Hence, SES differences in function to some extent remained unexplained. Further study in unraveling the mechanism underlying SES differences in health is needed, followed by interventions - also in old age - to decrease SES health differences. 


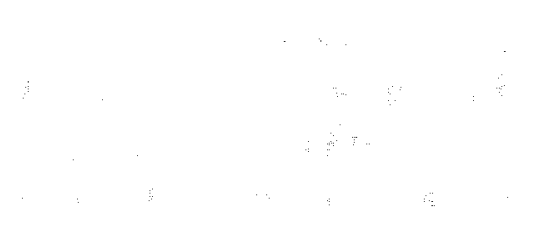


Samenvatting 
Hoofdstuk 1 schetst de achtergrond van de studies die in dit proefschrift worden beschreven en presenteert de doelstellingen van dit proefschrift. Een lage sociaal-economische status (SES), gemeten door bijvoorbeeld inkomen of opleiding, is een belangrijke voorspeller voor verschillende domeinen van functioneren. Vooral de relatie tussen een lage SES en slecht fysiek functioneren is goed beschreven in de literatuur. Er zijn ook aanwijzingen dat een lage SES gerelateerd is aan een lager niveau van cognitief functioneren, hoewel er nog niet veel longitudinale studies op dit terrein zijn uitgevoerd. Daarnaast zijn er ook SES verschillen gevonden in mentaal functioneren, waaronder depressie. Over het algemeen is er relatief weinig onderzoek gedaan naar de relatie tussen SES en functioneren bij oudere mensen en zijn er weinig longitudinale studies. Om de negatieve gevolgen van slecht functioneren te voorkomen en vooral de SES verschillen daarin, is het belangrijk om inzicht te krijgen in de onderliggende mechanismen. Biomedische factoren (zoals ziekten), gedragsfactoren (zoals roken en drinken) en psychosociale factoren (zoals langdurig belastende omstandigheden en sociale steun) spelen hierin mogelijk een belangrijke rol.

Het eerste doel van dit proefschrift is het beschrijven van de relaties tussen SES en veranderingen in fysiek, cognitief en mentaal functioneren. Het tweede doel van dit proefschrift is om te onderzoeken in hoeverre biomedische factoren, gedragsfactoren en psychosociale factoren de relatie tussen SES en verschillende domeinen van functioneren kunnen verklaren. De studies die beschreven worden in dit proefschrift hebben belangrijke sterke punten. Ten eerste, de relaties tussen SES en drie verschillende domeinen van functioneren die verschillende aspecten van iemands gezondheidsstatus weergeven, worden onderzocht. Ten tweede, de rol van drie verschillende groepen van verklarende factoren wordt onderzocht. Ten derde, de relaties tussen SES en functioneren worden longitudinaal bestudeerd. Ten vierde, er wordt onderzocht of deze SES verschillen in functioneren nog steeds aanwezig zijn op oudere leeftijd. Tot slot, verschillende indicatoren van SES, waaronder opleiding en inkomen, die verschillende dimensies van SES weergeven, worden gebruikt. Deze punten dragen bij aan het verkrijgen van een beter inzicht in de mechanismen die ten grondslag liggen aan SES verschillen in functioneren.

Er wordt gebruik gemaakt van gegevens van drie longitudinale cohortonderzoeken: de GLOBE (Gezondheid en LevensOmstandigheden Bevolking Eindhoven en omstreken) studie, LASA (Longitudinal Aging Study Amsterdam) en de Health $A B C$ (Health, Aging and Body Composition) studie.

Hoofdstuk 2 beschrijft de relatie tussen SES en achteruitgang in mobiliteit in 4 groepen chronisch zieken (astma/COPD, hartziekte, diabetes mellitus en lage 
rugpijn). Gegevens van de GLOBE studie werden gebruikt. Daarnaast wordt onderzocht in hoeverre de ernst van de chronische ziekte en co-morbiditeit (het hebben van andere ziekten) deze relatie kunnen verklaren De resultaten laten zien dat bij mensen in de leeftijd van 15 tot 74 jaar een laag beroepsniveau en een laag inkomen een verhoogd risico vormen op een achteruitgang in mobiliteit gedurende een follow-up van 6 jaar. Slechts een klein deel van deze relatie kon verklaard worden door een ernstigere zjekte en ca-morbiditeit in de lage SES groepen. De bevindingen waren vergelijkbaar voor mensen met astma/COPD, hartziekte, diabetes mellitus en lage rugpijn.

Hoofdstuk 3 bouwt - eveneens met gegevens uit de GLOBE studie - voort op het vorige hoofdstuk waarbij de rol van psychosociale factoren, onafhankelijk van ernst van de ziekte, co-morbiditeit en gedragsfactoren, wordt bepaald in de verdere verklaring van SES verschillen in fysiek functioneren bij chronisch zieken. Ondanks dat een lage SES geassocieerd was met meer negatieve psychosociale kenmerken konden deze factoren de SES verschillen in een achteruitgang in mobiliteit niet verder verklaren.

In Hoofdstuk 4 wordt de relatie tussen SES en veranderingen in fysiek functioneren bij jongere ouderen ( 55 tot 70 jaar) en oudere ouderen ( 70 tot 85 jaar) onderzocht. Bovendien worden verschillende verklarende factoren waaronder ziekten, gedragsfactoren en psychosociale factoren, gelijktijdig onderzocht in het verklaren van de SES verschillen. Gebruikmakend van gegevens van LASA laten we zien dat bij oudere mensen een lage SES is gerelateerd aan slechter fysiek functioneren gedurende 9 jaar follow-up. In de groep van 55 tot 70 jaar werden de SES verschillen in fysiek functioneren zelfs groter gedurende de follow-up; dit was niet het geval in de groep van 70 jaar en ouder. Gedragsfactoren verklaarden het meest van de SES verschillen in de jongere groep, terwijl in de oudere groep psychosociale factoren de grootste bijdrage hadden in het verkleinen van de SES verschillen. Deze bevindingen wijzen erop dat zowel de beschrijving van de SES verschillen in fysiek functioneren als de verklaring hiervan leeftijdspecifiek is bij ouderen.

Hoofdstuk 5 beschrijft de relatie tussen SES en verschillende ontstekingsmarkers. Daarnaast bepalen we of de relatie blijft bestaan na correctie voor ziekten en gedragsfactoren die geassocieerd zijn met hoge bloedwaarden van ontstekingsmarkers. Bij 70 tot 79 jaar oude mensen uit de Health $A B C$ studie was een lage SES geassocieerd met hoge bloedwaarden IL-6 (interleukine-6), CRP (C- 
reactieve proteine) en TNF-a (tumor necrosis factor- $a$ ) vergeleken met een hoge SES. Dit is een belangrijke bevinding omdat hoge waarden van ontstekingsmarkers samenhangen met een hogere kans op sterfte. Verhoogde waarden van ontstekingsmarkers in lage SES groepen werden vooral veroorzaakt door ongezonde gedragsfactoren (vooral overgewicht, roken en drinken), meer dan door het vaker voorkomen van ziekten in lage SES groepen.

Hoofdstuk 6 beschrijft de relatie tussen SES en het ontstaan van beperkingen in mobiliteit bij 70 tot 79 jaar oude mensen zonder beperkingen in mobiliteit bij aanvang van de studie (Health $A B C$ studie). Daarnaast werd de rol van biomedische factoren in de verklaring van deze verschillen bepaald. Een lage SES was een sterke voorspeller voor het ontstaan van beperkingen in mobiliteit gedurende 4,5 jaar followup. Biomedische factoren, waaronder een breed scala aan ziekten en biologische risicofactoren, verklaarden een deel van dit verband. Gemiddeld verklaarden de biomedische factoren $41 \%$ van de opleidingsverschillen; dit was $17 \%$ voor inkomen en $29 \%$ voor het aantal financiële bezittingen (zoals spaarrekeningen, beleggingen en huisbezit) dat iemand had. Hoge waarden van ontstekingsmarkers, een hoge body mass index en hoge bloeddruk waren de belangrijkste factoren in het verklaren van de SES verschillen in het ontstaan van beperkingen in mobiliteit. Deze studie laat zien dat biomedische factoren belangrijk zijn in het mechanisme dat ten grondslag ligt aan de relatie tussen SES en fysiek functioneren. Echter in het terugdringen van lichamelijke beperkingen (en mogelijk invaliditeit) en vooral de SES verschillen daarin is het niet voldoende om te interveniëren op biologische risicofactoren en de kans op ziekten.

Hoofdstuk 7 laat zien dat in een gezonde oudere populatie (Health ABC studie), mensen met een lage SES ook een verhoogd risico hebben op een achteruitgang in cognitief functioneren in vergelijking met mensen met een hoge SES. Ondanks dat in deze studie een hogere prevalentie van ziekten en de risicofactoren geassocieerd is met zowel een lage SES als slecht cognitief functioneren, konden de biomedische factoren slechts $5 \%$ van de SES verschillen in een cognitieve achteruitgang verklaren. De hypothese dat biomedische factoren belangrijk zijn in het mechanisme dat ten grondslag ligt aan de relatie tussen SES en cognitief functioneren kon niet ondersteund worden.

In Hoofdstuk 8 wordt onderzocht in hoeverre een lage SES het ontstaan van depressie bij oudere mensen voorspelt (LASA). De bijdrage van verschillende verklarende factoren, waaronder psychosociale factoren, ziekten en gedragsfactoren, 
zal daarnaast gelijktijdig worden onderzocht in de verklaring van de SES verschilien. De resultaten laten zien dat een lage SES inderdaad het ontstaan van depressie gedurende 9 jaar follow-up voorspelt. Psychosociale factoren konden een deel van deze SES verschillen verklaren. Een klein sociaal netwerk, een lage eigen effectiviteit (geloof in eigen kunnen) en slecht fysiek functioneren hadden de grootste individuele bijdrage in het verkleinen van de SES verschillen in het ontstaan van depressie. SES verschillen in het ontstaan van depressie bij ouderen bleven echter voor een groot gedeelte onverklaard.

In Hoofdstuk 9 worden de belangrijkste bevindingen samengevat. Verder worden er dit hoofdstuk conceptuele en methodologische beperkingen van de studies besproken. Ondanks een aantal beperkingen, kunnen we concluderen dat een lage SES sterk gerelateerd is aan slechter fysiek, cognitief en mentaal functioneren. Dit werd gevonden voor verschillende indicatoren van SES en deze gezondheidsverschillen blijven bestaan op oudere leeftijd. Biomedische factoren, gedragsfactoren en psychosociale factoren konden SES verschillen in functioneren siechts gedeeltelijk verklaren. Derhalve blijven SES verschillen in functioneren voor een deel onverklaard. Verder onderzoek is nodig om de onderliggende mechanismen verder te onderzoeken, gevolgd door interventies - ook op oudere leeftijd - om SES verschillen in gezondheid terug te dringen. 
f 


\section{List of publications}

Cox DN, Koster A, Russell CG. Predicting intentions to consume functional foods and supplements to offset memory loss using an adaptation of protection motivation theory. Appetite 2004:43:55-64.

Koster A, Bosma H, Broese van Groenou MI, Kempen GI, Penninx BW, van Eijk JT, Deeg DJ. Explanations of socioeconomic differences in changes in physical function in older adults, submitted.

Koster A, Bosma H, Kempen GI, van Lenthe FJ, van Eijk JT, Mackenbach JP. Socioeconomic inequalities in mobility decline in chronic disease groups (asthma/COPD, heart disease, diabetes mellitus, low back pain): only a minor role for disease severity and comorbidity. J Epidemiol Community Health 2004;58:8629.

Koster A, Bosma H, Kempen GI "Penninx BW, Beekman AT, Deeg DJ, van Eijk JT. Explaining socioeconomic differences in incident depression in older adults, submitted.

Koster A. Bosma H, van Lenthe FJ, Kempen GI, Mackenbach JP, van Eijk JT. The role of psychosocial factors in explaining socio-economic differences in mobility decline in a chronically III population: results from the GLOBE study. Soc Sci Med 2005;61:123-32.

Koster A, Bosma H, Penninx BW, Newman AB, Harris TB, van Eijk JT, Kempen GI, Simonsick EM, Johnson KC, Rooks RN, Ayonayon HN, Rubin SM, Kritchevsky $\mathrm{SB}$. Association of inflammatory markers with socioeconomic status, submitted. Koster A. Penninx BW, Bosma H, Kempen GI, Harris TB, Newman AB, Rooks RN, Rubin SM, Simonsick EM, van Eijk JT, Kritchevsky SB. Is there a biomedical explanation for socioeconomic differences in incident mobility limitation? J Gerontol A Biol Sci Med Sci 2005;60:1022-7.

Koster A, Penninx BW, Bosma H, Kempen GI, Newman AB, Rubin SM, Satterfield S, Atkinson $\mathrm{HH}$, Ayonayon HN, Rosano $\mathrm{C}$, Yaffe K, Harris TB, Rooks RN, van Eljk لT, Kritchevsky SB. Socioeconomic differences in cognitive decline and the role of biomedical factors. Ann Epidemiol 2005;15:564-571.

Veldink $\mathrm{JH}$, Kalmijn S, Groeneveld $G J$, Wunderink W, Koster A, de Vries JH, van der Luyt J, Wokke JH, van den Berg LH. Nutritional intake of polyunsaturated fatty acidls and vitamin $E$ reduce the risk of developing ALS, submitted. 



\section{Dankwoord (Acknowledgment)}

De afigelopen jaren heb ik met veel plezier gewerkt aan het onderzoek zoals dat in dit proefschrift beschreven staat. I realiseer me dat ik zonder de hulp en steun van anderen nooit zover gekomen zou zjin daarom wil ik hier graag een aantal personen bedanken.

Allereerst wil ik mijn promotores, Jacques van Eijk en Ruud Kempen en copromotores Hans Bosma en Brenda Penninx bedanken. Ik heb de samenwerking met jullie alle vier als erg prettig ervaren. Jacques, bedankt voor de vrijheid die je mij hebt gegeven om mezelf te ontwikkelen en dat ik mijn onderzoek toch ook een persoonlijke invulling heb kunnen geven. Verder will ik je bedanken voor het steeds weer kritisch lezen van mijn concepten. Ruud, bedankt voor je inhoudelijke bijdrage aan mijn onderzoek. Zoals je zelf vaak zei, keek je als "advocaat van de duivel" naar mijn stukken. Dit hielp me om scherp te blijven en om mijn eigen onderzoek ook eens vanuit een ander oogpunt te zien. Hans, jij hebt me geïntroduceerd in de wereld van sociaal-economische gezondheidsverschillen en je enthousiasme voor dit vakgebied werkte aanstekelijk. Ook heb ik veel van je geleerd als het gaat om de strategie van data-analyse, dit laatste blifft voor mij toch een van de leukste onderdelen van onderzoek doen. Als directe begeleider kon ik altijd bij je binnenlopen met een vraag en had je altijd even tijd voor me; dat werkte voor mil erg prettig. Brenda, ik ben blij dat ook jij mijn copromotor bent. In de maanden dat ik in Amerika verbleef was je heel direct betrokken bij mijn onderzoek maar ook daanna, terug in Nederland, heb ik veel aan je imbreng gehad en veel van je geleerd, bedankt daarvoor. lk heb bewondering voor je enthousiasme en gedrevenheid in onderzoek doen. Daarnaast will ik jou en Wouter bedanken voor de hartelijke ontvangst in Amerika; dat heb ik erg gewaardeerd.

De leden van de beoordelingscommissie, prof. dr. J. van Os, prof. dr. R.A. de Bie, prof. dr. G.A.M. van den Bos en prof. dr. J.M.J.P. van der Linden, wil ik hartelijk danken voor het beoordelen van dit proefschrift.

Voor mijn onderzoek heb ik gebruik mogen maken van gegevens van drie grote studies: GLOBE, LASA en Health ABC. Graag wil ik liedereen bedanken die betrokken is geweest bij de data verzameling van de verschillende studies. Johan Mackenbach en Dorly Deeg will ik harteljik danken voor het gebruiken van gegevens van GLOBE en LASA en voor de inhoudelijke bijdrage aan mijn artikelen. Frank van Lenthe, Marjolein Broese-van Groenou en Aartjan Beekman wil ik bedanken voor hun zinvolle bilidrage als coauteur. Steve Kritchevsky, I enjoyed working with you on 
the Health $A B C$ papers and $I$ am looking forward to working with you in the future. Furthermore, I would like to thank all co-authors for their contribution to the Health ABC papers: Hal Atkinson, Hilsa Ayonayon, Tamara Harris, Karen Johnson, Anne Newman, Ronica Rooks, Caterina Rosano, Susan Rubin, Suzanne Satterfield, Eleanor Simonsick, and Kristine Yaffe.

De collega's bij Medische Sociologie wil ik bedanken voor het prettige werkklimaat op de afdeling. De lunch-en theepauzes zorgden voor een welkome afleiding om even achter de computer vandaan te komen. Daarnaast wil ik in het bijzonder alle collega-aio's en junioren bedanken hun betrokkenheid en voor de gezelligheid, niet alleen op de afdeling maar ook daarbuiten! Rixt en Jolanda, bedankt voor jullie luisterend oor en gezelligheid op 'onze' kamer.

Aan het eind van dit proefschrift wil ik ook al mijn vrienden bedanken. Bedankt voor jullie betrokkenheid, jullie steun en voor alle gezelligheid!

Thomas en Rixt, ik ben erg blij dat jullie mijn paranimfen willen zijn en me willen bijstaan op 22 december. Bedankt dat jullie er voor me zijn!

Tot slot wil ik graag mijn ouders bedanken. Lieve papa en mama, jullie hebben me altijd gestimuleerd om er uit te halen wat er in zit en staan daarmee aan de basis van dit proefschrift. Bedankt voor alle mogelijkheden die jullie me gegeven hebben en jullie onvoorwaardelijke steun. Met veel plezier draag ik dit proefschrift aan jullie op.

Annemarie

Maastricht, oktober 2005 


\section{About the author}

Annemarie Koster was born on April 5, 1978 in Helmond the Netherlands. She spent her youth in Gemert, Zoetermeer, Aalst, and Doetinchem. in 1997 she finished her secondary education at the St. Ludgercollege in Doetinchem. That same year she started with the study Nutrition and Health at Wageningen University. She wrote her major master thesis in the field of Human Nutrition and an additional thesis in the field of Marketing and Marketing Research. After an internship at CSIRO (Commonwealth Scientific and Industrial Research Organisation) in Adelaide, Australia, she obtained her Master of Science degree in 2002. In 2003 she also obtained her Master of Science in Epidemiology degree and is registered with the Netherlands Epidemiological Society.

In December 2002 she started as a PhD student at Maastricht University, department of Health Care Studies, Medical Sociology section where she conducted the work described in this thesis. From July to December 2003 she conducted part of her research at the J. Paul Sticht Center on Aging, Wake Forest University in Winston Salem, North Carolina in the United States.

In the coming years Annemarie will remain affiliated with the University of Maastricht as a postdoc. Within this period, she will spend one year (2006) at the National Institute on Aging (NIA) in Bethesda, USA for which she will receive a fellowship from the American National Institutes of Health. During this fellowship, she will continue her aging research activities through collaborations with Dr. Tamara Harris (NIA) and Dr. Stephen Kritchevsky (Wake Forest University). 



\section{De auteur}

Annemarie Koster werd op 5 april 1978 geboren in Helmond. Zij bracht haar jeugd door in Gemert, Zoetermeer, Aalst en Doetinchem. In 1997 behaalde zij haar WWO dipioma aan het St. Ludgercollege in Doetinchem. In datzelfde jaar begon zij met haar studie Voeding en Gezondheid aan de Wageningen Universiteit. Doctoraalonderzoeken werden gedaan bij de vakgroep Humane Voeding en bij de vakgroep Marktkunde en Marktonderzoek $\mathrm{Na}$ een afsluitende stage bij CSIRO (Commonwealth Scientific and Industrial Research Organisation) in Adelaide, Australië studeerde zij in 2002 af. Sinds 2003 staat zij geregistreerd als Epidemioloog A bij de Nederlandse Vereniging voor Epidemiologie.

In december 2002 begon zij als assistent in opleiding bij de sectie Medische Sociologie, capaciteitsgroep Zorgwetenschappen van de Universiteit Maastricht waar zij het onderzoek deed zoals in dit proefschrift beschreven staat. Van juli tot december 2003 deed zij een deel van haar onderzoek in Amerika bij het J. Paul Sticht Center on Aging, Wake Forest University in Winston Salem, North Carolina in Amerika.

De komende jaren zal Annemarie verbonden blijven aan de Universiteit Maastricht als postdoc. In deze periode zal zij een jaar (2006) doorbrengen bij het National Institute on Aging (NIA) in Bethesda, Amerika waarvoor zij een beurs van het American National Institutes of Health zal ontvangen. Gedurende deze tijd zal zij haar werk op het gebied van verouderingsonderzoek voortzetten en daarbij samenwerken met Dr. Tamara Harris (NIA) en Dr. Stephen Kritchevsky (Wake Forest University). 